\title{
Recent Advances Towards Syntheses of Diterpenoid Alkaloids
}

\author{
Christian Dank \\ Randy Sanichar ${ }^{(D)}$ \\ Ken-Loon Choo \\ Madeline Olsen \\ Mark Lautens* (1)
}

Davenport Research Laboratories, Department of Chemistry, University of Toronto, Toronto, Ontario M5S 3H6, Canada mark.lautens@utoronto.ca

Dedicated to the $50^{\text {th }}$ anniversary of SYNTHESIS

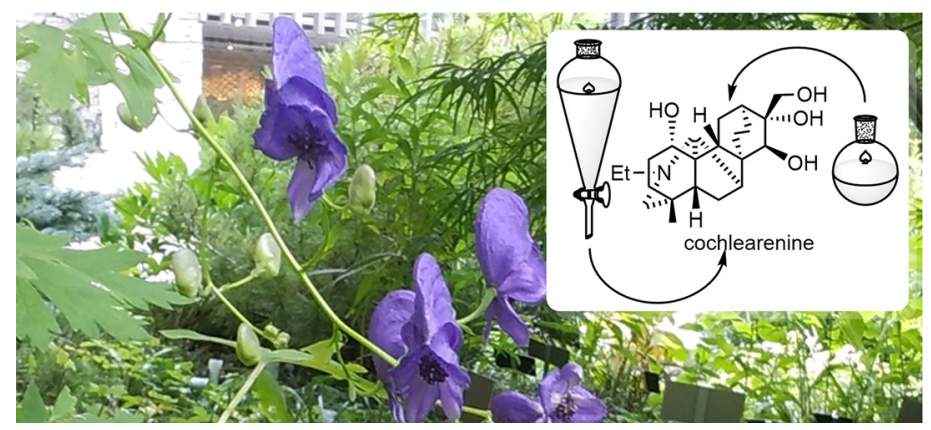

Received: 20.06.2019

Accepted: 28.06.2019

Published online: 05.08 .2019

DOI: 10.1055/s-0037-1611897; Art ID: ss-2019-z0341-r

License terms: (C)

Abstract The diterpenoid alkaloids serve as a rich source of synthetic targets for organic chemists, due to the intriguing structure of the overlapping ring systems, along with biological activities commonly associated with compounds of this group. Fifteen total syntheses and numerous synthetic studies towards construction of ring fragments have been reported since 2010 . This review article gives a brief overview of diterpenoid alkaloids and summarizes the recent synthetic efforts.

1 Introduction

1.1 Structural Classification and Biosynthetic Origin

1.2 Structure Elucidation of the Aconitum Alkaloids

2 Total Syntheses

2.1 $\quad \mathrm{C}_{18}$-Diterpenoid Alkaloids

$2.2 \mathrm{C}_{19}$-Diterpenoid Alkaloids

$2.3 \mathrm{C}_{20}$-Diterpenoid Alkaloids

3 Strategies To Synthesize Ring Systems

3.1 Radical-Based Cyclizations

3.2 Ruthenium-Mediated Enyne Cycloisomerization

3.3 Reductive Coupling

3.4 Diels-Alder Reactions

3.5 Oxidative Dearomatization/Diels-Alder Sequence

3.6 Transannular Aziridation

3.7 Intramolecular [5+2] Cycloaddition

3.8 Miscellaneous

4 Conclusion

Key words diterpenoids, alkaloids, total synthesis, aconitine, natural products

\section{Introduction}

The diterpenoid alkaloids $\left(\mathrm{C}_{18}, \mathrm{C}_{19}\right.$, and $\left.\mathrm{C}_{20}\right)$ are a group of chemically and structurally complex natural products that possess a long list of pharmaceutical properties. ${ }^{1}$ This list includes, but is not limited to, anti-inflammatory, analgesic, and antiarrhythmic properties. ${ }^{2}$ Most of these properties are reported to be derived from interactions between the natural products and voltage-gated ion channels, particularly potassium and sodium channels. ${ }^{3}$
While researchers worldwide are still discovering new compounds within this class from numerous plant species, these pseudoalkaloids have been traditionally linked to the Aconitum, Consolidum, and Delphinium genus of plants, from which they were extracted and used in traditional medicine. However, research into broader applications still continues. ${ }^{4}$ The most common uses included the treatment of cardiovascular diseases and as an analgesic.

\subsection{Structural Classification and Biosynthetic Origin}

The diterpenoid alkaloids family is generally grouped by key conserved structural features and size of the carbon scaffolds. The smallest of the three main groups are the $\mathrm{C}_{18^{-}}$ diterpenoid alkaloids, with over 50 discrete compounds already known. ${ }^{2 b}$ These $\mathrm{C}_{18}$-diterpenoid alkaloids can be further subdivided into two distinct types; the lappaconitinetype $\mathbf{1}$, and the ranaconitine-type $\mathbf{2}$ (Figure 1 ) with the major difference being the presence of the additional oxygenation at the $\mathrm{C} 7$ position in the ranaconitine core.

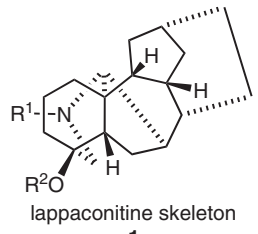

1

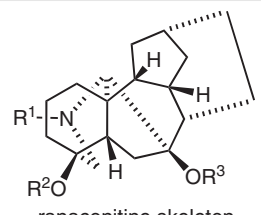

2
Figure $1 \quad C_{18}$-type diterpenoid alkaloid skeletons

The $\mathrm{C}_{19}$-diterpenoid alkaloids are the largest of the three groups and represent over 600 fully characterized molecules. ${ }^{1 \mathrm{c}}$ They are structurally closer to the $\mathrm{C}_{18}$-diterpenoid core, with the variation being an additional carbon at the piperidine ring junction. This group is divided into 6 unique types, with the aconitine- $\mathbf{3}$ and lycoctonine-type $\mathbf{4}$ seemingly the most prevalent in Nature (Figure 2). The other 


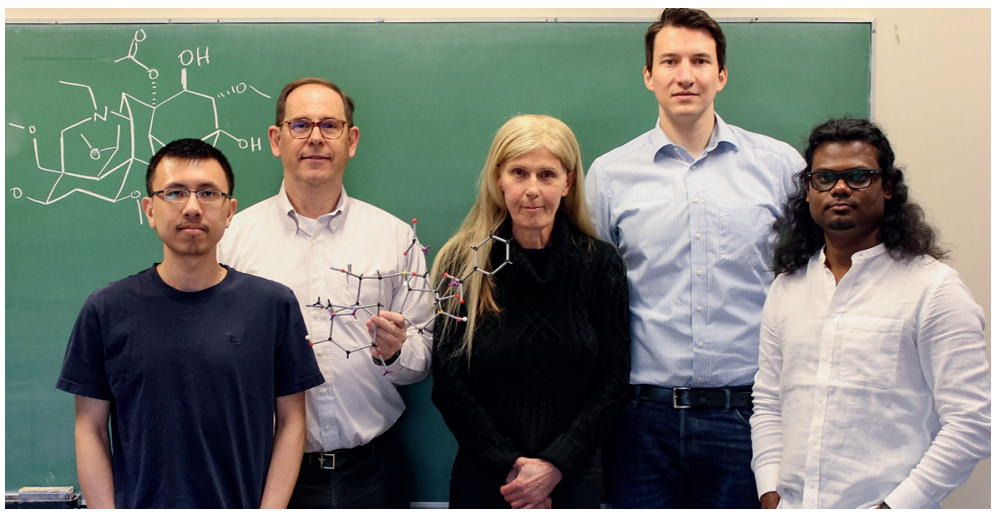

Christian Dank (second from right) studied chemistry at the University of Vienna. After receiving the degree Master of Science (M.Sc.) in the group of Prof. Johann Mulzer, during his Ph.D. he worked on syntheses of novel antimalarials, supervised by Dr. Hubert Gstach and Prof. Walther Schmid. In 2016, he joined the medicinal chemistry department of Boehringer Ingelheim in Vienna, working on oncology projects. During his postdoctoral fellowship in the Lautens group, he contributes in his fields of expertise, total synthesis and medicinal chemistry, and explores the field of metal catalysis.

Randy Sanichar (rightmost) completed his Bachelor of Science (B.Sc.) degree in chemistry at the University of Guyana in 2011, graduating with distinction. After working at a local rum distillery as a process chemist for two years, he travelled to Canada to further his education at the University of Alberta. In 2018, he completed his Ph.D. under the supervision of Professor John C. Vederas where he worked on the design and syntheses of probes for the elucidation of biosynthetic pathways of pharmaceutically relevant polyketides; all to facilitate a chemobiosynthetic production platform. He joined the Lautens group in November 2018, as a postdoctoral researcher, where his current research interests include the total synthesis of novel natural products and the development of new catalytic asymmetric reactions.
Ken-Loon Choo (leftmost) received his B.Sc. degree with honors from the University of Toronto. He then ventured into the oleochemical industry as a research chemist developing a process to synthesize high purity sulfonated fatty acid esters. In 2016, he returned to pursue a graduate degree in the laboratories of Prof. Mark Lautens at the University of Toronto with interest in catalytic asymmetric reactions and total synthesis.

Madeline Olsen (center) enjoyed a thirtyyear career in electrical engineering, having been employed at Toronto's Hospital for Sick Children (1970-1974), Bell Northern Research Ottawa (1975-1978), The National Synchrotron Light Source, Brookhaven National Laboratory (1979-1994), and SLAC National Accelerator Laboratory (19951998). A specialist in digital logic design and signal processing, she nonetheless designed and constructed many of the magnet power supplies at the NSLS, ranging from $25 \mathrm{KW}$ to 2.2 MW. She was awarded two United States patents for her work at Bell Northern Research and in 1995, she was invited to CERN Geneva where she gave a lecture to the LEP power supply group outlining the high precision digital power control system she had designed for the NSLS. She enrolled as an undergraduate and having taken the specialist courses offered in organic chemistry, worked in the Lautens lab as a research assistant from 2001-2006. During this time, she worked on the synthesis and ring-open- ing of novel azabenzonorbornadienes and developed a reaction for the synthesis of dihydronaphthalenes via an aryne Diels-Alder reaction. Additionally, she devised and ran large-scale syntheses for early stage material of a total synthesis project.

Mark Lautens (second from left) was born in Hamilton, Ontario, Canada. He obtained his B.Sc. degree from the University of Guelph followed by doctoral studies at the University of Wisconsin-Madison under the direction of Professor Barry M. Trost where he discovered Mo-catalyzed allylic alkylation and the Pd-catalyzed enyne cycloisomerization. In 1985, he moved to Harvard University where he conducted his NSERC PDF with Professor David A. Evans on studies directed toward the synthesis of bryostatin. He joined the University of Toronto in 1987 as an NSERC University Research Fellow and Assistant Professor. Since 1998 he has held an Endowed Chair, the AstraZeneca Professor of Organic Synthesis, and from 20032013 he was named an NSERC/Merck Frosst Industrial Research Chair in New Medicinal Agents via Catalytic Reactions. In 2012, he was appointed as University Professor, the highest rank at the University of Toronto. Most recently he was awarded Officer of the Order of Canada, the highest civilian honor in Canada. His current research interests are in multicatalyst reactions, isomerization reactions, and applications of catalysis in the synthesis of bioactive compounds. 
four subgroups are less frequent in occurrence and are comprised of the pyro-type, 7,17-seco-type 5, lactone-type $\mathbf{6}$, and rearranged-type alkaloids.

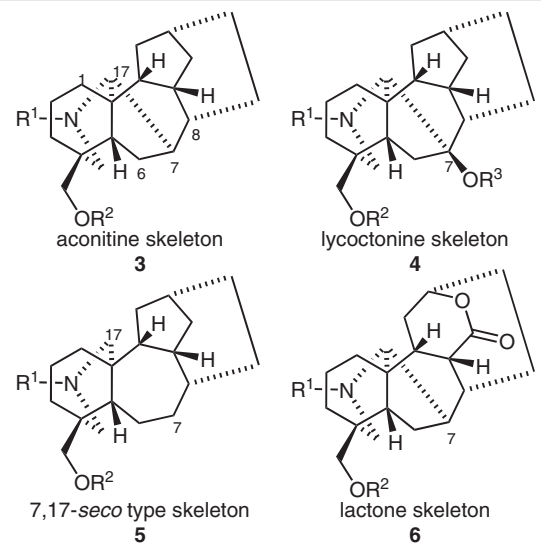

Figure $2 C_{19}$-type diterpenoid alkaloid skeletons

The $\mathrm{C}_{20}$-diterpenoid alkaloids (Figure 3 ) are a moderately large group, with over 300 known compounds. ${ }^{2 b}$ This group shows the broadest structural diversity of the main groups, and have been categorized into 16 distinct types of diterpenoid alkaloids: atisine $\mathbf{7}$, denudatine $\mathbf{8}$, hetidine $\mathbf{9}$, hetisine $\mathbf{1 0}$, cardionidine $\mathbf{1 1}$, albovionitine $\mathbf{1 2}$, vakognavine $\mathbf{1 3}$, veatchine 14 , napelline 15 , anopterine 16 , delnudine 17 , kusnezoline $\mathbf{1 8}$, actaline $\mathbf{1 9}$, racemulosine $\mathbf{2 0}$, arcutine $\mathbf{2 1}$, and tricalysiamide $22{ }^{2 \mathrm{~b}}$ Interestingly, while almost all of the $\mathrm{C}_{18}$ - and $\mathrm{C}_{19}$-diterpenoid alkaloids possess a [3.2.1]bicycle in the right side of their scaffolds, the majority of the $\mathrm{C}_{20}$-diterpenoid alkaloids contain a [2.2.2]bicycle.

Despite this vast structural diversity amongst the three groups, these natural products are all derived through biosynthetic insertion of the nitrogen into the mature diterpene scaffolds, which then undergoes further elaborations leading to the final product, as shown in Scheme $1 .{ }^{5}$ An enzyme-catalyzed cyclization of geranyl-geranyl pyrophosphate affords the ent-copalyl pyrophosphate, which then undergoes a series of transformations, including a critical Wagner-Meerwein rearrangement, affording the ent-kaurane $\mathbf{2 3}$ and ent-atisane $\mathbf{2 4}$ diterpene skeletons. These scaffolds then undergo amination to form the two main branching points, the veatchines 14 and the atisines 7 , notably these can interconvert through a [1,2]-sigmatropic rearrangement. ${ }^{1,2 b, 5}$ Through a series of elegant manipulations by Nature, these cores are later transformed into the numerous natural products observed. Some examples of these are the napellines $\mathbf{1 5}$ and denudatines $\mathbf{8}$, which are accessed through C7-C20 bond formation from the veatchines $\mathbf{1 4}$ and atisines 7, respectively. In other cases, after the requisite transformations, the scaffold may fragment to access the smaller core, as seen with the denudatines en route to the $\mathrm{C}_{19}$ scaffolds $\mathbf{2 5}$ and $\mathrm{C}_{18}$ scaffolds $\mathbf{2 6}$.

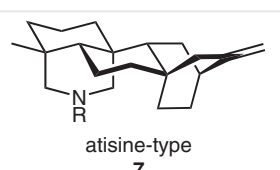

7

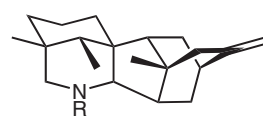

cardionidine-type

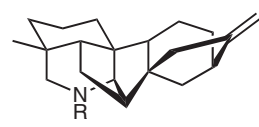

napelline-type

15

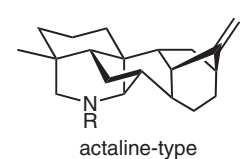

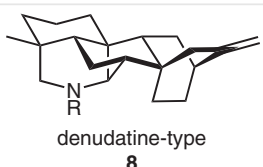

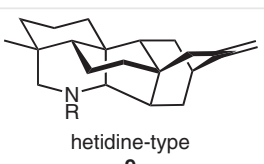

9

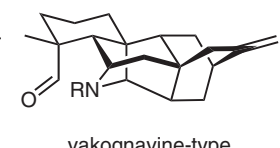

13

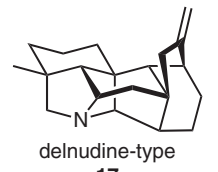

17

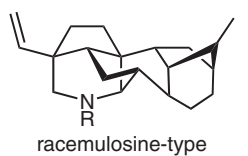

20

21

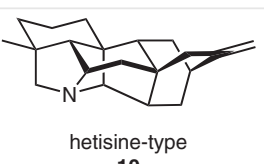

10
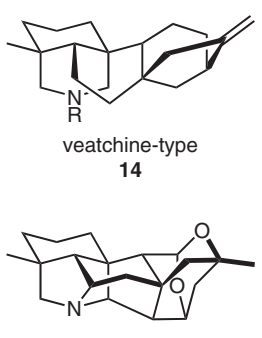

kusnezoline-type

18

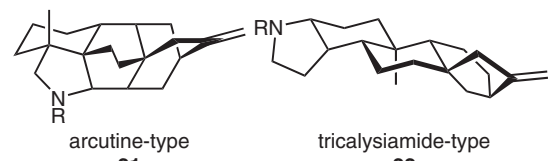

Figure 3 The 16 categories of the $\mathrm{C}_{20}$-diterpenoid alkaloids 


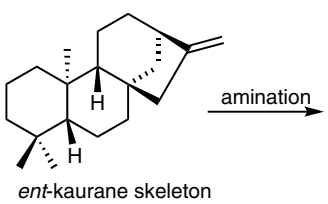

23

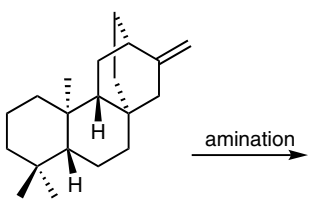

ent-atisane skeleton

24

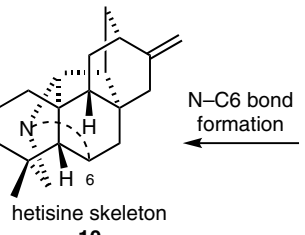

10

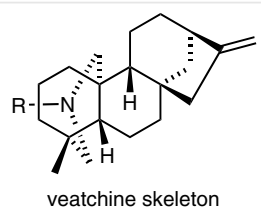

veatchine skeleton

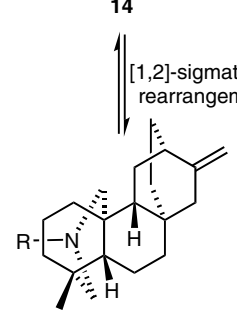

atisine skeleton

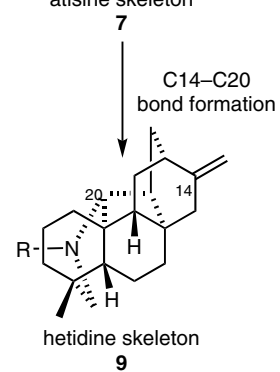

$\mathrm{C} 7-\mathrm{C} 20$

bond formation

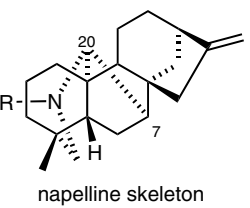

napelline skeleto
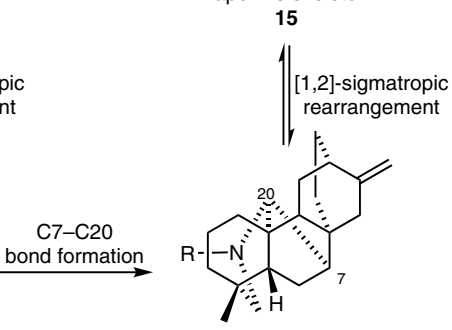

denudatine skeleton

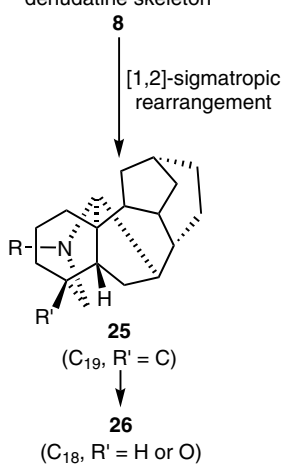

Scheme 1 Biosynthetic origins of diterpenoid alkaloids

\subsection{Structure Elucidation of the Aconitum Alkaloids}

The $\mathrm{C}_{18^{-}}$and $\mathrm{C}_{19^{-}}$-diterpenoid alkaloids have been of great interest to civilizations since antiquity. Preparations from members of the genera Aconitum and Delphinium have been used for such diverse applications as traditional Chinese medicine to surreptitious homicide, aconitine (27) being the most toxic; $\mathrm{LD}_{50}$ in mice $(\mathrm{mg} / \mathrm{kg}$ : 0.166 , i.v., 0.328 i.p.). ${ }^{6}$ However, due to the complexity of these molecules, very little progress beyond isolation was achieved for almost a century. The first published studies into the chemistry of aconitine did not appear until $1894^{7}$ with additional data published in $1895 .{ }^{8}$ Following a 29 year hiatus, three additional papers were published in the German literature (1924-1956). ${ }^{9}$ British researchers were also immersed in the aconitine problem, between 1894-1937, twelve papers related to structure determination were published by the Royal Society of Chemistry. ${ }^{10}$ In this time period, only one paper was published in the North American literature. ${ }^{11}$ Despite much information being obtained about occurrence and activities, little was known about the detailed structure due to the limited capabilities of the classical methods of analysis.

This situation changed with the introduction of UV and IR spectroscopy ${ }^{12}$ and later, NMR..$^{13}$ Due to their less complex structure, the $C_{20}$ alkaloids were the initial focus of at- tention. S. W. Pelletier and W. A. Jacobs made many contributions to the structural elucidation, both by chemical and spectroscopic means. ${ }^{14}$ A partial synthesis of atisine (28), isoatisine (29), and dihydroatisine (30) was achieved in 1956. ${ }^{15}$

The pioneer in the field of detailed structure determination and total synthesis of the Delphinium alkaloids was Karel Wiesner (1919-1986). He arrived at the University of New Brunswick in 1948 determined to clear up the "hopeless confusion' surrounding the structure. However, a review indicated that this had been tried many times in the past to no avail. He thus concluded that the best way to approach the problem would be to solve the structure of the more straightforward $\mathrm{C}_{20}$ members of the class. ${ }^{16}$ In the period 1948-1975, several total syntheses were achieved, employing $1^{\text {st }}$ through $4^{\text {th }}$ generation methods (Table 1, Figure 4). Some more recent syntheses are included in Table 1. Wiesner published two reviews of his work. ${ }^{17}$ Notably, even today, the total synthesis of the fully oxygenated, most complex members of the family, aconitine (27), and beiwutine (31) remain elusive. This article covers advances in total synthesis towards diterpenoid alkaloids from 2010 onwards after excellent coverage of the field by other review articles. ${ }^{5,18}$ Figure 5 depicts structurally unique diterpenoid alkaloids that have been synthesized since 2010 , such as salviamine $\mathrm{E}(\mathbf{3 2})$ and $\mathrm{F}(\mathbf{3 3}) ;{ }^{19}$ vitepyrroloid A (34) and B 
Table 1 Examples of Significant Total Syntheses by Compound and Year (see Figure 4)

\begin{tabular}{|c|c|c|c|c|c|c|c|}
\hline \multicolumn{2}{|c|}{ Compound } & \multirow[t]{2}{*}{$1960 \mathrm{~s}$} & \multirow[t]{2}{*}{1970 s } & \multirow[t]{2}{*}{$1980 \mathrm{~s}$} & \multirow[t]{2}{*}{$1990 \mathrm{~s}$} & \multirow[t]{2}{*}{$2000 s$} & \multirow{2}{*}{$\begin{array}{c}2010 \mathrm{~s} \\
2013^{27}\end{array}$} \\
\hline $\mathrm{C}_{18}$ & neofinaconitine (47) & & & & & & \\
\hline & weisaconitine D (48) & & & & & & $2015^{28}$ \\
\hline \multirow[t]{5}{*}{$C_{19}$} & talatisamine (49) & & $\begin{array}{l}1974^{29} \\
1975^{30}\end{array}$ & & & & \\
\hline & chasmanine (50) & & $\begin{array}{l}1977^{31} \\
1978^{32} \\
1979^{33}\end{array}$ & & & & \\
\hline & 13-desoxydelphonine (51) & & $\begin{array}{l}1978^{32} \\
1979^{33}\end{array}$ & & & & \\
\hline & liljestrandinine (52) & & & & & & $2015^{28}$ \\
\hline & (-)-cardiopetaline (53) & & & & & & $2017^{34}$ \\
\hline \multirow[t]{17}{*}{$C_{20}$} & atisine (28) & $\begin{array}{l}1963^{35} \\
1964^{36} \\
1966^{37} \\
1967^{38}\end{array}$ & & $1988^{39}$ & $1990^{40}$ & & $2012^{41}$ \\
\hline & garryine (54) & $\begin{array}{l}1964^{42} \\
1967^{43}\end{array}$ & & & & & \\
\hline & veatchine (55) & $\begin{array}{l}1964^{42} \\
1967^{43} \\
1968^{44}\end{array}$ & & & & & \\
\hline & napelline (56) & & $1974^{45}$ & $1980^{46}$ & & & \\
\hline & nominine (57) & & & & & $\begin{array}{l}2004^{47} \\
2006^{48} \\
2008^{49}\end{array}$ & \\
\hline & (-)-isoatisine (29) & & & & & & $2014^{50}$ \\
\hline & lepenine (58) & & & & & & $2014^{51}$ \\
\hline & cochlearenine (59) & & & & & & $2016^{52}$ \\
\hline & dihydroajaconine (60) & & & & & & $2016^{53,54}$ \\
\hline & $N$-ethyl-1 $\alpha$-hydroxy-17-veratroyldictyzine (61) & & & & & & $2016^{52}$ \\
\hline & gymnandine (62) & & & & & & $2016^{53}$ \\
\hline & paniculamine (63) & & & & & & $2016^{52}$ \\
\hline & $( \pm)$-spiramine C (64) & & & & & & $2016^{54}$ \\
\hline & $( \pm)$-spiramine $D(65)$ & & & & & & $2016^{54}$ \\
\hline & azitine (66) & & & & & & $2018^{55}$ \\
\hline & cossonidine (67) & & & & & & $2018^{56}$ \\
\hline & septedine (68) & & & & & & $2018^{57}$ \\
\hline
\end{tabular}

(35); ${ }^{20}$ paspaline (36); ${ }^{21}$ paspalinine (37);22 ileabethoxazole (38), pseudopteroxazole (39), and seco-pseudopteroxazole $(40) ;{ }^{23}(-)$-anominine (41), ( \pm )-terpendole E (42); ${ }^{24}$ aflavazole (43) and 14-hydroxyaflavinine (44); 25 chamobtusin A (45); ${ }^{26}$ and emindole PB (46). ${ }^{21 \mathrm{~b}}$ However, these diterpenoids are not from the Aconitum/Delphinium family. Thus, the total syntheses of these natural products are not covered in detail in this review article.

\section{Total Syntheses}

\section{$2.1 \quad C_{18}$-Diterpenoid Alkaloids}

\subsubsection{Total Synthesis of Neofinaconitine}

This convergent total synthesis of neofinaconitine (47) by Shi, Tan, and co-workers in 2013 was designed to begin with an intermolecular Diels-Alder cycloaddition between the in situ generated diene from enone 69 and cyclopropene 70 (Scheme 2). ${ }^{27}$ To allow for this strategy, the cyclopentenone intermediate $\mathbf{6 9}$ was prepared from commercially available furfuryl alcohol, ${ }^{58}$ while the cyclo- 


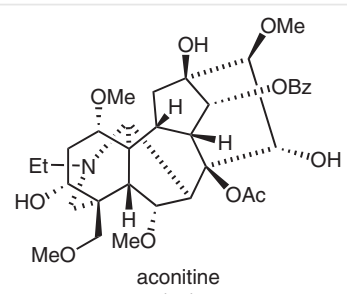

27)

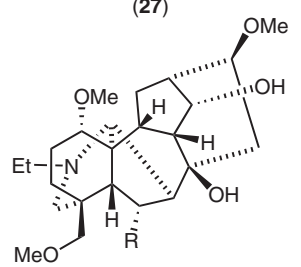

talatisamine $\mathrm{R}=\mathrm{H}(49)$ chasamanine $\mathrm{R}=\mathrm{OMe}(\mathbf{5 0})$

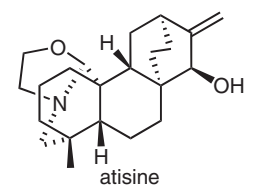

(28)

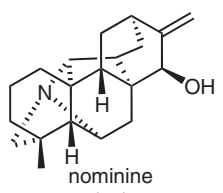

(57)
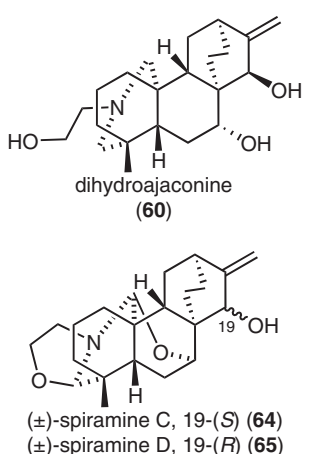

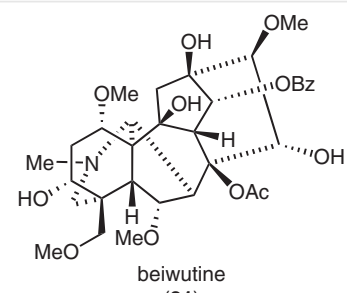

(31)

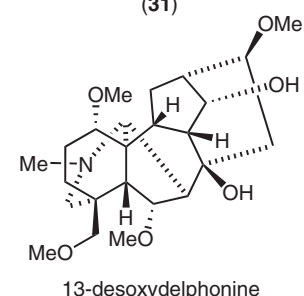

(51)

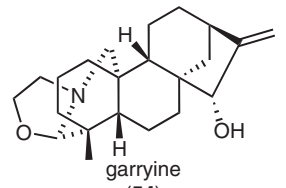

(54)
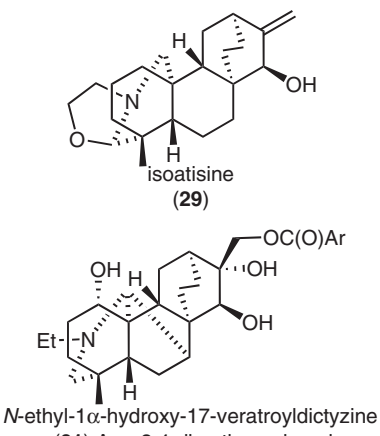

(61) $\mathrm{Ar}=3,4$-dimethoxyphenyl

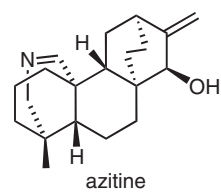

(66)

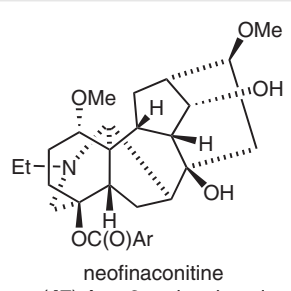

(47) $\mathrm{Ar}=2$-aminopheny

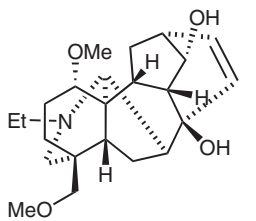

liljestrandinine

(52)

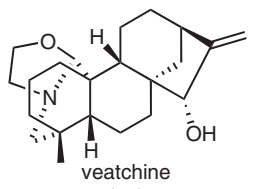

(55)
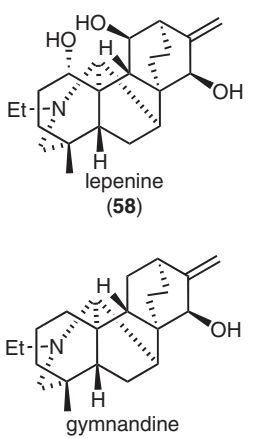

(62)

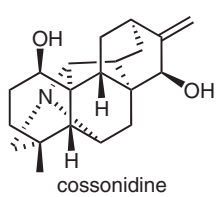

(67)

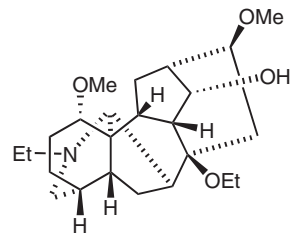

weisaconitine $D$

(48)

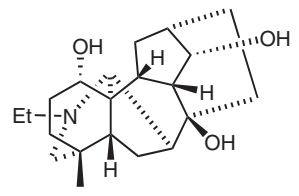

cardiopetaline

(53)

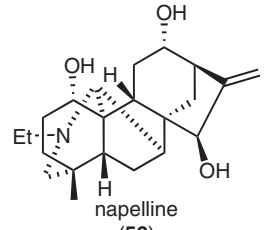

(56)

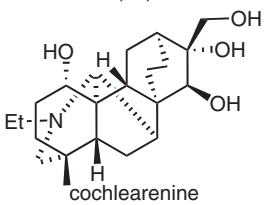

(59)

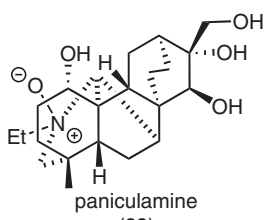

(63)

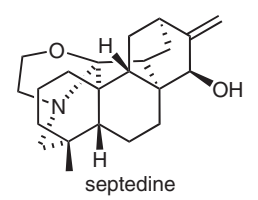

(68)

Figure 4 Structures of aconitine, beiwutine, and targets of total syntheses, listed in Table 1

propene starting material $\mathbf{7 0}$ was prepared in 6 steps from methyl acrylate. ${ }^{59}$ Notably, due to the rapid Alder-ene dimerization of the cyclopropene intermediate, this compound was isolated and was used immediately in the cycloaddition reaction. The Diels-Alder cycloaddition was conducted by addition of intermediate $\mathbf{7 0}$ directly to the in situ prepared diene from intermediate $\mathbf{6 9}$. Importantly, it was reported that attempts at isolating the enolization-silylation $^{60}$ product of $\mathbf{6 9}$ led to a difficult-to-control mixture of dimerized cyclopentadiene. Nonetheless, this direct addition to the in situ prepared diene allowed access to the desired product $\mathbf{7 1}$ as an inseparable mixture of diastereo- mers (1:1.6). Given that the major diastereomer was the desired product, this mixture was taken through the next four steps to access intermediate $\mathbf{7 3}$ (39\% over 6 steps). A series of functional group manipulations on intermediate $\mathbf{7 3}$ afforded access to diene $\mathbf{7 5}$ and set up the second intermolecular Diels-Alder cycloaddition between $\mathbf{7 5}$ and $\mathbf{7 6}$ catalyzed by $\mathrm{SnCl}_{4}{ }^{27}$ This is notably an essential step as it afforded a key intermediate $\mathbf{7 7}$ as a single diastereomer in excellent yield (87\%). This was then converted into the precursor for the Mannich-type $\mathrm{N}$-acyliminium cyclization by the selective oxidation of the exocyclic olefin to afford a carbonyl and followed by elimination of the $\beta$-bromide to form the 
<smiles>CC(=O)c1c(O)c2ccc3c(c2c2oc(C)nc12)CCCC3(C)C</smiles>

salviamine $E(\mathbf{3 2})$

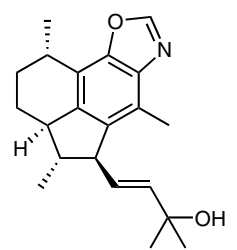

ileabethoxazole (38)

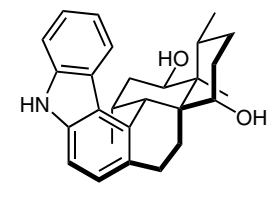

aflavazole (43)<smiles></smiles>

salviamine $F(\mathbf{3 3})$<smiles>CC(C)=C[C@H]1C[C@@H](C)[C@H]2CC[C@H](C)c3c2c1c(C)c1ncoc31</smiles>

pseudopteroxazole (39) seco-pseudopteroxazole (40)

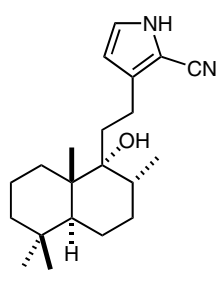

vitepyrroloid A (34)

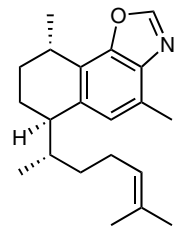

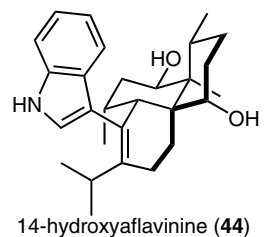

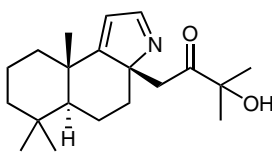

chamobtusin A (45)

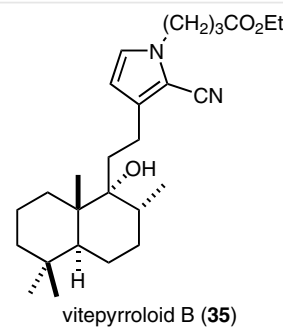<smiles></smiles>

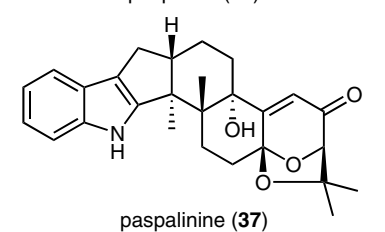<smiles>CCC1OC(C(C)(C)O)CC(O)C12CCCC1Cc3[nH]c4ccccc4c3CC1CCC2</smiles>
terpendole $\mathrm{E}$ (42)

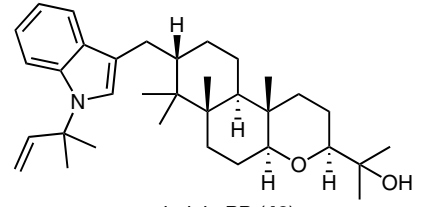

emindole PB (46)

Figure 5 Recently synthesized structurally unique diterpenoid alkaloids

enone 78. The Mannich-type $N$-acyliminium cyclization was achieved by treatment of intermediate $\mathbf{7 8}$ with $\mathrm{Tf}_{2} \mathrm{NH}$, thereby forming the $\mathrm{C} 11-\mathrm{C} 17$ bond, but was unfortunately also followed by the formation of the cyclic enol ether to form 79 (75\%). To overcome this undesired, but unavoidable, formation of the enol ether, a rather nifty trick was employed, a leaving group was introduced at the $\mathrm{C} 3$ position by treatment of $\mathbf{7 9}$ with CAN, followed by $\mathrm{MsCl} / \mathrm{Et}_{3} \mathrm{~N}$ in two steps, which was fortunately accompanied by the elimination to afford the dienone $\mathbf{8 0}$ (66\%, two steps). ${ }^{27}$ The last of the keys steps was completed by an intramolecular radical cyclization of dienone $\mathbf{8 0}$ in excellent yield to afford the completed neofinacotine scaffold $\mathbf{8 1}$ (99\%). Finally, installation of the C8 hydroxyl functionality was achieved via a highly strained enone, allowing for a spontaneous nucleophilic attack by water to give $\mathbf{8 2}$ and complete the structural requirements. Over an additional 8 steps, the remaining modifications and tailoring were accomplished to afford the total synthesis of racemic neofinaconitine (47). ${ }^{27}$

This divergent approach by Shi, Tan, and co-workers was achieved in 30 longest linear steps and afforded racemic neofinaconitine (47) from readily available materials. ${ }^{27}$ It should be noted that this strategy offers numerous opportunities to access other types of the diterpenoid alkaloids and as such should be exploited for the preparation of derivatives of such natural products.

\subsubsection{Total Synthesis of Weisaconitine D}

The Sarpong group completed the total synthesis of weisaconitine $\mathrm{D}(\mathbf{4 8})$, a ranaconitine-type diterpenoid alkaloid, in 2015 in 30 steps overall (Scheme 3). ${ }^{28}$ Starting with a Diels-Alder cycloaddition of diene $\mathbf{8 5}^{61}$ and a cyclopentenone derivative $86,{ }^{62}$ the resulting alkene was reduced to give the basic bicyclic ketone intermediate 87. Preparation of the vinyl triflate by treatment of $\mathbf{8 7}$ with LHMDS and phenyl triflimide, followed by $\operatorname{Pd}(0)$-catalyzed cross-coupling with cyanide ${ }^{63}$ afforded the $\alpha, \beta$-unsaturated nitrile 88. This approach allowed the assembly of the $A$ and $F$ rings, and serves as the substrate for their Rh-catalyzed conjugate addition with the lithium boronate $\mathbf{8 9}$ to access 90 in $60 \%$ yield. Notably, this guaiacol derivative was installed with high diastereoselectivity. This transformation should be well noted as the aryl ring of $\mathbf{9 0}$ after several transformations will eventually be fashioned into the $C / D$ ring and, as such, this is an excellent point to diverge/modify the oxidation patterns around these rings in the final diterpenoid alkaloid simply by use of the appropriately substituted arene. The ester group of $\mathbf{9 0}$ was selectively reduced over the nitrile functionality, followed by DessMartin oxidation of the resulting primary alcohol to give aldehyde 91. The newly formed aldehyde $\mathbf{9 1}$ underwent a Wittig olefination, followed by hydration of the nitrile group ${ }^{64}$ to provide the carboxamide $\mathbf{9 2}$. This carboxamide 92 was then rearranged via a Hofmann rearrangement using (diacetoxyiodo)benzene $\left[\mathrm{PhI}(\mathrm{OAc})_{2}, \mathrm{PIDA}\right]$, and the 

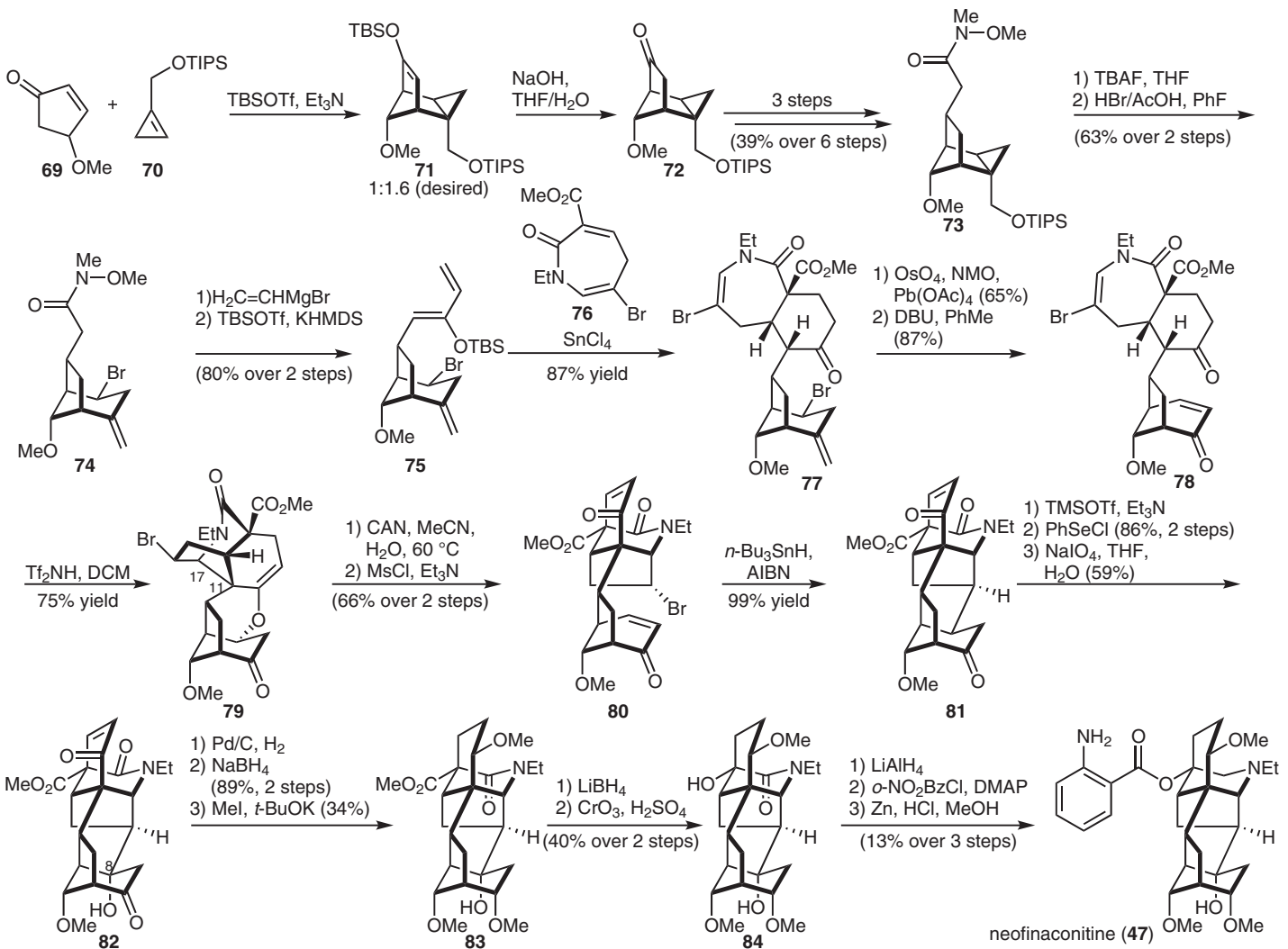

Scheme 2 Total synthesis of lappaconitine-type diterpenoid alkaloid neofinaconitine<smiles>CO/C=C\C=C/CO[13C](=O)c1ccccc1</smiles>
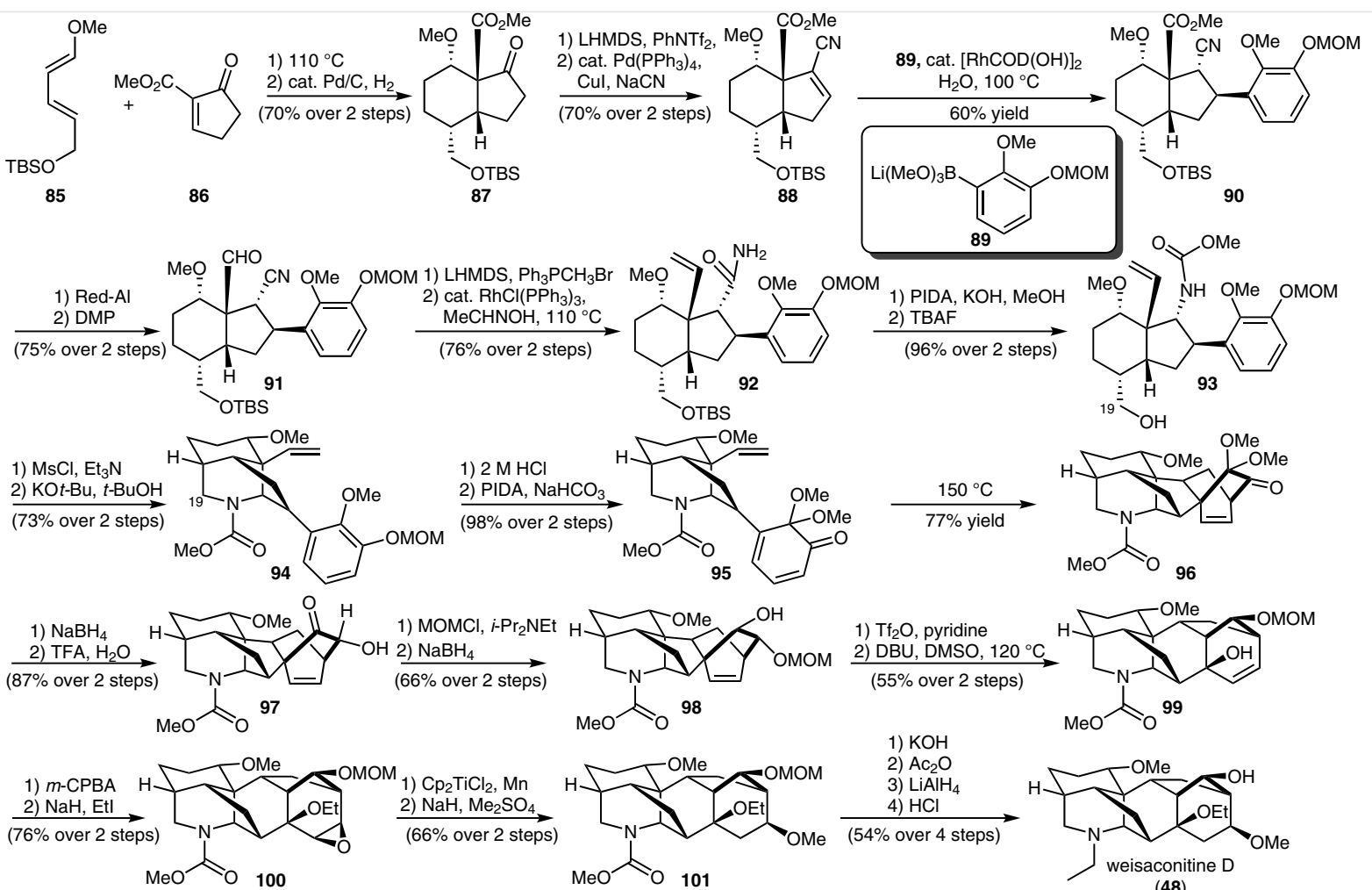

Scheme 3 Total synthesis of ranaconitine-type diterpenoid alkaloid weisaconitine D 
intermediate isocyanate was trapped with methanol, followed by deprotection to the tert-butyldimethylsilyl group with TBAF to give 93. The primary hydroxyl group was then activated by mesylation and treated with $\mathrm{KO}$-Bu to form the C19-N bond, thereby fashioning the piperidinyl ring of 94. This key step allowed completion of the $A, E$, and $F$ rings for the $C_{18}$-diterpenoid alkaloids. In order to set construction of the B, C, and D rings, the MOM protecting group of 94 was cleaved, and the phenol was then subjected to an oxidative dearomatization to afford the dienone 95. By merely heating intermediate $\mathbf{9 5}$, it underwent an intramolecular Diels-Alder cycloaddition forming 96. This step effectively allowed access to the $C_{20}$ core framework of the denudatine-type diterpenoid alkaloids. As such, this pathway can be viewed as an equally effective route to the denudatine-type diterpenoid alkaloids.

To effect the transformation of the bicyclo[2.2.2] structural motif to the bicyclo[3.2.1] core, the ketone functionality of 96 was stereoselectively reduced. It was postulated that this selectivity is as a result of torsional strain from the $\beta$-disposed methoxy group of the dimethyl ketal. The ketal protecting group was then hydrolyzed to afford $\mathbf{9 7}$. Intermediate $\mathbf{9 7}$ was then treated with $\mathrm{MOMCl}$ to protect the free secondary hydroxyl group, followed by the diastereoselective reduction of the ketone group to provide alcohol $\mathbf{9 8}$. The triflation of alcohol 98, followed by treatment with DBU and DMSO at $120{ }^{\circ} \mathrm{C}$ led to a Wagner-Meerwein-type rearrangement and thus completed the $\mathrm{B}, \mathrm{C}$, and $\mathrm{D}$ rings in 99. ${ }^{6}$ While several strategies were explored for a formal hydro-methoxylation of the C15-C16 double bond of 99, it was found that this was best achieved via an epoxide intermediate. They employed a hydroxyl-directed epoxidation from the $\beta$-face using $m$-CPBA, followed by alkylation of the tertiary hydroxyl to provide $\mathbf{1 0 0} .^{28}$ The epoxide was regioselectively opened ${ }^{65}$ to give a $\beta$-disposed secondary alcohol group that was methylated to furnish $\mathbf{1 0 1}$ and thus this completed the D-ring of weisaconitine D. The methoxycarbonyl protecting group was removed, the nitrogen was acylated, and the acetamide was reduced using $\mathrm{LiAlH}_{4}$. Finally, removal of the MOM protecting by acid treatment of afforded the final product weisaconitine $\mathrm{D}(\mathbf{4 8})$ in a total of 30 steps. $^{28}$

This successful total synthesis of weisaconitine D (48) by the Sarpong group ${ }^{28}$ should be viewed as a direct opening to other members of the $\mathrm{C}_{18}$-ranaconitine class of diterpenoid alkaloids as well as the $C_{20}$-denudatine types. Importantly, their synthetic plan shows great promise in allowing for the preparation of any number of unnatural analogues of this natural product.

\section{$2.2 \quad \mathrm{C}_{19}$-Diterpenoid Alkaloids}

In contrast to the numerous reports of total syntheses of $\mathrm{C}_{20}$-diterpenoid alkaloids, there are only a handful of recent total syntheses of $C_{19}$ norditerpenoid alkaloids. The total syntheses of liljestrandinine $(\mathbf{5 2})^{28}$ and (-)-cardiopetaline $(53)^{67}$ have been reported by the Sarpong group and Fukuyama, Yokoshima, and co-workers, respectively. The total synthesis of aconitine (27) can be considered a holy grail in organic synthesis due to its intricate, highly oxygenated caged framework. The synthesis of this molecule has remained elusive, and the most recent attempt was reported by Qin, Zhang, and co-workers. ${ }^{66}$ Several groups have made strategic efforts towards the construction of the $C_{19}$ cores and the reported methodologies will be covered here.

\subsubsection{Total Synthesis of Liljestrandinine}

The synthesis of liljestrandinine $(\mathbf{5 2})^{28}$ starting from synthon 93 is shown in Scheme 4; dienone $\mathbf{1 0 4}$ was prepared in 7 steps in a similar fashion to the synthesis of weisaconitine $\mathrm{D}(\mathbf{4 8})$. At this point, the stage is set for an intramolecular Diels-Alder reaction. The ketone moiety of the Diels-Alder adduct was then reduced to give the hexacyclic alcohol 105, which was converted into the $\mathrm{C}_{19}$-diterpenoid alkaloid liljestrandinine (52) in 9 steps.

In a unifying approach to the $\mathrm{C}_{18^{-}}, \mathrm{C}_{19^{-}}$, and $\mathrm{C}_{20}$-diterpenoid alkaloids, the Sarpong group accomplished the preparations of weisaconitine D (48), liljestrandinine (52), as well as the denudatine-type compounds cochlearenine (59), $N$-ethyl-1 $\alpha-17$-veratroyldictyzine (61), and paniculamine (63). ${ }^{4 a}$ The advanced intermediate $\mathbf{9 3}$ is common to all of these natural product syntheses.

\subsubsection{Total Synthesis of (-)-Cardiopetaline}

Fukuyama, Yokoshima, and co-workers disclosed a novel Wagner-Meerwein rearrangement of a sulfonyloxirane to construct the aconitine skeleton (Scheme 5). ${ }^{67}$ Sulfonyloxirane $\mathbf{1 1 4}$ was synthesized from synthetic intermediate $\mathbf{1 0 8}$ en route to their previous reported total synthesis of lepenine. ${ }^{51}$ Protection of the hydroxy group of $\mathbf{1 0 8}$ followed by removal of the methoxy groups under reductive conditions with $\mathrm{SmI}_{2}$ furnished ketone 109. Hydrogenation of the olefin was achieved using $\mathrm{Pd}(\mathrm{OH})_{2}$ on carbon to afford ketone 110, which was then converted into $\alpha$-phenylsulfanyl ketone 111 via a silyl enolate intermediate. Stereoselective reduction gave a secondary alcohol, which was subsequently acylated to yield 112. The sulfide group was oxidized into a sulfone using Oxone and then base-mediated elimination of the acetate group furnished the vinyl sulfone 113. Stereoselective epoxidation was then carried out with tert-butyl hydroperoxide (TBHP) to give sulfonyloxirane $\mathbf{1 1 4}$ with the appropriate stereoconfiguration for a Wagner-Meerwein rearrangement. 

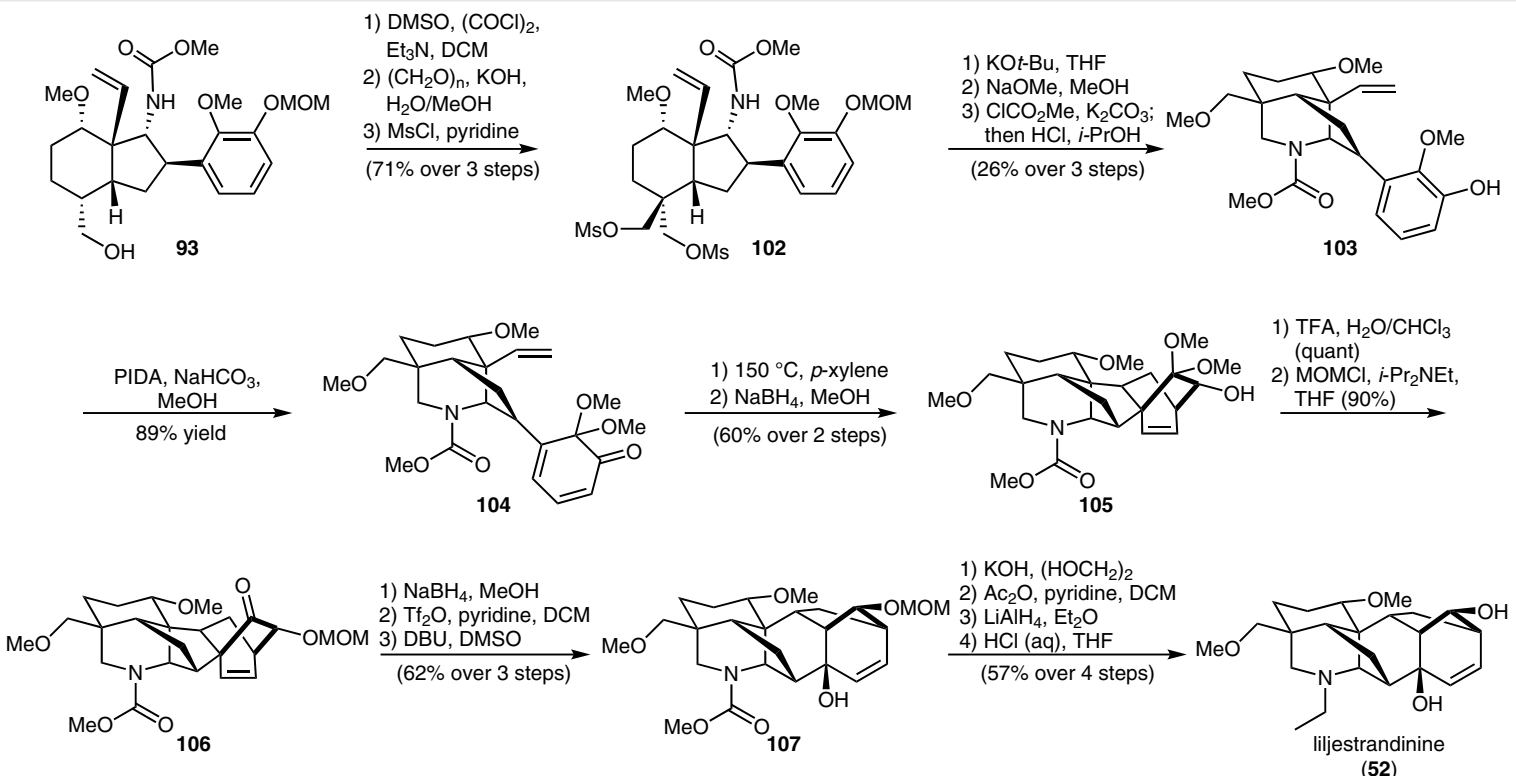

Scheme 4 Total synthesis of liljestrandinine

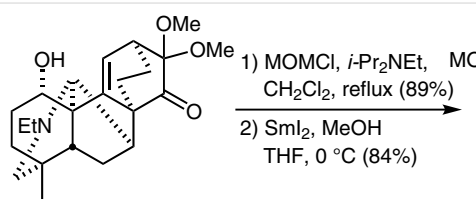

108

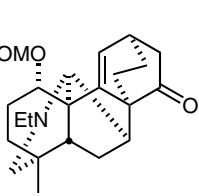

109

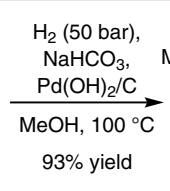

$93 \%$ yield

113

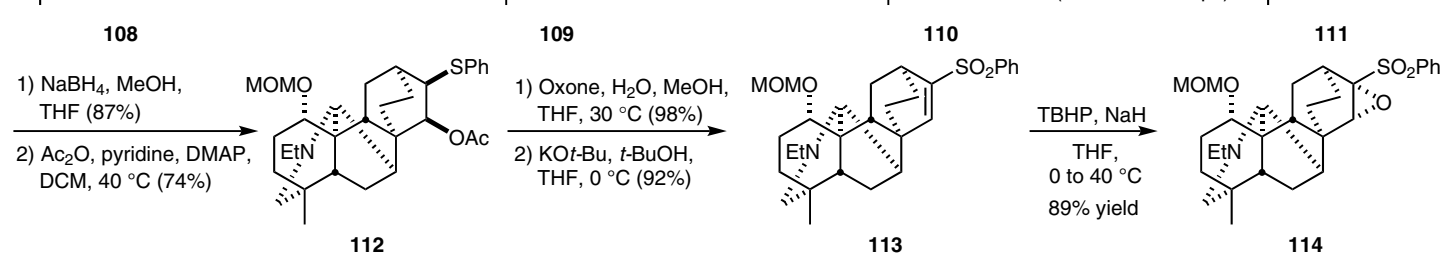

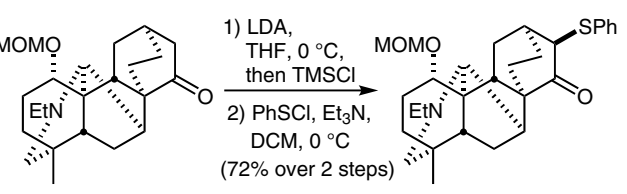

111

112

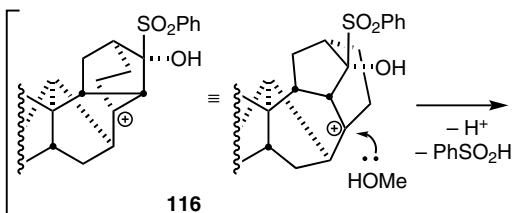

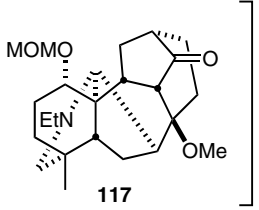

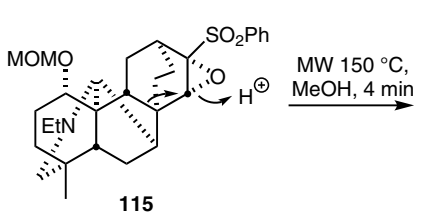

116

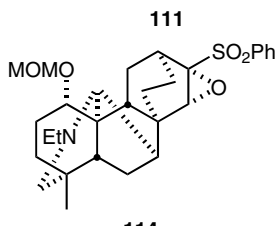

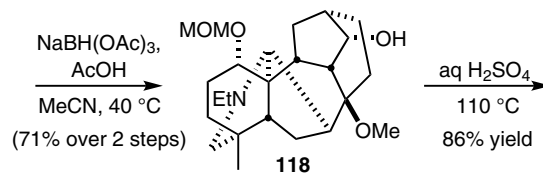

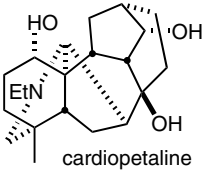

(53)

Scheme 5 Total synthesis of (-)-cardiopetaline via the Wagner-Meerwein rearrangement of a sulfonyloxirane

Surprising stability was observed with the sulfonyloxirane $\mathbf{1 1 4}$ where the intended rearrangement was not observed even under harsh acidic or thermal conditions. The desired rearrangement was finally realized by applying microwave irradiation at $150{ }^{\circ} \mathrm{C}$ in methanol. An alkyl shift first occurred to cleave the oxirane to give alcohol 116. The resulting carbocation was trapped by methanol followed by the extrusion of benzenesulfinic acid to form hexacyclic ketone 117. Reduction of the ketone was carried out immediately due to its instability to give alcohol 118. The total synthesis of (-)-cardiopetaline (53) was completed with heating in aqueous sulfuric acid to unmask the alcohol groups. 

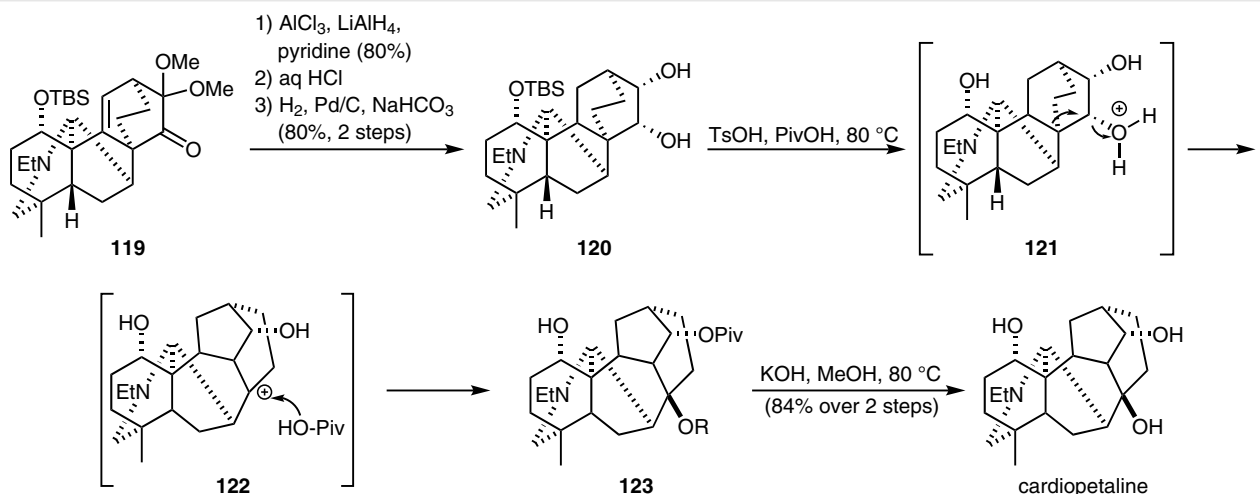

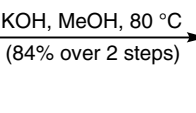

$\mathrm{R}=$ mixture of $\mathrm{H}$ and Piv

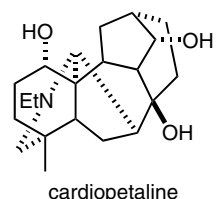

(53)

Scheme 6 Total synthesis of (-)-cardiopetaline via the Wagner-Meerwein rearrangement of a diol without pre-activation

In 2017, Fukuyama, Yokoshima, and co-workers published another variant (shown in Scheme 6) of the (-)-cardiopetaline (53) synthesis, which does not require pre-activation of the pivotal hydroxy group. ${ }^{34}$ The requisite diol $\mathbf{1 2 0}$ was also synthesized from intermediate 108. ${ }^{51}$ The ketone in TBS-protected $\mathbf{1 1 9}$ was stereoselectively reduced to alcohol 120 using alane with pyridine as an additive to prevent damage to the ketal moiety; hydrolysis of the ketal followed by exhaustive hydrogenation afforded diol $\mathbf{1 2 0}$, which was the target for the Wagner-Meerwein rearrangement. A number of reaction conditions were tested to initiate the rearrangement, but it was finally found that $p$-toluenesulfonic acid produced the desired rearranged product mixture
123. Pivalic acid was crucial for the suppression of the undesired acylation of the diol substrate. Hydrolysis was then carried out to liberate the alcohol groups to give (-)-cardiopetaline (53).

\subsubsection{Attempted Total Synthesis of Aconitine}

The most recent attempt at the total synthesis of aconitine (27) in 2019 was reported by Qin, Zhang, and co-workers (Scheme 7).66 The synthesis commenced with the decoration of $(-)-(R)$-carvone (124) to install the desired substituents on the A ring. Nitrone $\mathbf{1 2 6}$ was generated in situ from

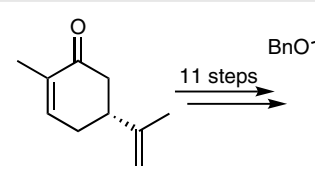

$(-)-(R)$-carvone (124)

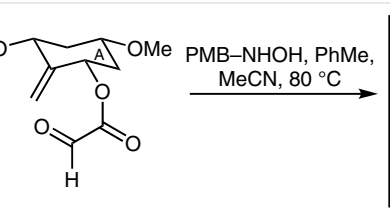

125

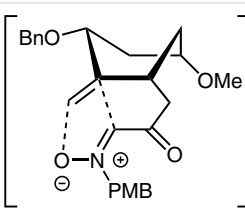

126<smiles>COC1CC2OC(=O)C3=NOCC32C1OBr</smiles>

128

1. $\mathrm{LiOH} \bullet \mathrm{H}_{2} \mathrm{O}$, $\mathrm{MeOH} / \mathrm{H}_{2} \mathrm{O}$ (3:1); then $150^{\circ} \mathrm{C}(95 \%)$ proton sponge, $3 \AA \AA$ MS, DCM, $10^{\circ} \mathrm{C}(80 \%)$
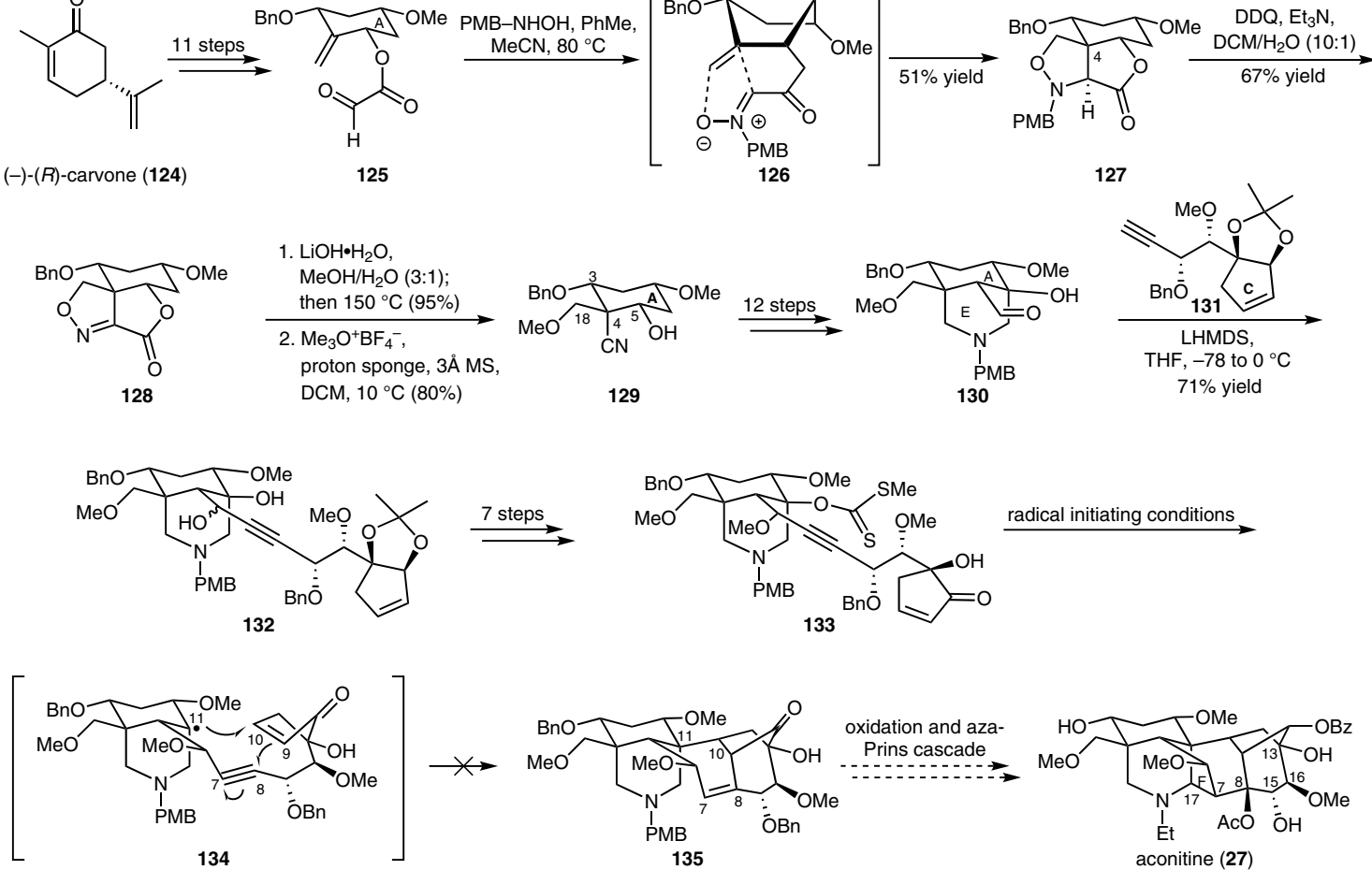

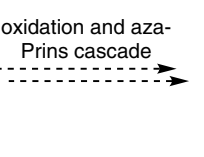

135

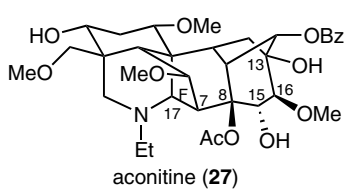

aconitine (27)

Scheme 7 Progress towards the total synthesis of aconitine 
glyoxylate 125 when treated with $\mathrm{N}$-PMB-hydroxylamine, which then induced an intramolecular [3+2] cycloaddition to give isoxazolidine $\mathbf{1 2 7}$ as a single diastereomer.

Deprotection of the $N$-PMB group followed by oxidation was achieved using DDQ to give imine 128. Hydrolysis, followed by Krapcho decarboxylation, and selective methylation afforded $\beta$-hydroxynitrile 129. Subsequent steps, including functional group manipulations and an intramolecular Mannich reaction, were carried out to build the E ring giving aldehyde 130. Addition of the alkyne fragment $\mathbf{1 3 1}$ provided propargyl alcohol 132. Further manipulations provided xanthate $\mathbf{1 3 3}$, which was the substrate required to carry out the key radical cascade for the formation of the $\mathrm{BD}$ ring systems. The planned cascade first generates a radical at C11 that subsequently cyclizes on to the C10 acceptor and is finally trapped by the alkyne moiety. Various radical initiating conditions were tested, but only decomposition of the substrate was observed without the formation of the desired cyclized product $\mathbf{1 3 5}$. The success of the cascade may be hampered by the premature interference of the alkyne moiety, the acceptor at C10 may be too distant, as well as the possibility of the formation of nitrogen-centered radicals on the tertiary amine. The final key transformation in the proposed route utilized an aza-Prins cascade to furnish the F ring of aconitine (27). Overall, the reported route achieved the synthesis of the fully functionalized $\mathrm{AE}$ ring systems of aconitine (27) in 27 steps with an overall yield of $1.64 \%$ from $(-)-(R)$-carvone (124).

\section{$2.3 \mathrm{C}_{20}$-Diterpenoid Alkaloids}

\subsubsection{Total Synthesis of Septedine}

The first and asymmetric total synthesis of septedine (68) was reported in 2018 by Li and co-workers. ${ }^{57}$ Septedine (68) is a hetidine type $\mathrm{C}_{20}$-diterpenoid alkaloid bearing an oxygenated heptacyclic scaffold. Highlights of the total synthesis are shown in Scheme 8. Starting from Weinreb

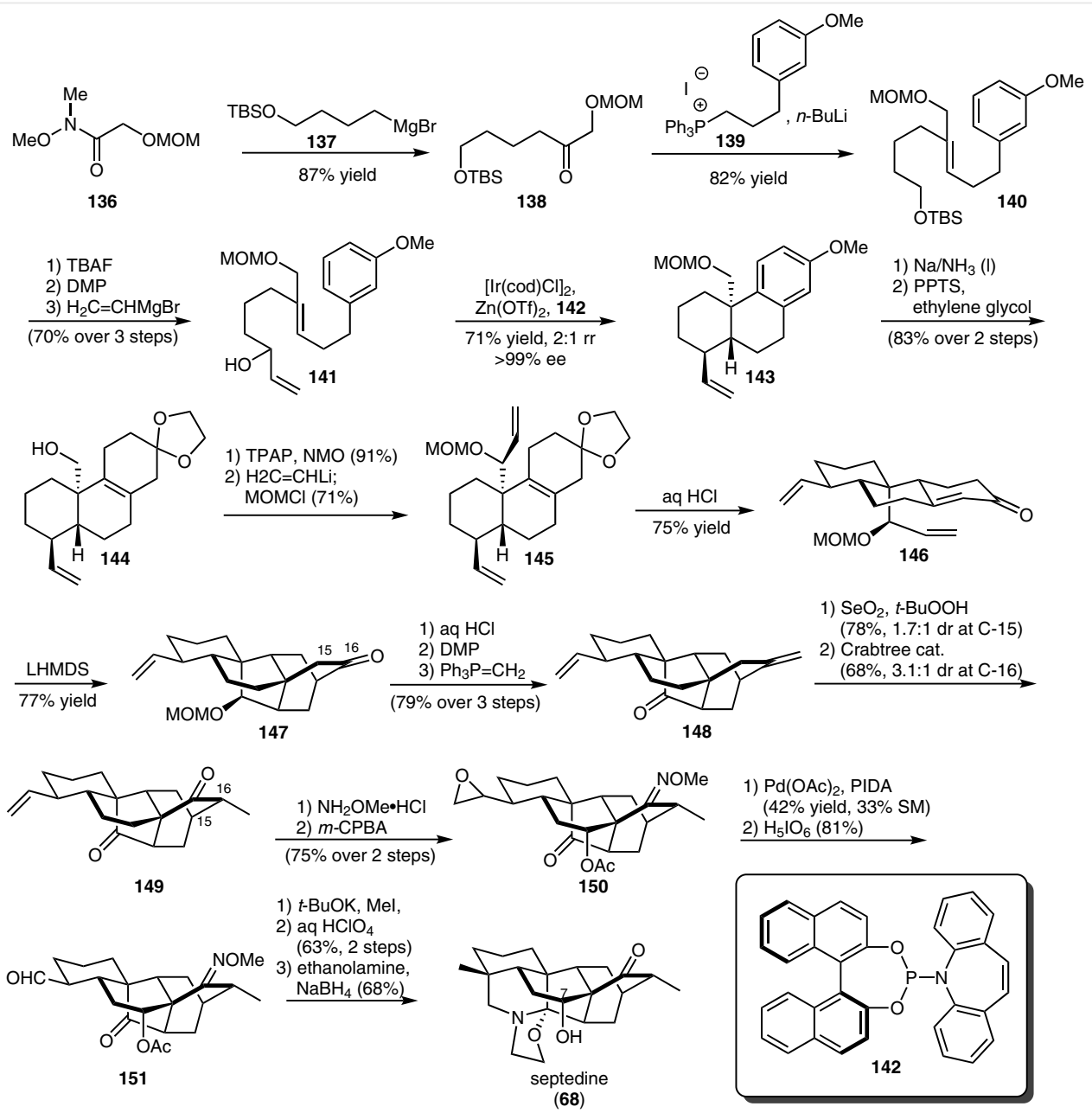

Scheme 8 Total synthesis of septedine 
amide 136, aryldiene 141 was accessible in 5 steps. Iridiumcatalyzed polyene cyclization using the conditions of Carreira gave tricyclic intermediate 143. Intermediate 146 was prepared in order to perform a Diels-Alder reaction. Surprisingly, treatment of $\mathbf{1 4 6}$ with LHMDS gave cyclized product 147. In a sequence of five steps, the protected secondary alcohol was transformed into a ketone, and several manipulations on $\mathrm{C}-15$ and $\mathrm{C}-16$ led to intermediate $\mathbf{1 4 9}$. C-H activation of C-7 via Sanford's oxidation conditions and conversion of the vinyl group, via an epoxide, into an aldehyde gave 151. The natural product septedine (68) was obtained through a methylation, ester hydrolysis, and reductive amination which occurred under concomitant condensation. In order to investigate the final steps (reductive amination and $\mathrm{N}, \mathrm{O}$-ketalization), 7-deoxyseptedine was prepared from a model substrate (not shown).

\subsubsection{Total Synthesis of Azitine}

A unified approach to assemble atisine-and hetidinetype diterpenoid alkaloids was presented by Liu and Ma. ${ }^{55}$ The total syntheses of azitine (66) and the reported structure of navirine C (156) are shown in Scheme 9. Both syntheses contain a common sequence from nitrile $\mathbf{1 5 7}$ to tetracyclic dinitrile $\mathbf{1 5 2}$ in 10 steps (Scheme 10). Reduction of 152 with $\mathrm{LiAlH}_{4}$ and $\mathrm{Li} / \mathrm{NH}_{3}$ (liq.) led to the formation of imine 153. The final steps towards natural product azitine (66) were a deprotection, olefination, and subsequent allylic oxidation. The other synthesis accomplished from tetracyclic dinitrile $\mathbf{1 5 2}$ started with the formation of the bond between C-20 and C-14 under Shenvi's conditions to give cyclized product 154. A further six steps were required to obtain a structure that was reported to be the natural product navirine C (156), but the spectroscopic data differed from the reported data after isolation.

$$
\text { OTBS }
$$

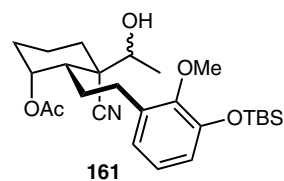

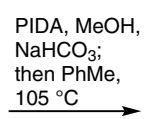
$105^{\circ} \mathrm{C}$

$88 \%$ yield
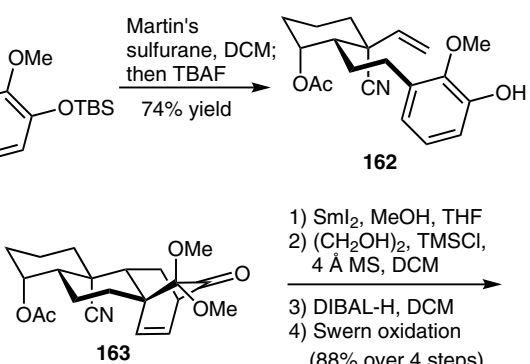

162 1) $\mathrm{Sml}_{2}, \mathrm{MeOH}, \mathrm{THF}$ $4 \AA \mathrm{MS}, \mathrm{DCM}$

3) DIBAL-H, DCM 4) Swern oxidation (88\% over 4 steps)

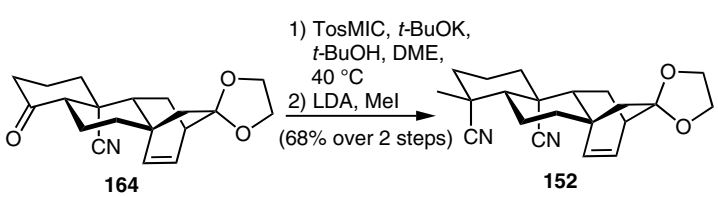

Scheme 10 Synthesis of the common intermediate for the total syntheses of azitine and the proposed structure of navirine $C$

\subsubsection{Formal Synthesis of ( \pm )-Atisine}

A formal synthesis of ( \pm )-atisine (28), utilizing a cascade of oxidative dearomatization/intramolecular Diels-Alder cycloaddition, was reported by Wang, Chen, and co-workers in 2012.41 As shown in Scheme 11, aldehyde $\mathbf{1 6 7}$ was accessible from commercially available ethyl 2-oxocyclohexanecarboxylate (165) in 9 steps. Wittig olefination gave styrene

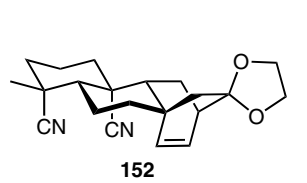

1) $\mathrm{LiAlH}_{4}, \mathrm{Et}_{2} \mathrm{O}, 50^{\circ} \mathrm{C}$ 2) $\mathrm{Li} / \mathrm{NH}_{3}, \mathrm{THF}$ $\underset{\text { (46\% over } 2 \text { steps })}{\stackrel{\text { - }}{\longrightarrow}}$ 152

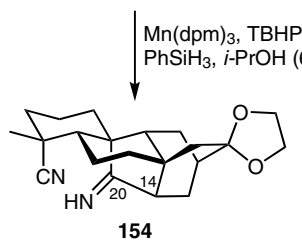

154

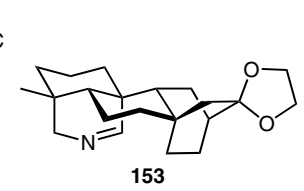

153

1) $\mathrm{Pd} / \mathrm{C}, \mathrm{H}_{2}, \mathrm{MeOH}, \mathrm{AcOH}$; then $\mathrm{HCHO}, \mathrm{NaCNBH}_{3}$ 2) $\mathrm{TsOH}$, acetone, $\mathrm{H}_{2} \mathrm{O}, 40^{\circ} \mathrm{C}$ ( $72 \%$ over 2 steps)

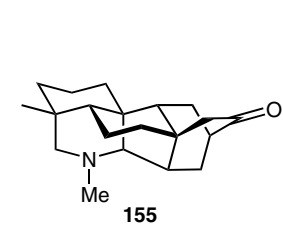

155
1) $\mathrm{TsOH}$ acetone, $\mathrm{H}_{2} \mathrm{O}, 40^{\circ} \mathrm{C}$

2) $\mathrm{Ph}_{3} \mathrm{PCH}_{3} \mathrm{Br}, n$-BuLi, THF, $70^{\circ} \mathrm{C}$

(91\%, 2 steps)

3) $\mathrm{SeO}_{2}, \mathrm{TBHP}, \mathrm{DCM}(56 \%)$

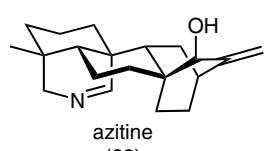

(66)

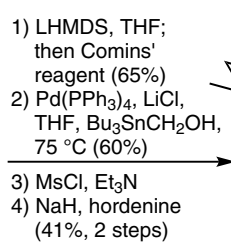

( $41 \%, 2$ steps)

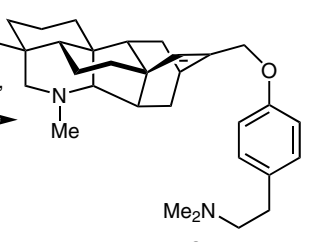

Scheme 9 Total syntheses of azitine and the proposed structure of navirine $C$ 
168, which was transformed into phenol 169 in five steps. Oxidative dearomatization and intramolecular Diels-Alder cycloaddition was followed by hydrogenation, olefination, and cleavage of an acetal group to give enone $\mathbf{1 7 0}$. This intermediate was previously used by Pelletier and coworkers, and therefore this constitutes a formal synthesis of ( \pm )-atisine $(\mathbf{2 8}) \cdot{ }^{15,68}$

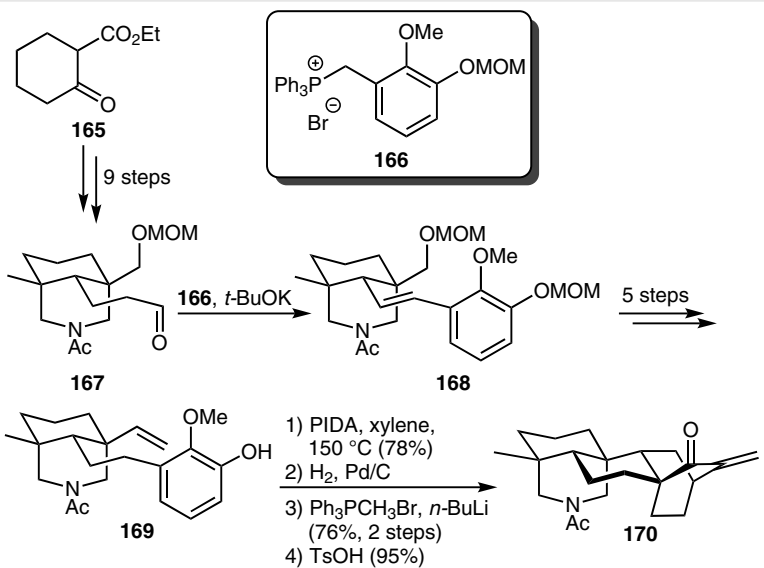

Scheme 11 Oxidative dearomatization/intramolecular Diels-Alder cycloaddition cascade for the synthesis of $( \pm)$-atisine

\subsubsection{Synthesis of the Hetidine Scaffold and Total Syn- thesis of Dihydroajaconine and Gymnandine}

A bioinspired synthetic approach to the skeleton of the $\mathrm{C}_{20}$-diterpenoid alkaloid type hetidine was presented by Qin, Liu, and co-workers;53,69 Scheme 12 outlines the synthetic path. Starting from 172, ${ }^{39,40}$ alkene 174 was obtained in 5 steps. Then, a Corey-Seebach reaction followed by the well-established oxidative dearomatization and intramolecular Diels-Alder cascade were performed to obtain intermediate 176. The synthesis of this intermediate also concluded the synthesis of the pentacyclic atisine skeleton.

Intermediate 177 was treated with $\mathrm{MeMgBr}$, the dithiane moiety was removed by reaction with Dess-Martin periodinane, and the resulting ketone was reduced to give diol 178. Deacetylation and subsequent amide formation gave intermediate 179, featuring the requisite C-7 hydroxy group and an $\boldsymbol{o}$-aminobenzamide moiety. Aminal $\mathbf{1 8 1}$ was obtained after reaction with $\mathrm{NaNO}_{2}, \mathrm{CuCl}$, and $\mathrm{HCl} / \mathrm{Et}_{2} \mathrm{O}$ reported by Weinreb and co-workers. ${ }^{70} \mathrm{~A}$ radical mechanism was postulated that proceeds via diazotization and a $1,5-\mathrm{H}$ shift to form intermediate 181, which has the ajaconine skeleton. Cyclization to give the desired hetidine-type product 183 was achieved by an aza-Prins reaction. Throughout the investigations, additional unwanted heptacyclic products were prepared (not shown).
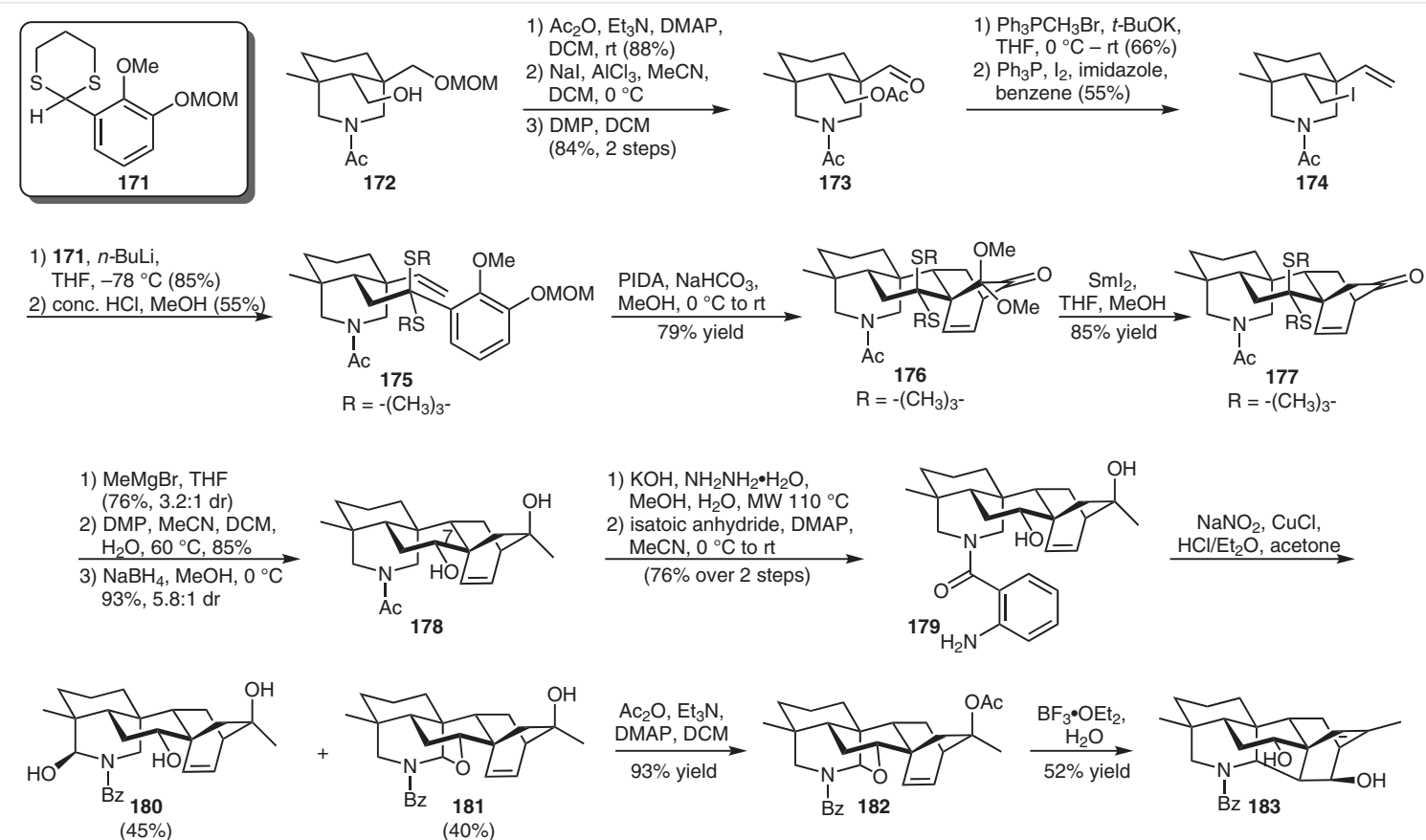

Scheme 12 Bioinspired synthesis of the hetidine skeleton 
Pentacyclic intermediate $\mathbf{1 7 7}$ was also used by Qin, Liu, and co-workers as starting point for the syntheses of dihydroajaconine (60) and gymnandine (62) (Scheme 13). ${ }^{53}$ Precursor 186 was subjected to the method developed by Weinreb and co-workers. ${ }^{70}$ Hemiaminal 187 was then successfully transformed into the atisine-type alkaloid diterpenoid dihydroajaconine (60) in 4 steps.

Simultaneous cleavage of the amide $\mathrm{C}-\mathrm{N}$ bond and the aminal $\mathrm{C}-\mathrm{O}$ bond of aminal 188 gave cyclic imine 191 in excellent yield. Oxidation of the secondary alcohol, as described by Iwabuchi and co-workers, ${ }^{71}$ and cyclization promoted by $\mathrm{SmI}_{2}$ and subsequent $N$-acetylation gave the hexacyclic intermediate 192 featuring the denudatine core. After construction of the carbon skeleton, natural product gymnandine (62) was obtained after six additional synthetic steps.

\subsubsection{Total Synthesis of Cossonidine}

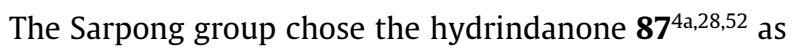
the entry point to their synthetic strategy (Scheme 14). They had previously enjoyed success towards the $C_{18}$-diterpenoid alkaloids scaffold, as well as the preparation of the 6-7-6 fused tricyclic core ${ }^{72}$ of the hetidine- and hetisinetypes using this compound as a starting point. ${ }^{56}$ In order to convert the ester into an aldehyde, $\mathbf{8 7}$ was treated with
$\mathrm{LiAlH}_{4}$, which led to the reduction of both the ester and ketone functionalities; Ley oxidation ${ }^{73}$ furnished the ketoaldehyde intermediate, which was immediately transformed into the olefin 195. Notably, the standard Wittig conditions were observed to give poor yields, so Lebel's Rh-catalyzed methylenation ${ }^{74}$ was employed. Acylation of intermediate 195 was accomplished using allyl cyanoformate (196), ${ }^{75}$ to afford the $\beta$-keto ester 197, which was followed by an aryne insertion assisted by CsF to provide intermediate 199. So as to later functionalize the $\mathrm{C} 6$ position, a deallylation reaction was performed ${ }^{76}$ using catalytic $\mathrm{Pd}\left(\mathrm{PPh}_{3}\right)_{4}$ and $\mathrm{PhSiH}_{3}$ to afford the carboxylic acid $\mathbf{2 0 0}$, which was then treated with 1,3-diiodo-5,5-dimethylhydantoin (DIH, 201) under photochemical conditions to achieve oxidative decarboxylation, ${ }^{77}$ and thus leave the C6 carbon as an internal olefin. The methyl group at C4 was installed by deprotection of the primary alcohol, followed by oxidation, then direct conversion into nitrile 203, which then directed the diastereoselective methylation of 203 leading to intermediate 204. This key intermediate bearing handles at C6 and C20 was now set up for formation of the piperidinyl ring. Treatment of 204 with a cobalt boride $\left(\mathrm{Co}_{2} \mathrm{~B}\right)$ and borane-tert-butylamine complex, ${ }^{78}$ followed by treatment with $\mathrm{LiAlH}_{4}$ to reduce the ketone and facilitate protodebromination, was accompanied by a serendipitous direct cyclization to form the N-C20 bond, thus accessing intermediate 205. Photochemical
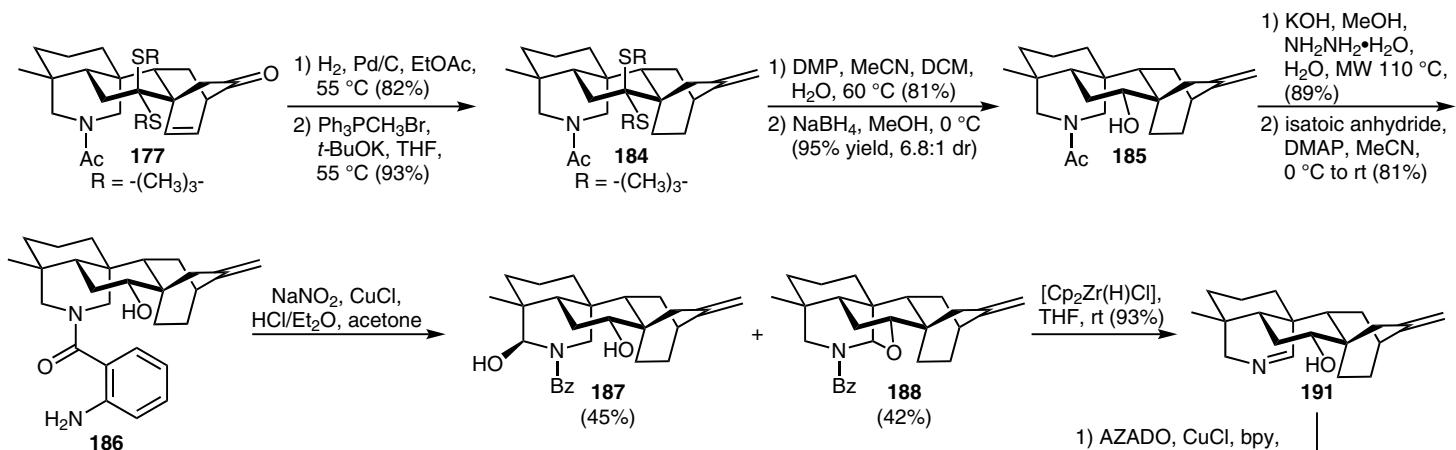

$\mathrm{EtSiH}, \mathrm{BF}_{3} \cdot \mathrm{OEt}_{2}$ DCM, $-788^{\circ} \mathrm{C}(64 \%)$

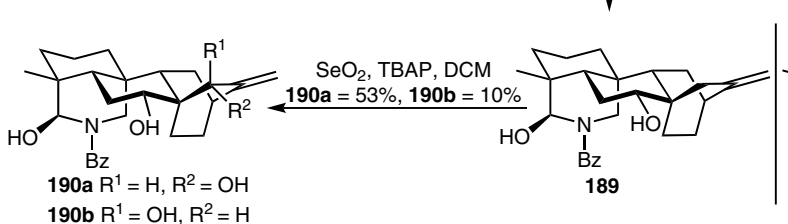

190a $R^{1}=H, R^{2}=O H$

1) $\left[\mathrm{Cp}_{2} \mathrm{Zr}(\mathrm{H}) \mathrm{Cl}\right]$, THF 2) 2-bromoethanol, $\mathrm{Cs}_{2} \mathrm{CO}_{3}, \mathrm{MeCN}$

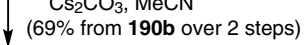
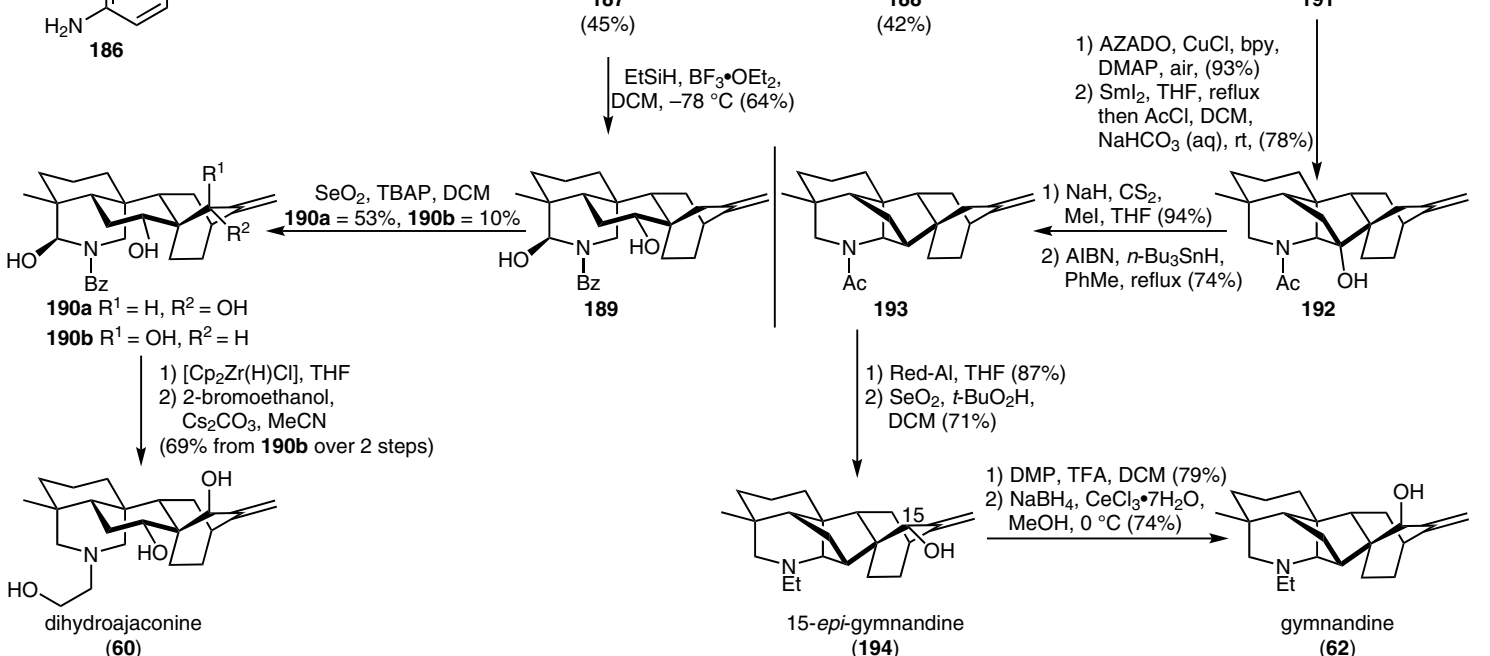

193

1) Red-Al, THF (87\%) $\mathrm{SeO}_{2}, t-\mathrm{BuO}_{2} \mathrm{H}$

) DMP, TFA, DCM (79\%) 2) $\mathrm{NaBH}_{4}, \mathrm{CeCl}_{3} \cdot 7 \mathrm{H}_{2} \mathrm{O}$

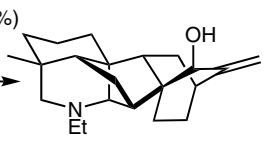
$(60)$ (194) gymnandine (62)

Scheme 13 Syntheses of dihydroajaconine and gymnandine; AZADO = 2-azaadamantane- $N$-oxyl 

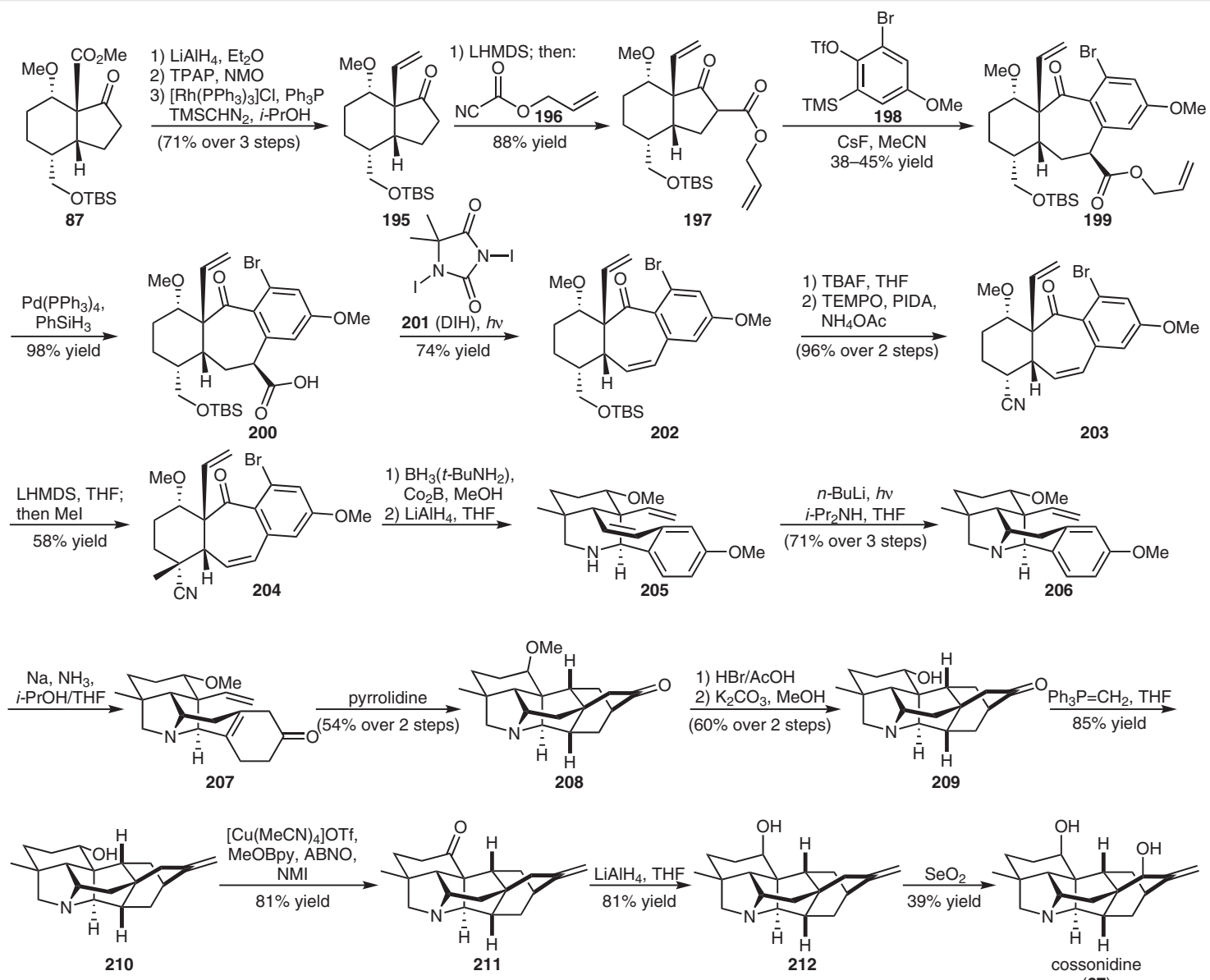

(67)

Scheme 14 Total synthesis of hetisine-type diterpenoid alkaloid cossonidine

hydroamination ${ }^{79}$ afforded the tertiary amine $\mathbf{2 0 6}$. The formation of the bicyclo[2.2.2] rings was effected through a Birch reduction/intramolecular Diels-Alder sequence ${ }^{80}$ to give the structural core 208. The selective cleavage of the $\mathrm{C1}$ methyl ether was carried out using $\mathrm{HBr} / \mathrm{AcOH}$, followed by treatment with $\mathrm{K}_{2} \mathrm{CO}_{3}$ in methanol to yield the free alcohol 209. Next, a standard Wittig methylenation was carried out to convert the ketone of $\mathbf{2 0 9}$ into an exocyclic methylene 210, and thus completing the $C_{20}$ carbon scaffold for the hetisine-type skeleton. A sequence of oxidation/reduction was then utilized to invert the stereochemistry at the C1 position affording 212, which simply left a selenium dioxide oxidation to furnish the allylic alcohol and the final product cossonidine (67) ${ }^{56}$

\subsubsection{Total Synthesis of Lepenine}

The strategy employed by Fukuyama and co-workers in 2014 focused on expanding from the scaffold of tetralone 218, which was accessed over 8 steps starting from L-lactic acid methyl ester and guaiacol (213) in excellent yields (Scheme 15). ${ }^{51}$ Having established a successful route to the tetralone, the ketone was then transformed into the diene 219 through a Grignard addition to the ketone followed by silver triflate mediated dehydration. Deprotection of the pivaloyl group in $\mathbf{2 1 9}$ was then followed by coupling to a methacrylic group to afford a key intermediate, triene $\mathbf{2 2 0}$. This intermediate is now set up for the intramolecular Diels-Alder cycloaddition reaction, and upon heating in the presence of a radical scavenger (BHT), it afforded the tetracyclic lactone 221. Hydroboration-oxygenation of the internal alkene in $\mathbf{2 2 1}$ followed by a half reduction of the lactone 222 with DIBAL-H allowed access to the aldehyde $\mathbf{2 2 3}$, which was then converted into a secondary amine by reductive amination and protected with AllocCl to yield 224. This intermediate was then treated with DMP to afford a ketoaldehyde that was treated with $\mathrm{Pd}\left(\mathrm{PPh}_{3}\right)_{4}$ catalyst and acetic acid to remove the Alloc group and resulted in an intramolecular Mannich reaction. This sequence of manipulations provided the polycyclic system $\mathbf{2 2 5}$ and sets up the framework for the formation of the bicyclo[2.2.2] structural core. Two steps of functional group transformations accessed the ortho-quinone monoketal $\mathbf{2 2 6}$ that was treated with ethylene at $70{ }^{\circ} \mathrm{C}$ resulting in an intermolecular Diels- 


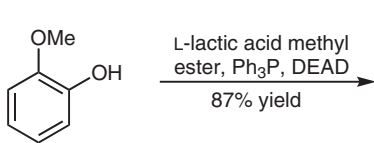

213<smiles>COc1ccccc1O[C@@H](C)C(C)=O</smiles>

214<smiles>C=C[C@H](O)[C@H](C)Oc1ccccc1OC</smiles><smiles>C/C=C/[C@H](CCC(C)=O)c1cccc(OC)c1O</smiles>

1) $\mathrm{MsCl}, \mathrm{Et}_{3} \mathrm{~N}(85 \%)$ \begin{tabular}{l} 
2) $\mathrm{O}_{3}, \mathrm{NaBH}_{4}(86 \%)$ \\
3) PivCl, DMAP $(80 \%)$ \\
\hline
\end{tabular}

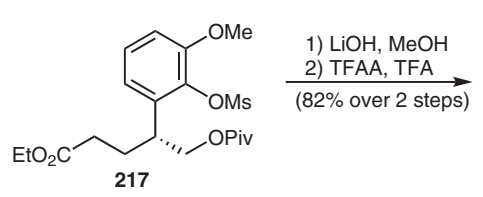

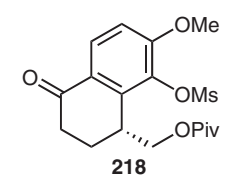

1) $\mathrm{H}_{2} \mathrm{C}=\mathrm{CHMgCl}(85 \%)$ 2) AgOTf, reflux (63\%)<smiles>C=CC1=CC[C@H](CO[Na])c2c1ccc(OC)c2OC</smiles>

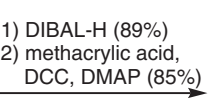<smiles>C=CC1=CC[C@H](COC(=O)C(=C)C)c2c1ccc(OC)c2OC</smiles>
$\underset{90 \% \text { yield }}{\stackrel{\mathrm{BHT}, \mathrm{PhCN}, 160^{\circ} \mathrm{C}}{\longrightarrow}}$<smiles>CCCC1(C)[C@]2(C)CCC=C3C(=O)COC[C@H](C[C@]12C)c1c3ccc(OC)c1OC</smiles>
$\underset{\substack{\mathrm{BH}_{3} \bullet \mathrm{THF}, \mathrm{THF} ; \\ \text { then } \mathrm{NaOH}, \mathrm{H}_{2} \mathrm{O}_{2}}}{\stackrel{97 \% \text { yield }}{\longrightarrow}}$

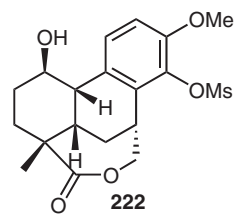

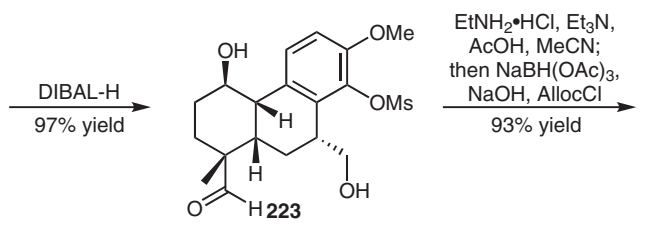<smiles>CCNC[C@]1(C)CC[C@@H](O)[C@H]2c3ccc(OC)c(OC)c3[C@H](CO)C[C@]2(C)[C@H]1CO</smiles>

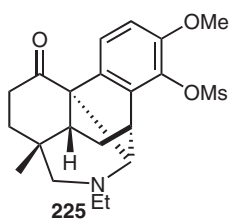

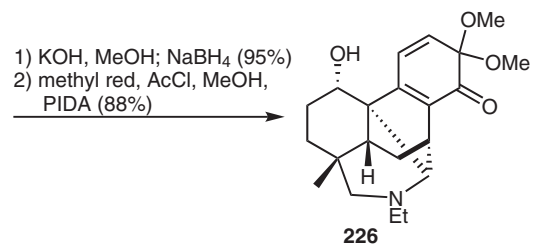
ethylene, DCM,
$\stackrel{70^{\circ} \mathrm{C}, 5 \mathrm{~d}}{\longrightarrow}$

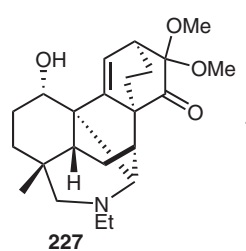
\begin{tabular}{l} 
1) $\mathrm{TBSOTf}$ lutidine (91\%) \\
2) $\mathrm{Sml}_{2}, \mathrm{MeOH}(96 \%)$ \\
\hline 3) $\mathrm{Red}-\mathrm{Al}, \mathrm{PhMe}(88 \%)$ \\
4) $\mathrm{BH}_{3} \cdot \mathrm{THF}, \mathrm{H}_{2} \mathrm{O}$, \\
$\mathrm{NaBO}_{3}\left(\mathrm{H}_{2} \mathrm{O}\right)(54 \%)$
\end{tabular}

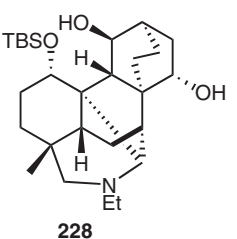
\begin{tabular}{l} 
1) $\mathrm{DMP}, \mathrm{DCM}(72 \%)$ \\
2) $\mathrm{HCO}_{2} \mathrm{Et}, \mathrm{KHMDS} ;$ \\
then $\mathrm{HCHO}(50 \%)$ \\
\hline
\end{tabular}

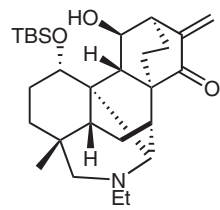
1) $\mathrm{NaBH}_{4}, \mathrm{CeCl}_{3} \bullet 7 \mathrm{H}_{2} \mathrm{O}(83 \%)$
2) TBAF, THF $(93 \%)$

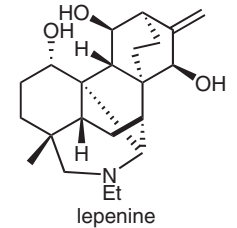

(58)

Scheme 15 Total synthesis of denudatine-type diterpenoid alkaloid lepenine

Alder reaction to give the bicyclo[2.2.2] 227; functional group manipulations and final deprotection of protecting groups gave lepenine (58). ${ }^{51}$

\subsubsection{Total Syntheses of Cochlearenine, $N$-Ethyl-1 $\alpha$ - hydroxy-17-veratroyldictyzine, and Paniculamine}

The Sarpong group embarked on the mammoth task to design a route that was suitably amenable to modifications at the latest possible stage and yet still access 59, 63, and 61/241; three denudatine-type diterpenoid alkaloids (Scheme 16). ${ }^{52}$ This was achieved by designing a route to intermediate cochlearenine (59); from $\mathbf{5 9}$, following a few late-stage manipulations of the functional groups on the bicyclo[2.2.2] structural element, each of the intended targets was successfully accessed. Starting from 93, which the
Sarpong group had previously designed and accessed in 10 steps ( $25 \%$ overall yield) ${ }^{28}$ the primary alcohol was converted into the corresponding aldehyde $\mathbf{2 3 0}$ via a Swern oxidation. An aldol-Cannizzaro sequence on $\mathbf{2 3 0}$ afforded the diol 231, which was then converted into the dimesylate 102 (76\%). Intermediate $\mathbf{1 0 2}$ was treated with $\mathrm{KH}$ to effect the cyclization yielding $\mathbf{2 3 2}$ as the sole product. Next, the methylene $\mathbf{O}$-mesylate group of $\mathbf{2 3 2}$ was transformed into a methyl group via reduction with the combination of $\mathrm{NaI} / \mathrm{Zn}$. This was a key step in the strategy, as stereoselective installation of the methyl group, which is present in all the $C_{20}$ alkaloids, was achieved. Following the removal of the MOM protecting group, oxidative dearomatization of the resulting phenol afforded the dienone 233. This dienone was then heated to $150{ }^{\circ} \mathrm{C}$ to allow formation of the intramolecular Diels-Alder cycloaddition product 234, thus forming 

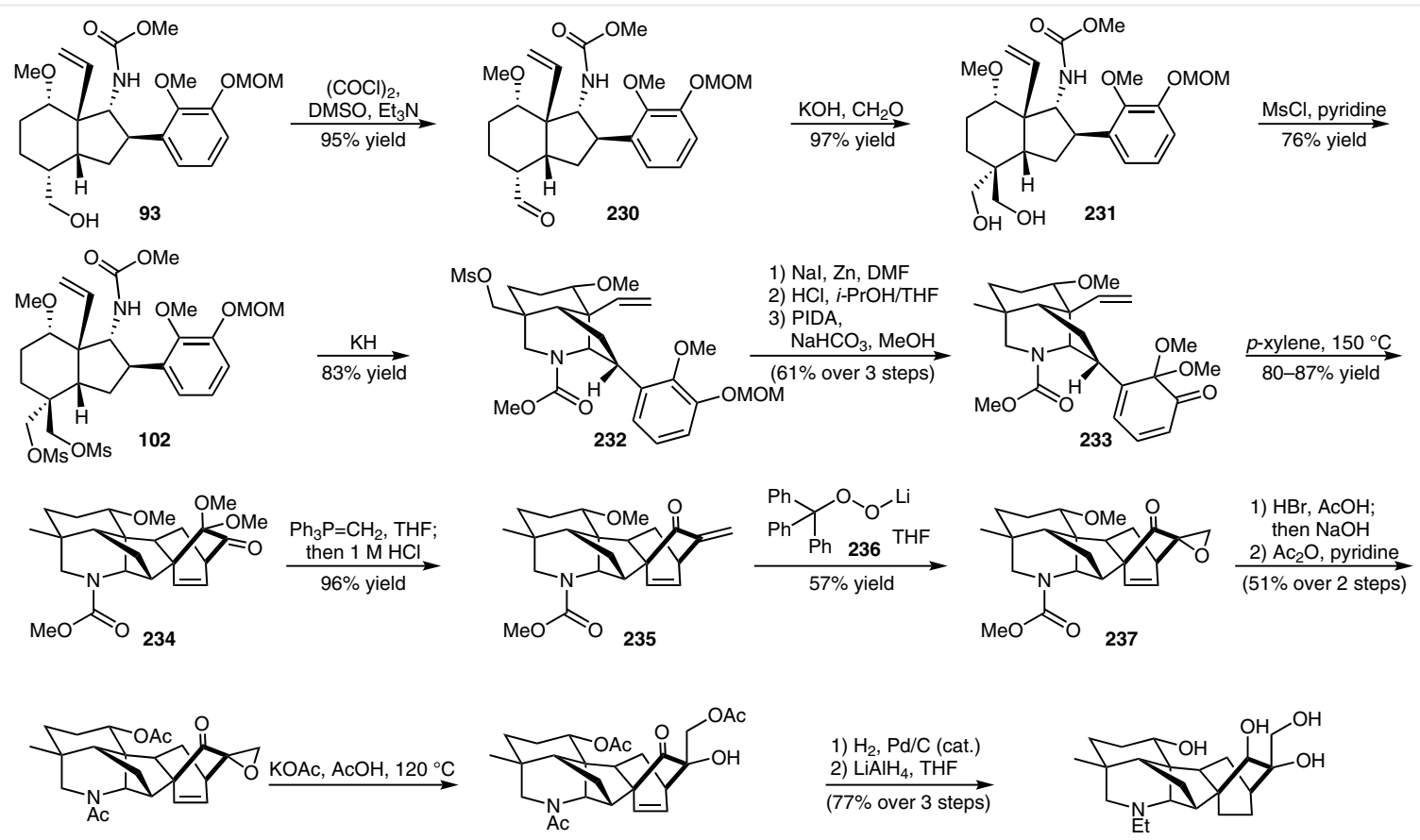

238

239
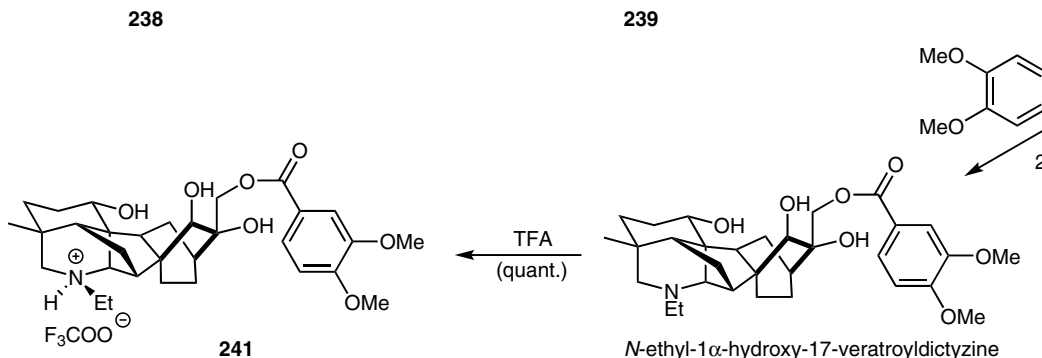

(61)

cochlearenine

(59)

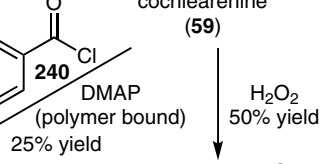

Scheme 16 Total synthesis of denudatine-type diterpenoid alkaloids cochlearenine, N-ethyl-1 $\alpha$-hydroxy-17-veratroyldictyzine, and paniculamine

all the requisite rings for the $\mathrm{C}_{20}$ scaffold. The addition of the carbon atom on the bicyclo[2.2.2] structure of $\mathbf{2 3 4}$ was achieved by Wittig methylenation and ketal hydrolysis to afford 235 and a modified Weitz-Scheffer epoxidation ${ }^{81}$ to install an $\alpha$-epoxide thus forming 237 . The epoxy ketone 237 was then treated with a solution of $\mathrm{HBr} / \mathrm{AcOH}$ at $110^{\circ} \mathrm{C}$ effectively cleaving the methyl carbamate and the methyl group on the $\mathrm{C} 1$ hydroxyl; the reaction mixture was quenched with $\mathrm{NaOH}$, then treated with $\mathrm{Ac}_{2} \mathrm{O}$ and pyridine to form intermediate 238. Functional group manipulations of $\mathbf{2 3 8}$ gave cochlearenine (59) which was coupled with veratroyl chloride to produce $N$-ethyl- $1 \alpha$-hydroxy-17-veratroyldictyzine (61) in $25 \%$ yield, and its protonated TFA salt form 241 upon treatment with TFA. Finally, treatment of $\mathbf{5 9}$ with $\mathrm{H}_{2} \mathrm{O}_{2}$ gave paniculamine $(63)$ in $50 \%$ yield. ${ }^{52}$
2.3.8 Total Syntheses of ( \pm )-Spiramilactone B, ( \pm )-Spiraminol, ( \pm )-Dihydroajaconine, and $( \pm)$-Spiramines $C$ and $D$

The strategy employed by Xu and co-workers in 2016 focused on targeting $\mathbf{2 4 2}$ as the entry point into this multitarget synthesis (Scheme 17). ${ }^{54}$ This tricyclic intermediate $\mathbf{2 4 5}$ was accessed in large quantities, over two steps, as a single diastereomer, in excellent yields. ${ }^{82,83}$ This tricyclo[6.2.2. $0^{1,6}$ structure $\mathbf{2 4 5}$ was then taken through a series of functional group transformations to afford intermediate 246, which was converted into the $\alpha, \beta$-unsaturated methyl ester 247. This key scaffold 247 was alkylated ${ }^{84}$ at C10 by treatment with lithium diisopropylamide and 1,3-dimethyl-3,4,5,6-tetrahydropyrimidin-2(1H)-one (DMPU) followed by addition of the electrophile $\mathbf{2 4 8}$ to give $\mathbf{2 4 9}$ 


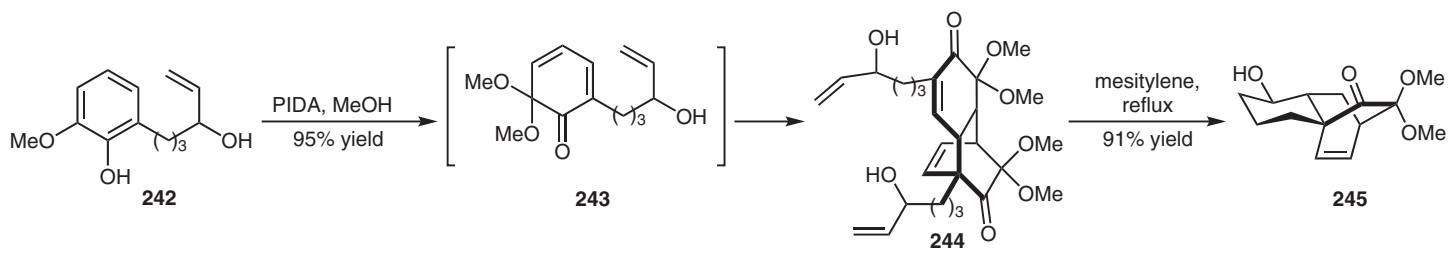
1) $\mathrm{Sml}_{2}, \mathrm{THF} / \mathrm{MeOH}(72 \%)$
2) $(\mathrm{CHOH})_{2}, \mathrm{CSA}(90 \%)$
3) $\mathrm{DMP}, \mathrm{DCM}, \mathrm{NaCO}{ }_{3}(92 \%)$
4) $\mathrm{H}_{2}, \mathrm{Pd} / \mathrm{C}, \mathrm{MeOH}(96 \%)$

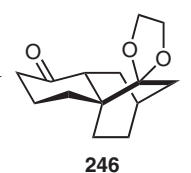

1) NaHMDS, $\mathrm{Tf}_{2} \mathrm{NPh}$ 2) $\mathrm{Pd}\left(\mathrm{PPh}_{3}\right)_{4}, \mathrm{Et}_{3}$ $\underset{(89 \%, 2 \text { steps })}{\longrightarrow}$

1) $\mathrm{K}_{2} \mathrm{CO}_{3}, \mathrm{MeOH}(95 \%)$ 2) $n$ - $\mathrm{BuLi}, \mathrm{ClCO}_{2} \mathrm{Me}, \mathrm{THF}(83 \%)$ 3) $\left[\mathrm{CpRu}(\mathrm{MeCN})_{3}\right] \mathrm{PF}_{6}, \mathrm{TsOH}(91 \%)$
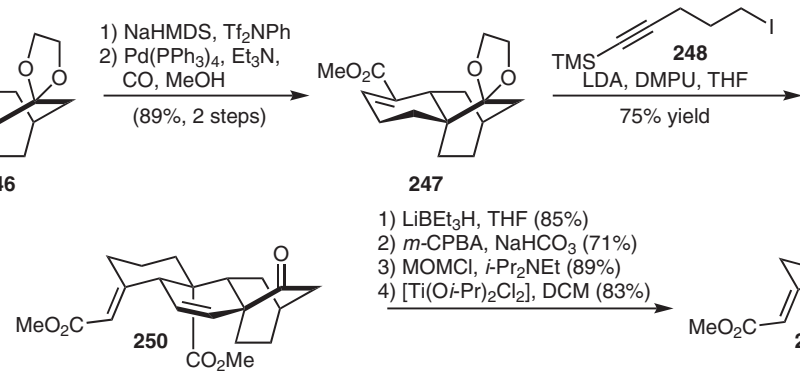

247

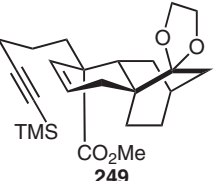

1) $\mathrm{LiBEt}_{3} \mathrm{H}, \mathrm{THF}(85 \%)$

2) $m$-CPBA, $\mathrm{NaHCO}_{3}(71 \%$

3) $\mathrm{MOMCl}, i-\mathrm{Pr}_{2} \mathrm{NEt}(89 \%)$

4) $\left[\mathrm{Ti}(\mathrm{O} i-\mathrm{Pr})_{2} \mathrm{Cl}_{2}\right], \mathrm{DCM}(83 \%)$

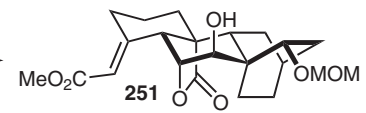

1) $\mathrm{DMP}, \mathrm{NaHCO}_{3}(90 \%)$

2) $\mathrm{Sml}, \mathrm{THF} / \mathrm{MeOH}$

3) $\mathrm{NaBH}_{4}, \mathrm{CeCl}_{3} \cdot 7 \mathrm{H}_{2} \mathrm{O}$

4) DIC, HOBt (75\%, 3 steps)

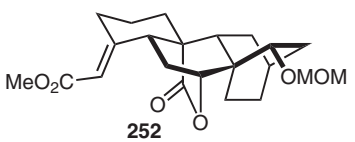

1) $\mathrm{O}_{3}, \mathrm{DCM}(95 \%$

2) $\mathrm{PbCl}_{2}, \mathrm{Zn}, \mathrm{TiCl}_{4}, \mathrm{CH}_{2} \mathrm{Br}_{2}(72 \%)$

3) DIBAL-H, DCM

4) PPTS, $\mathrm{MeOH}(85 \%, 2$ steps)

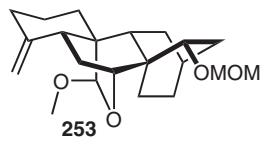

1) $\mathrm{BH}_{3} \cdot \mathrm{SMe}_{2}, \mathrm{H}_{2} \mathrm{O}_{2}, \mathrm{NaOH}(75 \%)$ 2) $\mathrm{DMP}, \mathrm{NaHCO}$

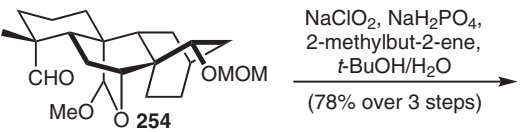

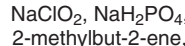

(78\% over 3 steps)

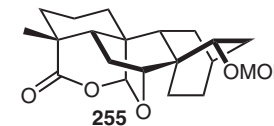

1) $\mathrm{ZnBr}_{2}, \mathrm{DCM}, n-\mathrm{PrSH}$ 2) $\mathrm{DMP}, \mathrm{NaHCO}_{3}$ (81\% over 2 steps)

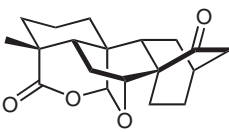

1) LHMDS, $\left(\mathrm{Me}_{2} \mathrm{~N}^{+}=\mathrm{CH}_{2}\right) I^{-}$, $\mathrm{Mel}, \mathrm{DBU}(71 \%)$ 2) $\mathrm{NaBH}_{4}, \mathrm{MeOH} / \mathrm{DCM}(95 \%)$ 256

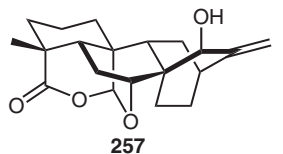

1) $\mathrm{PHSCl}, \mathrm{Et}_{3} \mathrm{~N}(99 \%)$ 2) $\mathrm{P}(\mathrm{OMe})_{3}, \mathrm{MeOH}(64 \%)$

257
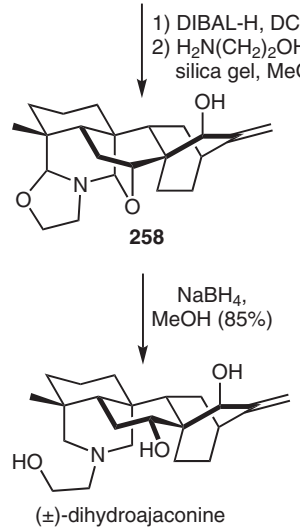

(60)

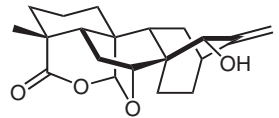

$( \pm)$-spiramilactone B (259)

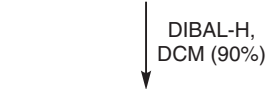

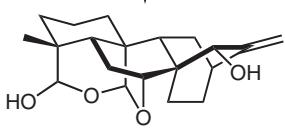

$( \pm)$-spiraminol (260)

$\mathrm{H}_{2} \mathrm{~N}\left(\mathrm{CH}_{2}\right)_{2} \mathrm{OH}$, THF, silica gel,

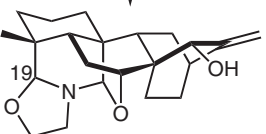

+)-spiramine C, $19-(S)(64,60 \%)$ ( \pm -spiramine $\mathrm{D}, 19-(R)(65,36 \%)$

Scheme 17 Total synthesis of atisine-type diterpenoid alkaloids spiramilactone B, spiraminol, dihydroajaconine, spiramine C, and spiramine D

The alkynyl-substituted ester $\mathbf{2 4 9}$ was desilylated and acylated, and then subjected to Ru-catalyzed cycloisomerization to give tetracyclic ketone $\mathbf{2 5 0}$ as a single diastereomeric product. To set up for the bridged core structure, intermediate 250 was treated with $\mathrm{LiBEt}_{3} \mathrm{H}$, the C6-C7 olefin was epoxidized using $m$-CPBA, and the free hydroxyl group was protected; regioselective epoxide opening catalyzed by $\left[\mathrm{Ti}(\mathrm{Oi}-\mathrm{Pr})_{2} \mathrm{Cl}_{2}\right]$ afforded the formation of hydroxy $\gamma$-lactone 251, thereby completing the pentacyclic core structure. This $\gamma$-lactone $\mathbf{2 5 1}$ was rearranged to the $\delta$-lactone $\mathbf{2 5 2}$ over a few synthetic manipulations. Treatment of $\mathbf{2 5 2}$ with ozone gave the ketone which was converted into a terminal olefin by Takai olefination; ${ }^{85}$ this lactone was then partially reduced to the aldolactol, followed by condensation with $\mathrm{MeOH}$ to afford 253. A hydroboration-oxidation reaction on the olefin of $\mathbf{2 5 3}$ allowed access to the primary alcohol, which was converted into the aldehyde, thus allowing for selective alkylation on treatment with potassium tert-butoxide and methyl iodide. The lactone $\mathbf{2 5 5}$ was directly accessed by a Pinnick oxidation ${ }^{86}$ of $\mathbf{2 5 4}$ and completed the 
core skeleton of spiramilactone B (259). At this point only a few tailoring steps were required to access the specific diterpenoids of the atisine type. ${ }^{54}$

\subsubsection{Total Syntheses of (-)-Methyl Atisenoate, (-)- Isoatisine, and a Hetidine Derivative}

The Baran group developed a unified approach to entatisane diterpenoids and related alkaloids. ${ }^{50}$ As illustrated in Scheme 18, (-)-methyl atisenoate (264), (-)-isoatisine (29), and also 268, a hetidine skeleton, were synthesized starting from (-)-steviol (261). The synthesis of ent-atisane started by methylation of $\mathbf{2 6 1}$ followed by treatment with Mukaiyama's conditions, ${ }^{87}$ which led directly to diketone 262. Cyclization of $\mathbf{2 6 2}$ was realized by Amberlyst-15 promoted aldol reaction and then dehydration reaction with Martin's sulfurane gave exomethylene 263, which underwent Wolff-Kishner reduction and re-esterification to complete the synthesis of (-)-methyl atisenoate (264). Intermediate 266 was obtained from (-)-steviol (261) in 6 steps. Neopentyl iodide $\mathbf{2 6 7}$ was obtained after a Hoffmann-Löffler-Freytag reaction. Condensation with allylamine led to Mannich-type reaction cyclization and thus formed the hetidine skeleton $\mathbf{2 6 8}$ in good yield. The synthesis of the other diterpenoid alkaloid presented, (-)-isoatisine (29), was also synthesized starting from intermediate $\mathbf{2 6 6}$. The ketone moiety on C13 was removed in 3 steps to give $\mathbf{2 6 9}$, $\mathrm{C}-\mathrm{H}$ activation led to neopentyl iodide $\mathbf{2 7 0}$, which was subsequently transformed into alcohol $\mathbf{2 7 1}$. Installation of an exomethylene group into $\mathbf{2 7 1}$, followed by allylic oxidation and the subsequent condensation with ethanolamine gave (-)-isoatisine (29).

\section{Strategies to Synthesize Ring Systems}

\subsection{Radical-Based Cyclizations}

In 2016, Inoue and co-workers disclosed the use of a radical-based cyclization/translocation/cyclization process followed by an aldol cyclization for the synthesis of the fused hexacycle of puberuline $C$ (278) (Scheme 19). ${ }^{88}$ Treatment of tricycle $\mathbf{2 7 2}$ with $n-\mathrm{Bu}_{3} \mathrm{SnH}$ and $\mathbf{2 7 3}(\mathrm{V}-40)$ under refluxed conditions initiated a 7-endo cyclization from $\mathrm{C} 11$ to C10, followed by a 1,5-hydrogen abstraction from C7 to $\mathrm{C} 17$, and finally resulting in a transannular 6-exo cyclization from $\mathrm{C} 17$ to $\mathrm{C} 8$. The efficiency of this cascade is remarkable as five stereocenters (C8, C9, C10, C11, and C17) are introduced with the desired stereoconfiguration despite the moderate yield of $\mathbf{2 7 4}$ (54\%). After treatment of $\mathbf{2 7 4}$

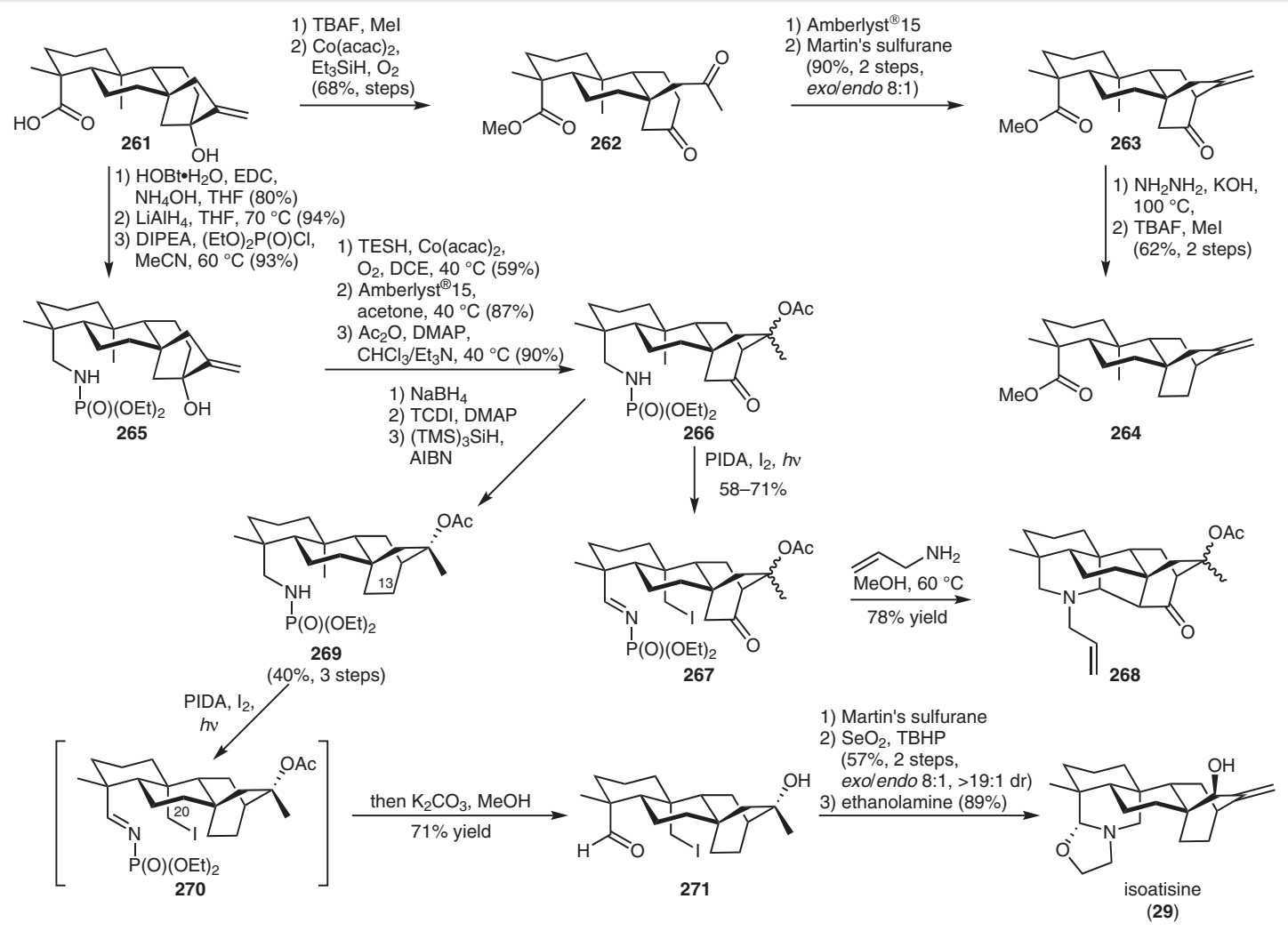

Scheme 18 Synthesis of (-)-methyl atisenoate, (-)-isoatisine, and hetidine derivative from the common precursor (-)-steviol 

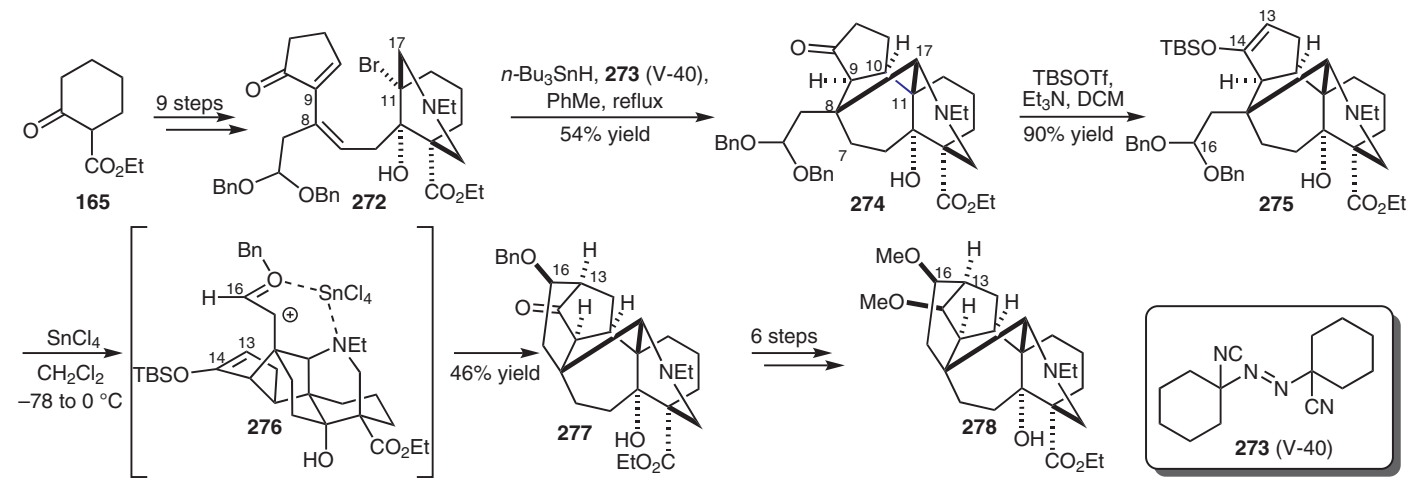

Scheme 19 Radical-based cyclization/translocation/cyclization process followed by an aldol reaction for the synthesis of the fused hexacycle of puberuline $C$

with TBSOTf to give the silyl enol ether $\mathbf{2 7 5}$, variety of Lewis acids were screen for the intramolecular Mukaiyama aldol reaction of 275; this reaction was realized using $\mathrm{SnCl}_{4}$ to activate the acetal moiety for the formation of the $\mathrm{D}$ ring in 277. The stereoconfiguration of $\mathrm{C} 16$ can be explained by the binding of $\mathrm{SnCl}_{4}$ between the oxygen and nitrogen atoms in $\mathbf{2 7 6}$ which dictates the nucleophilic attack of the silyl enol ether on to the $s i$-face of the oxocarbenium ion. Subsequent steps installed the stereocenter at C14 of the hexacyclic core of puberuline $\mathrm{C}$.

In 2016, Inoue and co-workers detailed the formation of the pentacyclic core of talatisamine (49) via radical and cationic cyclizations (Scheme 20). ${ }^{89}$ Treating 279 with $n-\mathrm{Bu}_{3} \mathrm{SnH}$ and $\mathbf{2 8 0}(\mathrm{V}-70)$ resulted in the formation of a stereochemi- cally fixed C11 bridgehead radical 283 that underwent stereo- and regioselective 7-endo cyclization on to C10 to form the $\mathrm{B}$ ring in 284. Steric repulsion between the C5-TMS ether and C14-acetal moieties favored the transition state 283 over 281.

Purification of $\mathbf{2 8 4}$ with silica gel caused C14-oxygen $\beta$ elimination and C9 epimerization to form enone $\mathbf{2 8 5}$ and trans-fused $\mathbf{2 8 6}$ from the initial cis-fused 284, respectively. Treatment of $\mathbf{2 8 5}$ with NaH yields $\mathbf{2 8 6}$ in a 79\% combined yield from 279. Pentacycle $\mathbf{2 8 6}$ was then converted into $\mathbf{2 8 7}$ in ten steps which were required to carry out a 6-endo cationic cyclization to install the $\mathrm{D}$ ring. The $\mathrm{C} 15-\mathrm{C} 16$ double bond was activated with $\mathrm{PhSeCl}$, allowing attack by the TBS

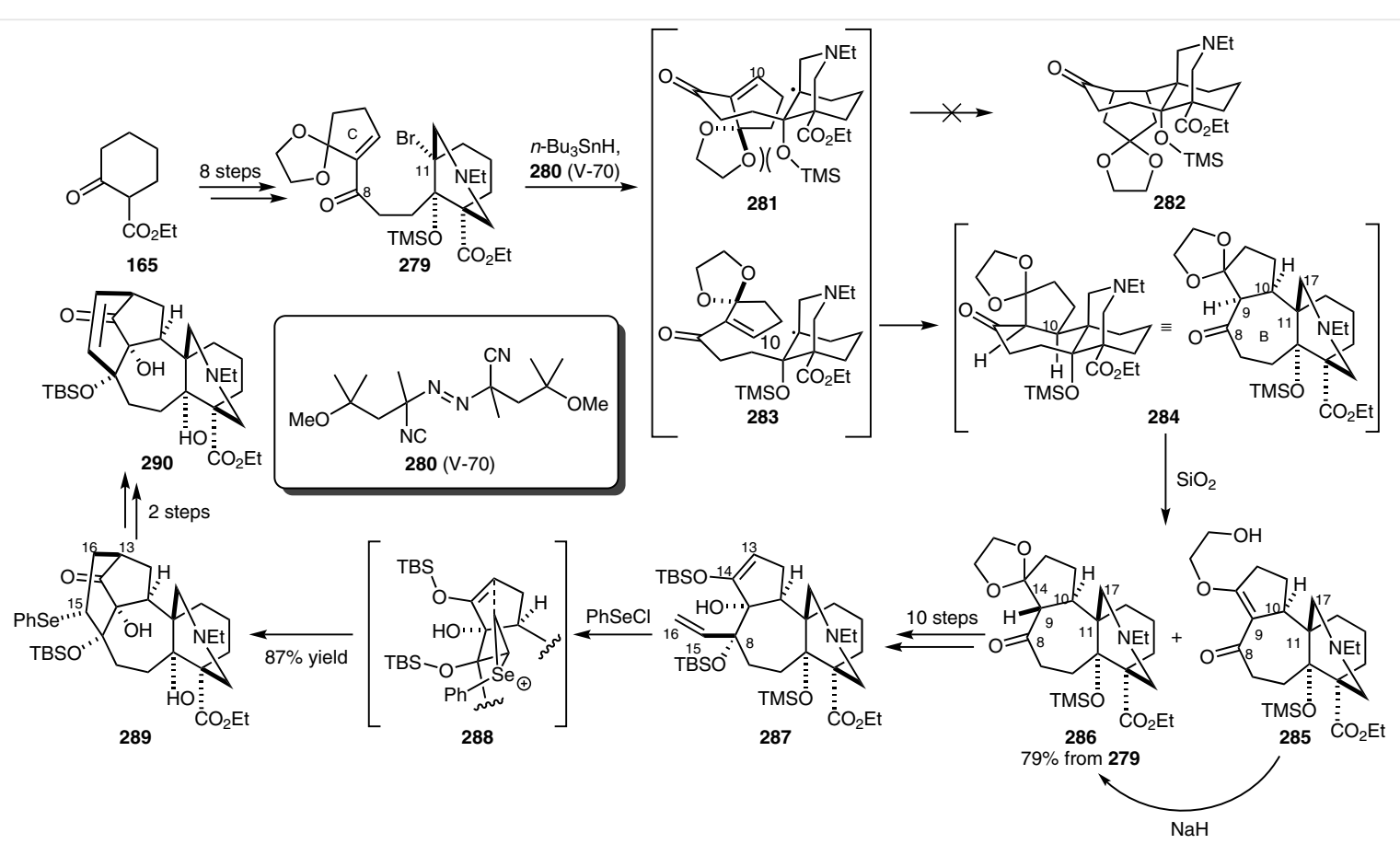

Scheme 20 Radical and cationic cyclizations for the formation of the pentacyclic core of talatisamine 
enol ether to afford pentacycle 289. Finally, oxidation of selenide $\mathbf{2 8 9}$ triggers a selenoxide elimination to give the pentacyclic core $\mathbf{2 9 0}$ of talatisamine (49).

In 2017, Inoue and co-workers disclosed a three-component coupling approach to append the $\mathrm{AE}$ ring systems to the $\mathrm{C}$ ring of $\mathrm{C}_{19}$-diterpenoid alkaloids in an expedient manner (Scheme 21). ${ }^{90}$ The strategy utilized a radical-polar crossover cascade initiated with $\mathrm{Et}_{3} \mathrm{~B} / \mathrm{O}_{2}$ and iodide $\mathbf{2 9 1}$ to form a bridgehead radical that first underwent conjugate addition with enone $\mathbf{2 9 2}$ on the opposite side of the OTBS substituent. The boron enolate intermediate 293 then underwent an aldol addition with alkynal 294 via the sixmembered transition state $\mathbf{2 9 5}$ to form the coupled product 296. High chemoselectivity was demonstrated as no addition to the alkyne was observed. The simultaneous generation of three new stereocenters in a single step under mild reaction conditions proved to be an efficient method to provide the advanced intermediate for the synthesis of $\mathrm{C}_{19}$-diterpenoid alkaloids.
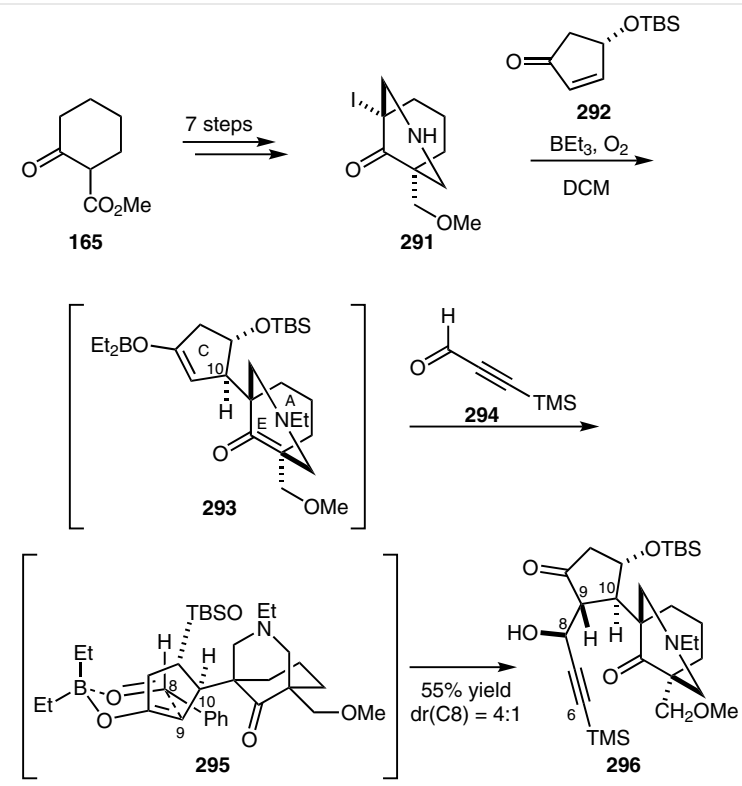

Scheme 21 Three-component radical-polar crossover cascade for the formation of the ACE ring systems of $\mathrm{C}_{19}$-diterpenoid alkaloids

Wang, Xu, and co-workers utilized, in 2018, a 1,7-enyne reductive radical cyclization and double condensation for the synthesis of lycoctonine-type $\mathrm{C}_{19}$-norditerpenoid alkaloid (Scheme 22). ${ }^{91}$ 1,7-Enyne 297, which was prepared from a previously reported intermediate, ${ }^{92}$ underwent a reductive cyclization to form the A ring of pentacyclic intermediate $\mathbf{2 9 8}$ when treated with $n-\mathrm{Bu}_{3} \mathrm{SnH}$ and AIBN. Double reductive amination of $\mathbf{2 9 9}$ with ethylamine followed by an acetonide removal furnished the hexacycle $\mathbf{3 0 0}$ which was the precursor to the pentacyclic core of methyllycaconitine (301).
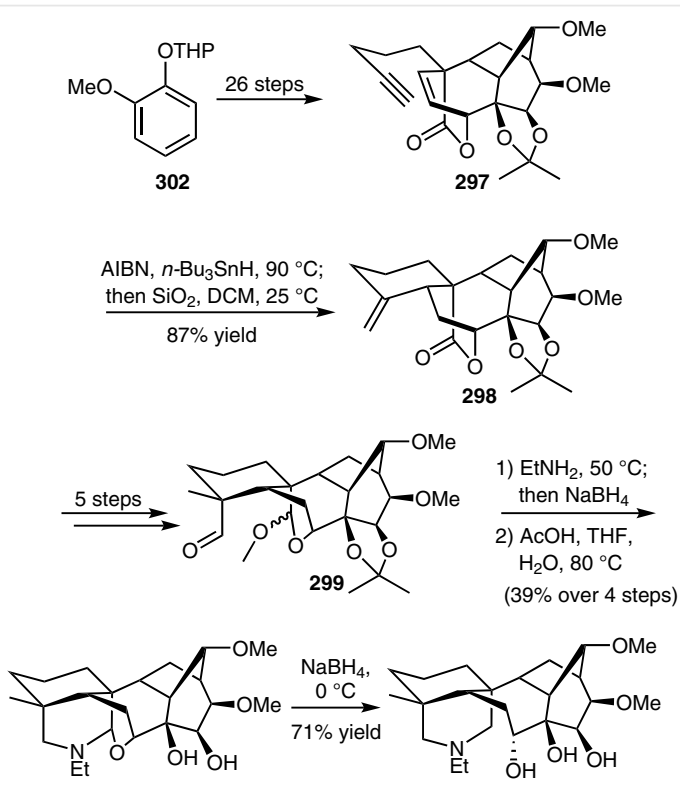

300

301

Scheme 22 1,7-enyne reductive radical cyclization and double condensation for the synthesis of lycoctonine-type $C_{19}$ norditerpenoids

Another radical-based cyclization was adopted by $\mathrm{Xu}$ and co-workers in the synthesis of the BCD ring systems of 7,17-seco-type $\mathrm{C}_{19}$-norditerpenoid alkaloids (Scheme 23). ${ }^{93}$ It was shown that similar ring systems can be accessed via a [3+2] cycloaddition of a nitrile oxide. Bicyclic iodide 304 participated in a radical cyclization when treated with $n$ $\mathrm{Bu}_{3} \mathrm{SnH}$ and AIBN to form tricyclic lactone $\mathbf{3 0 5}$ which can then be transformed into 306, a key intermediate to the $\mathrm{ABEF}$ ring system of $\mathrm{C}_{19}$-norditerpenoids. The alternative approach utilized an intramolecular [3+2] nitrile oxide cycloaddition to form the tricyclic system. Oxime $\mathbf{3 0 7}$ was oxidized into the nitrile oxide upon treatment with NCS, and this nitrile oxide underwent an intramolecular cycloaddition to form tricycle 308. Cleavage of the $\mathrm{N}-\mathrm{O}$ bond was achieved under hydrogenolysis conditions with Raney nickel to afford $\beta$-hydroxy ketone $\mathbf{3 0 9}$, which can then be transformed into the key tricyclic core $\mathbf{3 1 0}$.

\subsection{Ruthenium-Mediated Enyne Cycloisomeriza- tion}

Song, Qin, and co-workers drew inspiration from Trost's ruthenium-mediated enyne cycloisomerization ${ }^{94}$ for the synthesis of the $\mathrm{CD}$ ring systems of aconitine (27) (Scheme 24). ${ }^{95}$ Chiral enyne 311 was treated with 50 mol\% Cp$\mathrm{Ru}(\mathrm{MeCN})_{3} \mathrm{PF}_{6}$ to give the five-membered ruthenacycle $\mathbf{3 1 2}$ which then underwent $\beta$-hydride elimination followed by reductive elimination to give stereoisomers 313 and 314 in $2: 3$ ratio. Initial attempts were made with palladium catalysts, but they did not give cyclized products. 


\section{(1)}

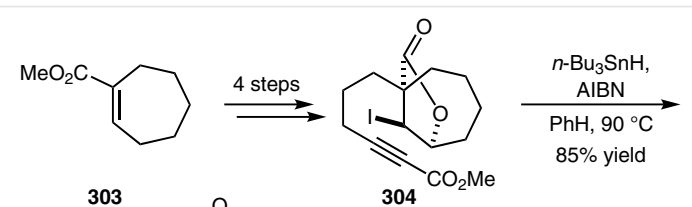<smiles>COc1ccccc1C1CCCC2(C=O)CCCCC12O</smiles><smiles>C=CCCC1(C=O)CCCC2(C=O)CCCC[C@@H]12</smiles>
305

306
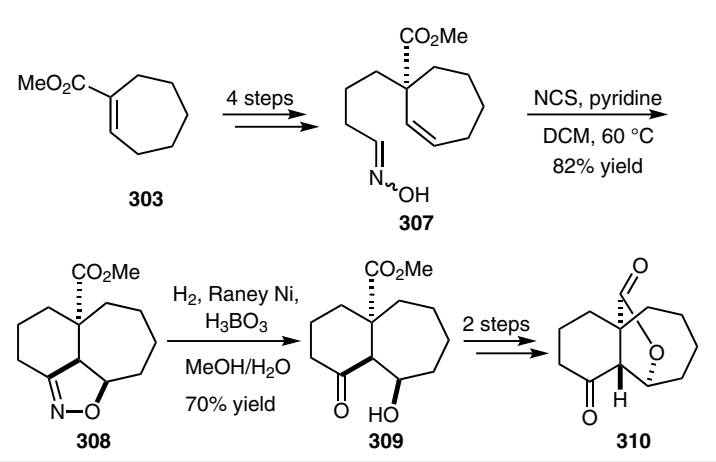

Scheme 23 Radical cyclization and [3+2] cycloaddition for the formation of the $B C D$ ring system of 7,17-seco-type $C_{19}$ norditerpenoids

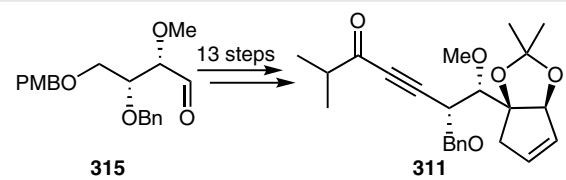

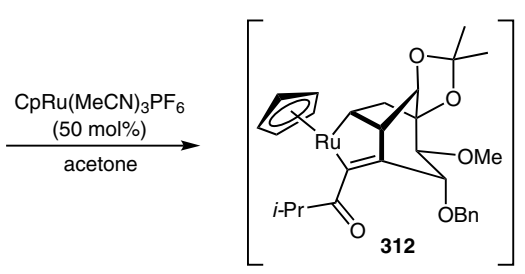

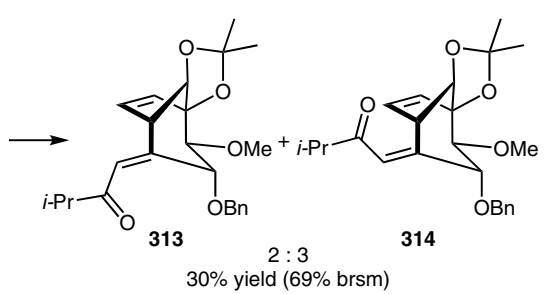

Scheme 24 Ruthenium-mediated enyne cycloisomerization for the construction of $C D$ ring systems of aconitine

\subsection{Reductive Coupling}

In 2014, Xu and co-workers reported the synthesis of ABEF ring systems of lycoctonine-type and 7,17-seco-type $\mathrm{C}_{19}$-norditerpenoid alkaloids starting from the trans-fused 6,7-bicycle $\mathbf{3 1 8}$ formed from a ruthenium-catalyzed diastereoselective enyne cycloisomerization protocol developed by Trost $^{94}$ (Scheme 25). ${ }^{96}$ Treatment of bicycle 318 with $m$-CPBA in the presence of catalytic $\mathrm{TsOH}$ resulted in the stereoselective epoxidation of the olefin with concurrent ring-opening by the ester group to give tricyclic lactone 319. A series of transformations on $\mathbf{3 1 9}$ afforded tetracycle 320. Finally, reductive coupling between the ketone and $\mathrm{N}, \mathrm{O}$-acetal in 320 was accomplished using $\mathrm{SmI}_{2}$ to form tetracycle 321 bearing the ABEF ring systems of Lycoctoninetype and 7,17-seco-type $\mathrm{C}_{19}$-norditerpenoid alkaloids.
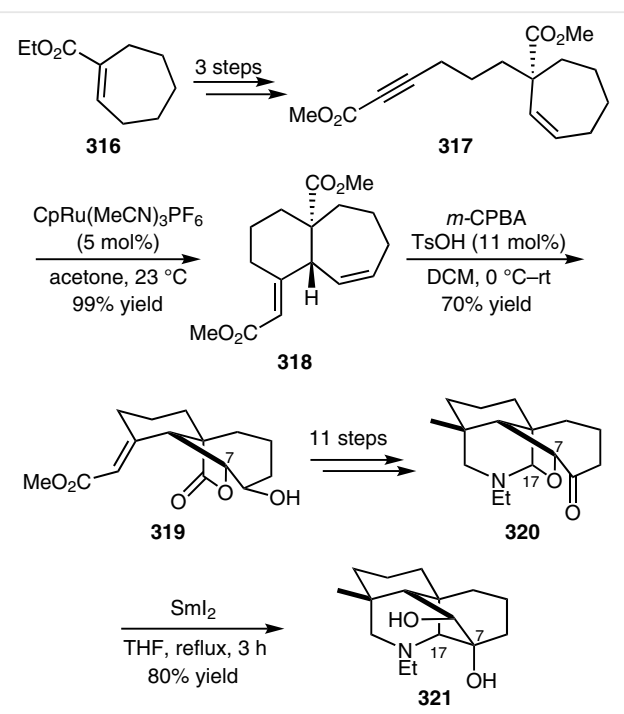

Scheme 25 Construction of the ABEF ring system with rutheniumcatalyzed enyne cycloisomerization and $\mathrm{Sml}_{2}$-induced reductive coupling

Sugita and co-workers reported a reductive cyclization strategy of $\alpha, \beta$-epoxy ketone $\mathbf{3 2 2}$ to synthesize the CD ring system of aconitine (27) (Scheme 26). ${ }^{97} \mathrm{SmI}_{2}$ initiates the formation of samarium enolate $\mathbf{3 2 3}$ that subsequently underwent an intramolecular aldol cyclization with the pendant aldehyde. The reaction was expected to proceed through cyclic transition state $\mathbf{3 2 4}$. Initial reaction conditions either gave low yields of bicyclic ketone $\mathbf{3 2 5}$ or side products from premature protonation of 324 or with observed TES group migration. Optimized conditions with $\mathrm{SmI}_{2}$ (6 equiv) and HMPA (24 equiv) furnished the desired product 327 in $71 \%$ yield. 


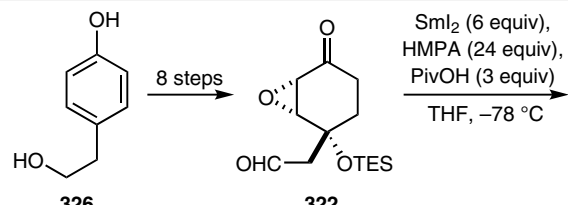

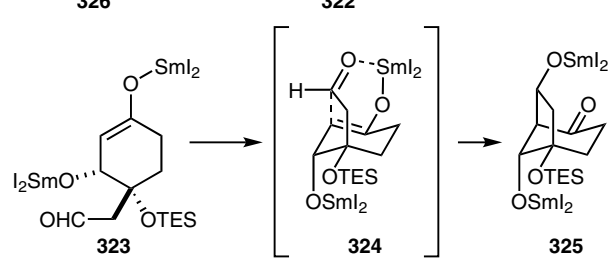

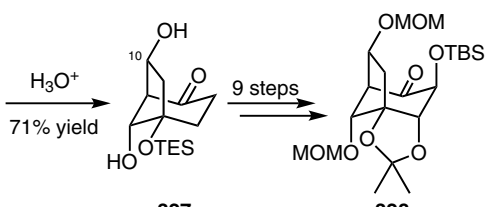

327

Scheme 26 Reductive cyclization of $\alpha, \beta$-epoxy ketone for the synthesis of $C D$ ring systems of aconitine

\subsection{Diels-Alder Reactions}

Brimble and co-workers reported the enantioselective synthesis of the ABEF ring systems of methyllycaconitine analogues (Scheme 27). ${ }^{98}$ The elegant approached utilized sequential Diels-Alder reaction, aldol, Mannich, and Wacker-type cyclizations to furnish the tetracyclic scaffold 337. The enantioselective synthesis commenced with a cobalt(III)-salen complex $\mathbf{3 3 1}$ catalyzed Diels-Alder reaction between enal $\mathbf{3 2 9}$ and diene $\mathbf{3 3 0}$ to give the endoadduct $\mathbf{3 3 2}$ in excellent yield and enantioselectivity; the benzyl group on the amine was necessary to affect high enantioselectivity. The endo-adduct $\mathbf{3 3 2}$ was then treated with LDA to promote intramolecular aldol cyclization between the ester and the aldehyde to give $\beta$-hydroxy ester 333. A three-step sequence ending with an intramolecular Mannich reaction was used to construct the ABE tricyclic ring system 334. Reduction of the ketone in $\mathbf{3 3 4}$ gave alcohol 335, which underwent an intramolecular Wacker-type oxidative cyclization to install the $\mathrm{F}$ ring of the tetracycle 336. Subsequent transformations provided alcohol 337, representing the ABEF scaffold of methyllycaconitine analogues.

$\mathrm{Xu}$, Wang, and co-workers initiated the synthesis of the AEF ring systems of $C_{19}$-norditerpenoid alkaloids with a stereoselective intramolecular Diels-Alder reaction (Scheme 28). ${ }^{99}$ The cycloadduct furnished the bicyclic lactone $\mathbf{3 4 1}$ with 5:1 endo selectivity thus establishing the A ring of the target. Subsequent transformations provided the $\mathrm{N}$-protected aminoaldehyde 342. Deprotection of the Boc group in $\mathbf{3 4 2}$ under acidic conditions was followed by intramolecular Mannich reaction to furnish the tricyclic ketone $\mathbf{3 4 3}$, thus completing the synthesis of the AEF ring systems.
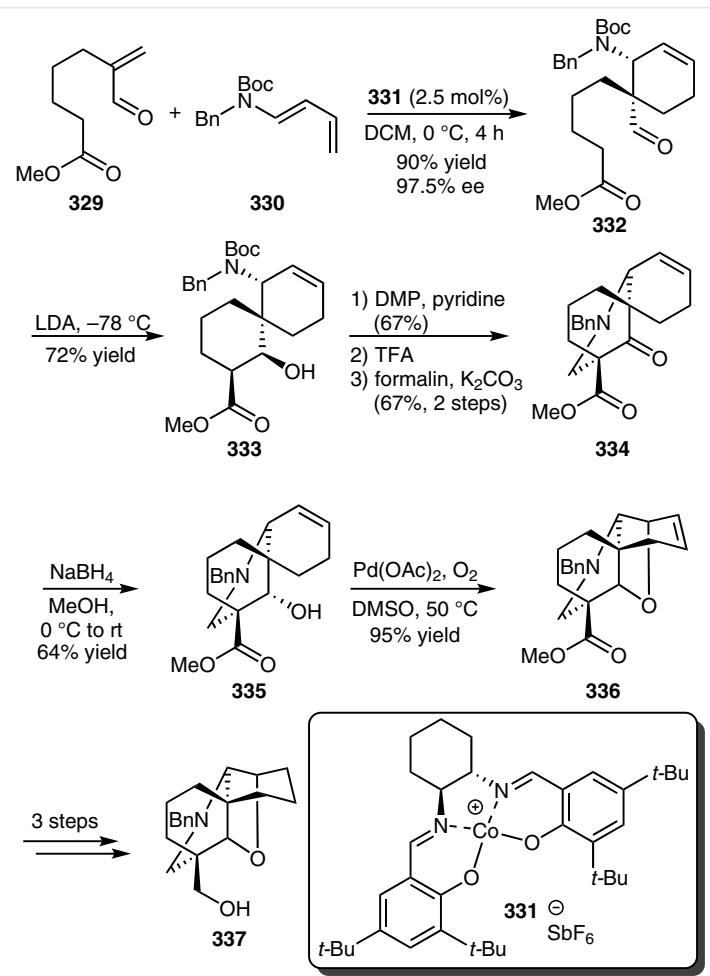

Scheme 27 Sequential Diels-Alder reaction, aldol, Mannich, and Wacker-type cyclizations for the formation of the ABEF ring systems of methyllycaconitine analogues

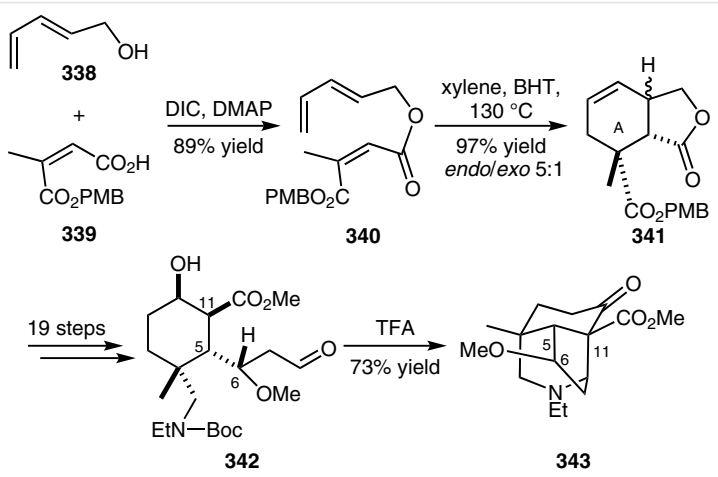

Scheme 28 Stereoselective Diels-Alder reaction and intramolecular Mannich reaction for the synthesis of the AEF ring systems of $C_{19}$-norditerpenoid alkaloids

Barker and co-workers drew inspiration from the work of Yang and co-workers ${ }^{100}$ by applying a tandem DielsAlder/Mannich reaction for the construction of the AE and ABE ring systems of Delphinium alkaloids (Scheme 29). ${ }^{101} \mathrm{~A}$ titanium-mediated [4+2] cycloaddition was carried out between the $\alpha$-\{[(cyanomethyl)amino]methyl\}acrylate $\mathbf{3 4 4}$ and diene $\mathbf{3 4 5}$ to form cyclic enolate intermediate $\mathbf{3 4 6}$. This enolate intermediate then underwent an intramolecular Mannich reaction with the unmasked iminium ion to give bicyclic ketone $\mathbf{3 4 7}$, which mapped on to the AE ring 
systems of Delphinium alkaloids. Similarly, using the dienecontaining a cyclohexene moiety 349 resulted in the formation of tricyclic ketone 350, which maps on to the ABE ring systems. Installation of the succinimide-bearing benzoyl group furnished the methyllycaconitine analogue 351. It was also shown that various derivatizations of the bicyclic core 347 could be used to give a wide variety of possible precursors of Delphinium and Aconitum alkaloids analogues (Scheme 30). Substitution patterns of methyllycaconitine (352), grandiflorine (353), talatisamine (354), delcosine (355), eldeline (356), inuline (357), ajacine (358), delvestine (359), and majusine $A(\mathbf{3 6 0})$ were amongst the presented examples, as well as their $N$-benzyl analogues 364-368.
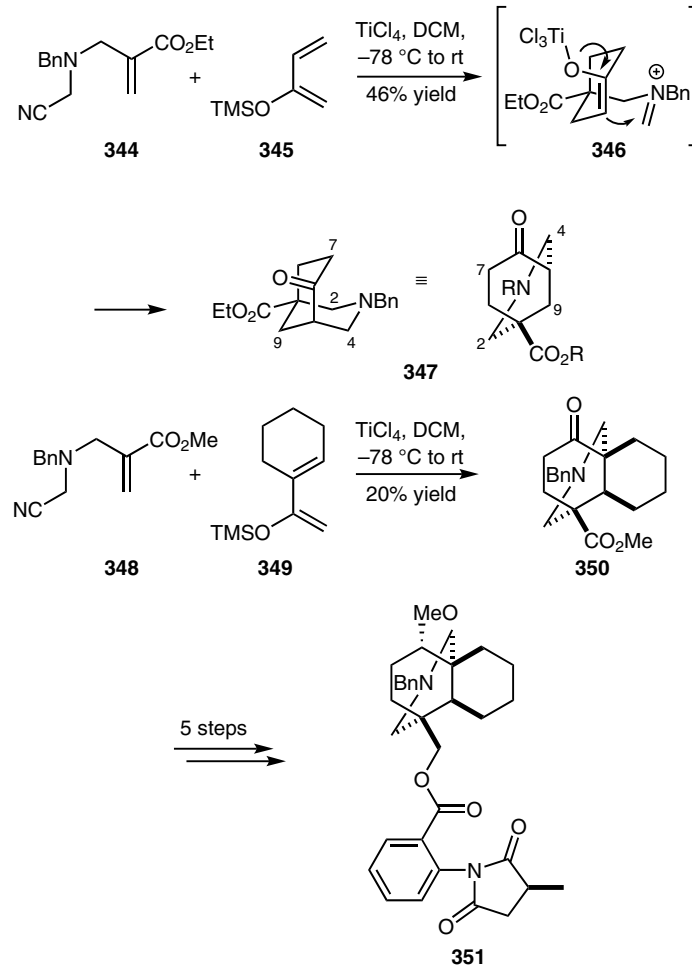

Scheme 29 Tandem titanium-mediated Diels-Alder/Mannich reaction for the construction of the ABE ring systems of Delphinium alkaloids

\subsection{Oxidative Dearomatization/Diels-Alder Se- quence}

One of the extensively used strategies in syntheses of diterpenoid alkaloids and related diterpenes is the oxidative dearomatization/Diels-Alder cycloaddition cascade. ${ }^{102}$

$\mathrm{Xu}$, Wang, and co-workers also demonstrated the synthetic versatility of the Diels-Alder reaction by applying it to the synthesis of the $B C D$ ring systems of $C_{19}$-norditer-
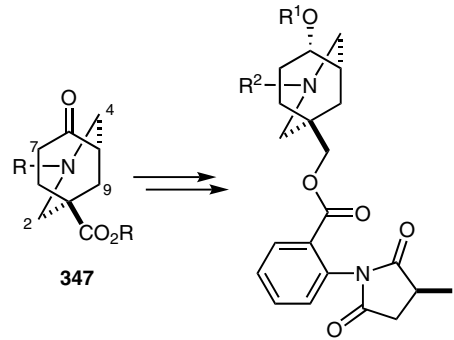

$352 \mathrm{R}^{1}=\mathrm{Me}, \mathrm{R}^{2}=\mathrm{Bn}$ $353 \mathrm{R}^{1}=\mathrm{H}, \quad \mathrm{R}^{2}=\mathrm{Bn}$ $361 \mathrm{R}^{1}=\mathrm{Me}, \mathrm{R}^{2}=\mathrm{Ph}\left(\mathrm{CH}_{2}\right)_{3}$ $362 R^{1}=M e, R^{2}=E t$ $363 R^{1}=H, \quad R^{2}=E t$
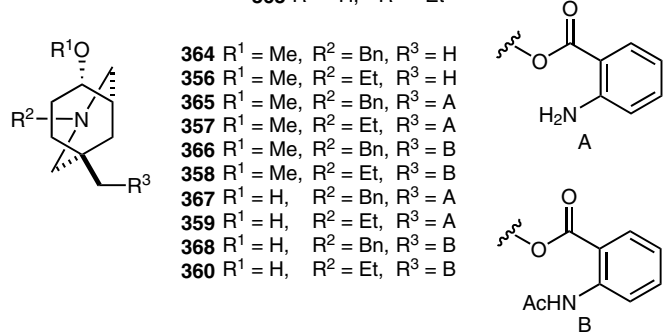

Scheme 30 Derivatization of a bicyclic ketone to furnish various synthons for Delphinium and Aconitum alkaloids

penoid alkaloids (Scheme 31). ${ }^{92}$ An intramolecular DielsAlder reaction of a masked $\boldsymbol{o}$-benzoquinone $\mathbf{2 4 3}$ developed by Liao and co-workers was applied to synthesize the tetracyclic ketone 245. ${ }^{82}$ PIDA-mediated oxidative dearomatization of phenol 242 in the presence of methanol gave diene 243 that underwent an intramolecular [4+2] cycloaddition to give 245. Subsequent transformations of $\mathbf{2 4 5}$ formed triflate 369, which underwent Wagner-Meerwein rearrangement, an alkyl shift with extrusion of the triflate group, in the presence of DBU and DMSO to form carbocation $\mathbf{3 7 0}$ that was trapped by DMSO giving 371. Elimination of dimethyl sulfide from $\mathbf{3 7 1}$ gave enone $\mathbf{3 7 2}$ thus constructing the $\mathrm{BCD}$ ring systems of $\mathrm{C}_{19}$-norditerpenoid alkaloids.

A similar PIDA-promoted oxidative cyclization strategy was applied by $\mathrm{Xu}$, Wang, and co-workers to furnish the $\mathrm{BCD}$ ring systems of aconitine (27) (Scheme 32). ${ }^{103}$ Treatment of phenol 374 with PIDA in the presence of methanol resulted in the dimer $\mathbf{3 7 5}$. Fortunately, the desired cycloadduct $\mathbf{3 7 6}$ was formed under thermodynamic conditions to induce a retro-[4+2]/intramolecular Diels-Alder reaction from 375; reduction of the ketone in $\mathbf{3 7 6}$ provided alcohol 377. Sulfonylation of the alcohol in $\mathbf{3 7 7}$ on exposure to triflic anhydride initiated the Wagner-Meerwein rearrangement to form tricyclic alcohol 378, containing the BCD ring systems of aconitine (27), from intermediate $\mathbf{3 7 9}$. 
<smiles>COc1ccccc1Oc1cccc(OC)c1O</smiles><smiles>COC1(OC)C=CC=C(N=C(C)C=C(C)C)C1=O</smiles>

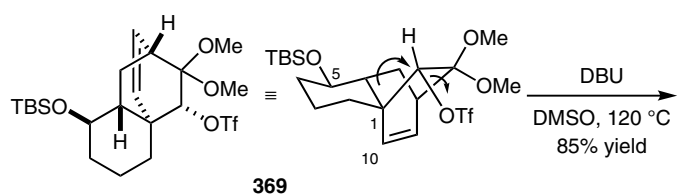

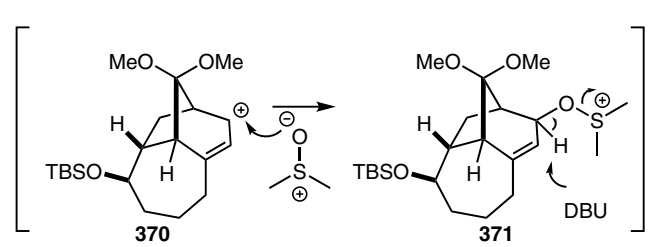

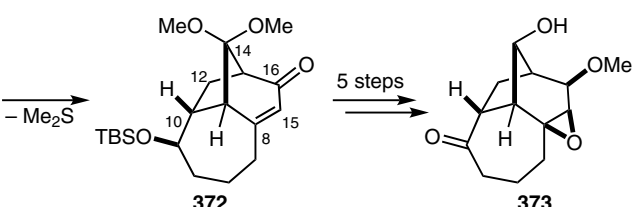

Scheme 31 Intramolecular Diels-Alder reaction and a WagnerMeerwein rearrangement for the construction of the BCD ring systems of $\mathrm{C}_{19}$-norditerpenoid alkaloids

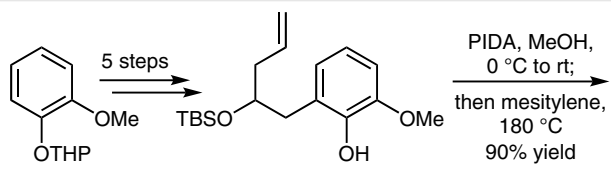

302

374

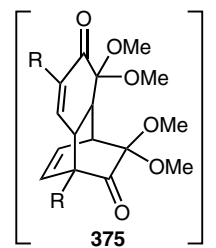<smiles>[R5]C(CC=C)CC(C)(C)C</smiles>

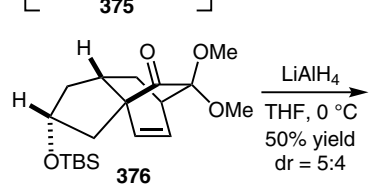
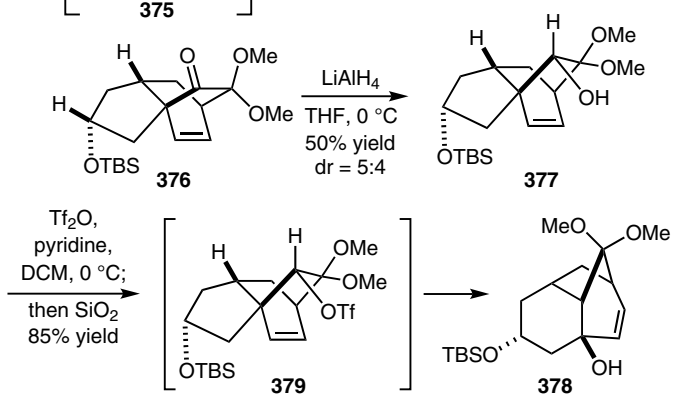

Scheme 32 PIDA-promoted oxidative cyclization and a WagnerMeerwein rearrangement to furnish the BCD rings systems of aconitine
The Sarpong group presented studies in 2014 on $\mathrm{C}_{20}$-diterpenoid alkaloids, showing the synthesis of hetidine framework and its conversion into the atisine core structure. ${ }^{104}$ Starting from commercially available $\beta$-keto ester $\mathbf{3 8 0}$, advanced intermediate $\mathbf{3 8 1}$ was obtained in 14 steps. Treatment of $\mathbf{3 8 1}$ with the hypervalent iodide reagent [bis(trifluoroacetoxy)iodo]benzene (PIFA) facilitated oxidative dearomatization to give cyclic carbamate 383. A sequence of dihydroxylation, periodate cleavage, and Michael addition, promoted by simple stirring with silica gel in dichloromethane, gave aldehyde $\mathbf{3 8 4}$. Hydrogenation and aldol reaction gave synthon $\mathbf{3 8 5}$ (Scheme 33).
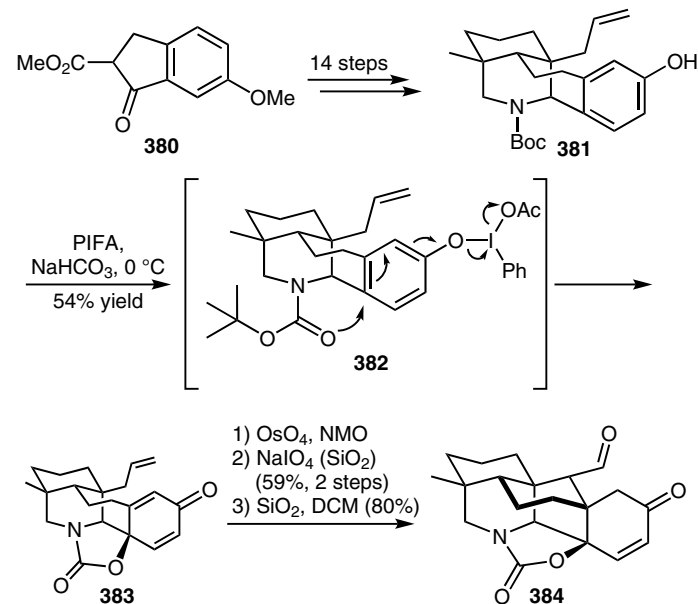

1) $\mathrm{H}_{2}$, cat. $\mathrm{Rh} / \mathrm{Al}_{2} \mathrm{O}_{3}(55 \%)$ 2) $\mathrm{K}_{2} \mathrm{CO}_{3}(78 \%)$

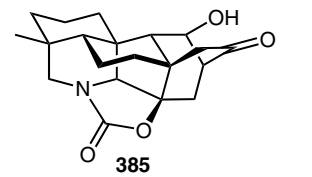

Scheme 33 Synthesis of a versatile intermediate for the hetidine framework
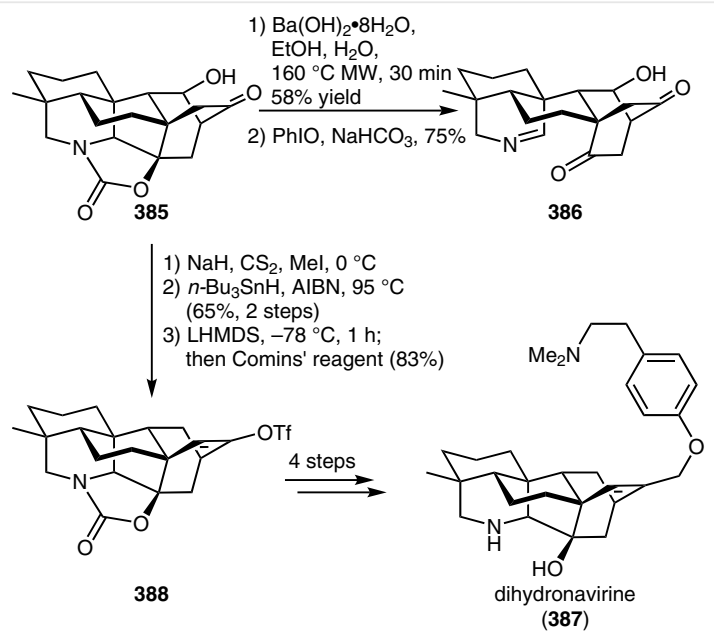

Scheme 34 Construction of atisine and hetidine frameworks 
The versatile synthon $\mathbf{3 8 5}$ was used to synthesize compound 386 having the atisine carbon skeleton in 2 steps (Scheme 34). The same synthon was also used to synthesize dihydronavirine (387), which unfortunately could not be converted into the natural product navirine.

In a methodological study, Chen and Wang presented an efficient synthesis of the C/D rings (Scheme 35) of atisinetype $\mathrm{C}_{20}$-diterpenoid alkaloids. ${ }^{105}$ The synthesis also relies on the oxidative dearomatization/intramolecular DielsAlder strategy.

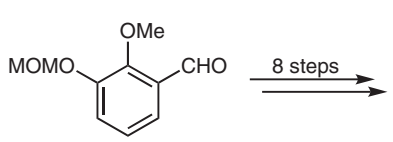

389

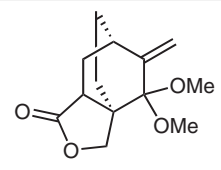

390
Scheme 35 Synthesis of the $C / D$ rings of atisine-type $C_{20}$-diterpenoid alkaloids

$\mathrm{Xu}$ and co-workers accessed the core ring systems of Spiraea atisine-type diterpenoid alkaloids through a bio-inspired synthetic route. ${ }^{106} \mathrm{~A}$ four-step process led from commercially available methyl cyclohex-1-enecarboxylate (391) to trans-decalin 392 (Scheme 36). Epoxidation of $\mathbf{3 9 2}$ in the presence of catalytic amounts of TsOH gave $\gamma$-lactone 393. Intermediate 393 was converted into $\delta$-lactone 394 in 4 steps; a further 8 transformations led to tetracyclic lactone 395. This synthon was successfully converted into pentacyclic target 396, featuring the ABEFG rings of spiramine $C$ (64) and D (65).

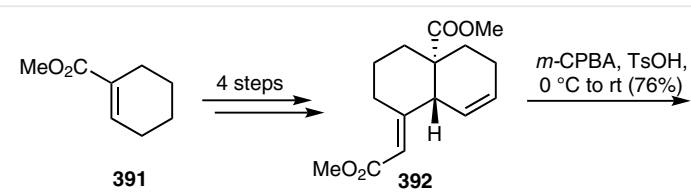

1) $\mathrm{DMP}, \mathrm{NaHCO}_{3}$ $0{ }^{\circ} \mathrm{C}(85 \%)$

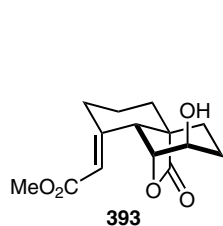

2) $\mathrm{Sml}$

2) $\mathrm{Sm}_{2}, \mathrm{O}^{\circ}(76 \%)$

3) $\mathrm{NaBH}_{4}, \mathrm{CeCl}_{3}, 0^{\circ} \mathrm{C}$

4) $\mathrm{DIC}, \mathrm{PhMe}, 80^{\circ} \mathrm{C}$ 393 $\mathrm{MeO}_{2} \mathrm{C}^{\prime}$

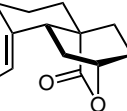

394

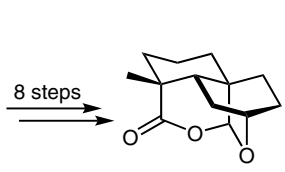

395

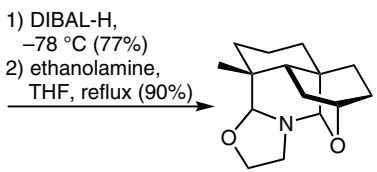

396
Scheme 36 Biomimetic synthesis of the ABEFG pentacyclic amine of Spiraea atisine-type diterpenoid alkaloids

\subsection{Transannular Aziridination}

Xu and co-workers reported a PIDA-promoted intramolecular transannular aziridination strategy for the formation of the AEF ring systems of lycoctonine-type $\mathrm{C}_{19}$-nordi- terpenoid alkaloids (Scheme 37). ${ }^{107}$ Starting from symmetric 397, intermediate $\mathbf{3 9 8}$ was obtained in 5 steps. $\beta$-Keto acrylate 398 was subjected to $\mathrm{TiCl}_{4}$-mediated conjugate propargylation ${ }^{108}$ followed by a gold(I)-catalyzed cyclization ${ }^{109}$ to afford the $\beta$-keto ester $\mathbf{4 0 0}$. Subsequent transformations of $\mathbf{4 0 0}$ furnished the amine $\mathbf{4 0 1}$ ready for intramolecular transannular aziridination. Initial conditions developed by Nagata and co-workers using lead(IV) acetate did not provide the desired product. ${ }^{110}$ It was found that using PIDA together with silica gel as an additive gave the optimal yield of the aziridine $\mathbf{4 0 2}$. Finally, regioselective ring cleavage was achieved with ethyl iodide and DMF followed by treatment with $\mathrm{NaOAc}$ to give the tricyclic amine $\mathbf{4 0 3}$ that models the AEF ring systems of lycoctonine-type $\mathrm{C}_{19}$-norditerpenoid alkaloids.
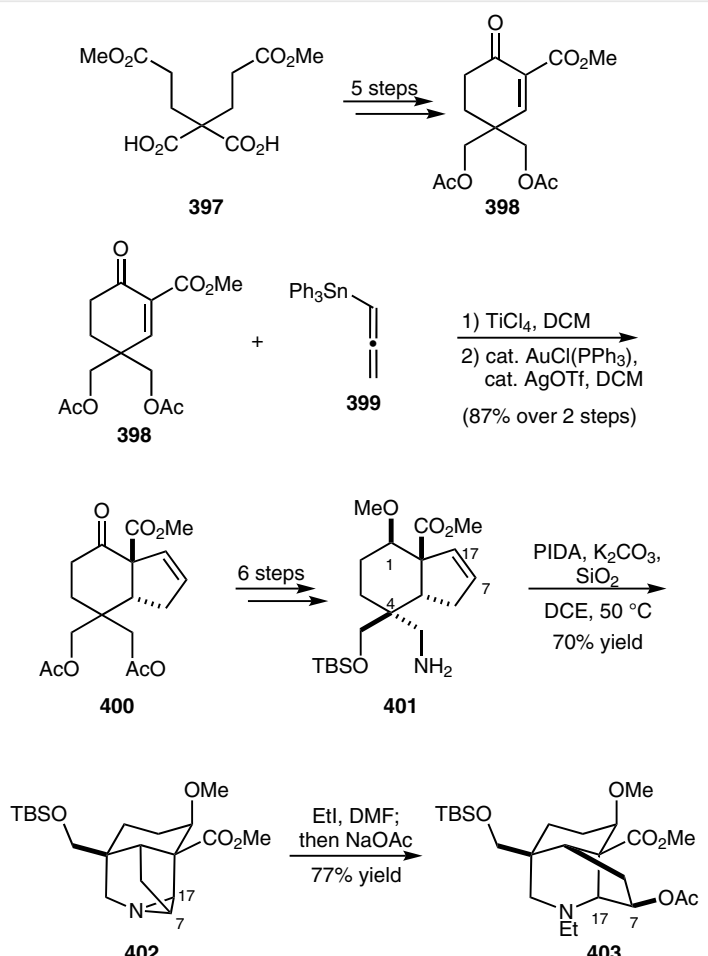

Scheme 37 PIDA-promoted intramolecular transannular aziridination followed by regioselective ring cleavage to deliver the AEF ring systems of lycoctonine-type $C_{19}$-norditerpenoid alkaloids

The racemulsonine family has been an evasive core in terms of successful attempts at its total synthesis. However, work by Wang and co-workers has made it significantly easier to access the 10-azatricyclo[3.3.2.0 $\left.0^{4,8}\right]$ decane skeleton precursor towards the final product (Scheme 38). ${ }^{111}$

The strategy employed towards this synthesis of the cage-like azatricyclic skeleton was fashioned after the intramolecular aziridination reaction by Nagata and coworkers, ${ }^{110}$ transforming the unsaturated primary amine $\mathbf{4 0 9}$ to afford the bridged aziridine $\mathbf{4 1 0}$ that will later be transformed into 415. Starting with diol 404, it was globally 

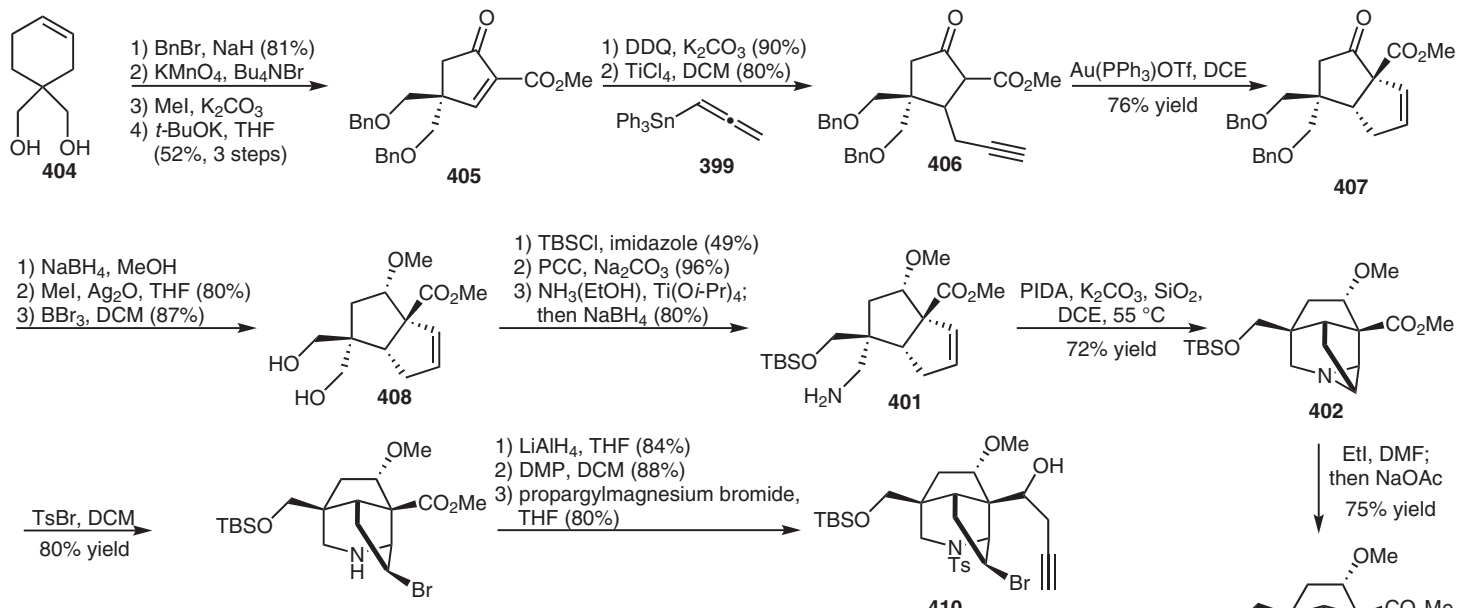

409

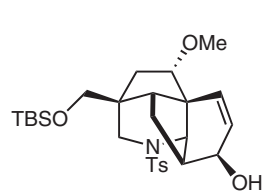

1) $\mathrm{OsO}_{4}, \mathrm{NaIO}_{4}, \mathrm{NMO}$ $\mathrm{THF}, \mathrm{H}_{2} \mathrm{O}(76 \%)$

$\mathrm{MsCl}, \mathrm{Et}_{3} \mathrm{~N}$,
$\mathrm{DCM}(91 \%)$

3) $\mathrm{CeCl}_{3} \cdot 7 \mathrm{H}_{2} \mathrm{O}, \mathrm{NaBH}_{4}$, $\mathrm{MeOH},-40^{\circ} \mathrm{C}(90 \%)$

412
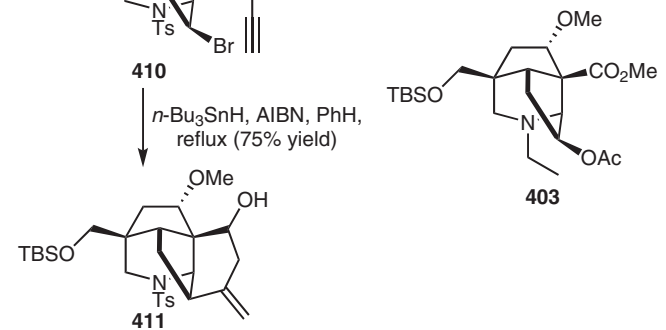

403

Scheme 38 Synthetic studies towards racemulsonine

protected and then converted into the $\beta$-keto ester $\mathbf{4 0 5}$ in four steps. This diprotected diol $\mathbf{4 0 5}$ was then treated with DDQ, to provide the conjugated enone, ${ }^{112}$ which underwent conjugate propargylation with allenyltriphenylstannane yielding 406. A Au(I)-catalyzed annulation via a modified Toste conditions ${ }^{109}$ accessed the cis-fused cyclopentene scaffold $\mathbf{4 0 7}$ as a single diastereomer, thus completing the $\mathrm{A} / \mathrm{F}$ ring core. Reduction of the ketone in $\mathbf{4 0 7}$ and protection with MeI installed the final C3-OMe group, and this was followed by deprotection of the benzyl protecting groups and monoprotection with TBSCl to afford the product as a mixture of the desired and undesired isomers (1.2:1); the alcohol was transformed into the primary amine 401. A modification of the method by Nagata and co-workers using 401 with PIDA and $\mathrm{K}_{2} \mathrm{CO}_{3}$ in 1,2-dichloroethane at $55^{\circ} \mathrm{C}$ gave the optimized yields of $\mathbf{4 0 2}$. The selective aziridine ring cleavage was then achieved by treatment of $\mathbf{4 0 2}$ with acetic anhydride, yielding the 10-azatricyclo[3.3.2.0 $\left.0^{4,8}\right] \mathrm{dec}-$ ane core (OAc analogue of $\mathbf{4 0 9}$ ) as a single regio- and stereoisomer in an excellent $90 \%$ yield. Notably, the direct introduction of the $N$-ethyl group to form the tricyclic amine was achieved by treatment of $\mathbf{4 0 2}$ with ethyl iodide followed by NaOAc to give $N$-ethyl tricyclic amine 403. ${ }^{111}$ This work was expanded in $2016^{113}$ by using exo-cyclization under radical conditions to furnish the $B$ ring, thus expanding the scaffold. With just a few tailoring steps they were able to access 410 from compound $\mathbf{4 0 9}$, and cyclization occurred upon treatment of $\mathbf{4 1 0}$ with $n-\mathrm{Bu}_{3} \mathrm{SnH}$ and AIBN under reflux conditions in benzene to give $\mathbf{4 1 1}$ in $75 \%$ yield. At this stage, the ABEF core was completed, and with minor tailor- ing, the scaffold was further functionalized to give $\mathbf{4 1 2}$ which allows for further elaborations. This was an important development as this synthesis brought the work of $\mathrm{Xu}$ and co-workers much closer to the final racemulosine core.

\subsection{Intramolecular [5+2] Cycloaddition}

The synthesis of a 6/5/6/7 ring system (Scheme 39) matching parts of the skeleton of $\mathrm{C}_{18} / \mathrm{C}_{19}$-diterpenoid alkaloids was reported by Liu and co-workers in 2018. ${ }^{114}$ The synthesis features an iron-catalyzed intramolecular [5+2] cycloaddition that they had reported earlier. ${ }^{115}$ Cycloaddition adduct $\mathbf{4 1 5}$ was transformed into tetracyclic synthon 416 in 3 steps. It was also demonstrated that the chemoselective reduction of a ketone moiety is feasible. The result-
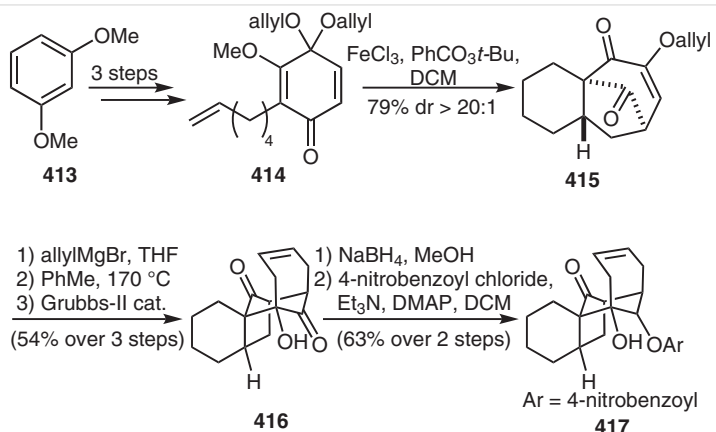

Scheme 39 Synthesis of the tetracyclic 6/5/6/7 core skeleton of $\mathrm{C}_{18} / \mathrm{C}_{19}$-diterpenoid alkaloids 
ing synthon 417 features the $\mathrm{A}, \mathrm{B}$, and $\mathrm{F}$ rings and the precursor of the C/D ring system of the diterpenoid alkaloid skeletons.

\subsection{Miscellaneous}

The Sarpong group aimed to study the structural activity relationship of aconitine (27) and the variation of substituents on the $D$ ring while maintaining the structure of the AEF ring systems (Scheme 40). ${ }^{116}$ Starting with vinylnitrile 88, aryl nucleophiles with different substitution pattern were appended in a conjugate fashion under Hayashitype Rh-catalysis ${ }^{117}$ or with the Cu-mediated strategy to give conjugate addition product $\mathbf{4 1 8}$. Subsequent elaborations on the products afforded tetracycle $\mathbf{4 1 9}$ or the dearomatized spirocycle $\mathbf{4 2 0}$.
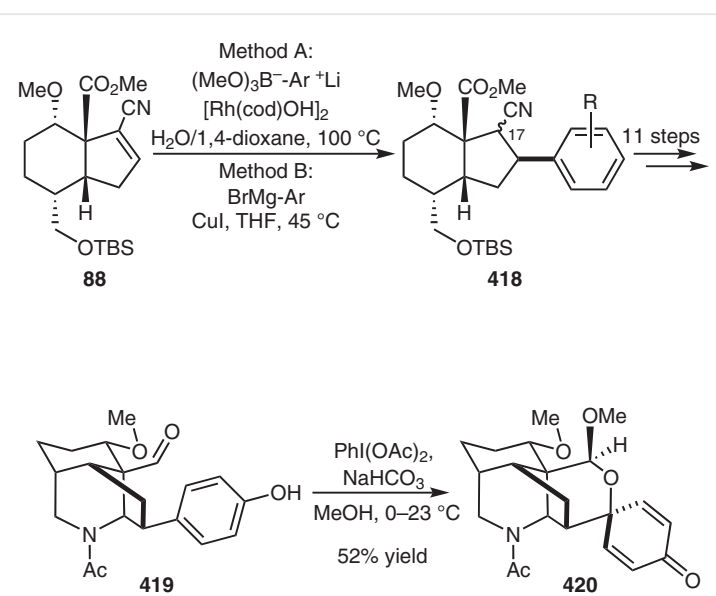

Scheme 40 Conjugate arylation of vinylnitrile to study the structural activity relationship for aconitine

An expedient synthesis of the $\mathrm{AE}$ ring systems bearing a $5 \beta$-hydroxyl group for $\mathrm{C}_{19}$-norditerpenoid alkaloids was reported by Wang and co-workers utilizing a series of intramolecular Claisen condensation, double Mannich reaction, and stereoselective aldol addition (Scheme 41). ${ }^{118}$ Starting with keto carbonate $\mathbf{4 2 2}$, Claisen condensation followed by methylation furnished the bicyclic $\beta$-keto lactone 423. Double Mannich reaction with benzylamine in the presence of formaldehyde installed the E ring to give $\mathbf{4 2 4}$. Finally, stereoselective addition of a carbonyl group dictated by the $1 \beta$ substituent formed the 5 $\beta$-hydroxyl group in $\mathbf{4 2 5}$.

\section{Conclusion}

The diterpenoid alkaloids have proven to be an intriguing and challenging target to researchers worldwide. A century following their discovery, synthetic strategies towards diterpenoid alkaloids have continuously expanded. Herein, we summarized synthetic efforts over the past decade, dis-

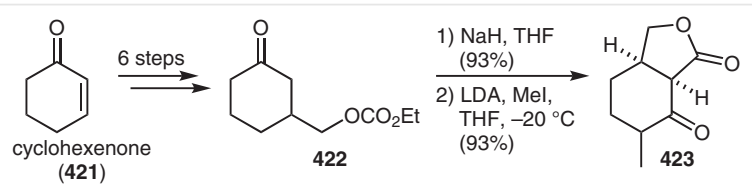

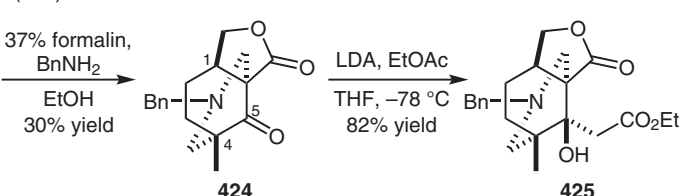

Scheme 41 Sequential intramolecular Claisen condensation, double Mannich reaction and stereoselective aldol addition for the formation of the $A E$ ring systems bearing a $5 \beta$-hydroxyl group for $C_{19}$-norditerpenoid alkaloids

cussing successful total syntheses and pioneering work towards future attempts of total syntheses. The current success can be viewed as an open door towards accessing unnatural derivatives of these diterpenoid alkaloids in an effort to tune the prevalent biological activities.

Despite the great successes reported, there are still challenging targets left to synthesize, which is especially true for the $\mathrm{C}_{19}$-diterpenoid alkaloids with aconitine (27) as the most popular representative. Further, it can be expected that natural product isolation will yield additional structurally challenging compounds with interesting biological activities.

\section{Funding Information}

We thank the University of Toronto, and the Natural Sciences and Engineering Research Council (NSERC), and the Audrey and Ragnar Olsen Fellowship for financial support. Christian Dank was supported by an Erwin Schroedinger postdoctoral fellowship awarded by the Austrian Science Fund (FWF) J 4348-N28.

\section{Acknowledgment}

We would like to thank Mark Stewart and the Toronto Botanical Garden for providing us with the image of the Aconitum in bloom.

\section{References}

(1) (a) Wang, F.-P.; Liang, X.-T. C20-Diterpenoid Alkaloids, In The Alkaloids: Chemistry and Biology, Vol. 59; Cordell, G. A., Ed.; Academic Press: San Diego, 2002, 1-280. (b) Wang, F.-P.; Chen, Q.H.; Liang, X.-T. The C18-Diterpenoid Alkaloids, In The Alkaloids: Chemistry and Biology, Vol. 67; Cordell, G. A., Ed.; Academic Press: San Diego, 2009, 1-78. (c) Wang, F.-P.; Chen, Q.-H. The C19-Diterpenoid Alkaloids, In The Alkaloids: Chemistry and Biology, Vol. 69; Cordell, G. A., Ed.; Academic Press: San Diego, 2010, $1-577$.

(2) (a) Atta-ur-Rahman, Iqbal, Choudhary. M. Nat. Prod. Rep. 1999, 16, 619. (b) Wang, F.-P.; Chen, Q.-H.; Liu, X.-Y. Nat. Prod. Rep. 2010, 27, 529. (c) Wang, X. W.; Xie, H. Drugs Future 1999, 24, 877. (d) Wang, C.-F.; Gerner, P.; Wang, S.-Y.; Wang, G. K. Anes- 
thesiology 2007, 107, 82. (e) Yang, X.; Wang, G.; Ling, S.; Qiu, N.; Wang, G.; Zhu, J.; Liu, J. J. Chromatogr., B 2000, 740, 273. (f) Sadikov, A. Z.; Shakirov, T. T. Chem. Nat. Compd. 1988, 24, 79.

(3) Catterall, W. A.; Cestèle, S.; Yarov-Yarovoy, V.; Yu, F. H.; Konoki, K.; Scheuer, T. Toxicon 2007, 49, 124.

(4) (a) Kou, K. G. M.; Kulyk, S.; Marth, C. J.; Lee, J. C.; Doering, N. A.; Li, B. X.; Gallego, G. M.; Lebold, T. P.; Sarpong, R. J. Am. Chem. Soc. 2017, 139, 13882. (b) Song, M. K.; Liu, H.; Jiang, H. L.; Yue, J. M.; Hu, G. Y.; Chen, H. Z. Neuroscience 2008, 155, 469. (c) Wada, K. Chemistry and Biological Activity of Diterpenoid Alkaloids, In Studies in Natural Products Chemistry, Vol. 38; Atta-ur-Rahman, Ed.; Elsevier: Amsterdam, 2012, 191-223. (d) Zhao, X.-Y.; Wang, Y.; Li, Y.; Chen, X.-Q.; Yang, H.-H.; Yue, J.-M.; Hu, G.-Y. Neurosci. Lett. 2003, 337, 33. (e) Wada, K.; Ohkoshi, E.; Zhao, Y.; Goto, M.; Morris-Natschke, S. L.; Lee, K.-H. Bioorg. Med. Chem. Lett. 2015, 25, 1525.

(5) Cherney, E. C.; Baran, P. S. Isr. J. Chem. 2011, 51, 391.

(6) The Merck Index: An Encyclopedia of Chemicals, Drugs, and Biologicals, 15th ed; O'Neil, M. J.; Heckelman, P. E.; Dobbelaar, P. H.; Roman, K. J.; Kenny, C. M.; Karaffa, L. S., Ed.; Royal Society of Chemistry: Cambridge, 2013.

(7) (a) Dunstan, W. R. Ber. Dtsch. Chem. Ges. 1894, 27, 664. (b) Freund, M.; Beck, P. Ber. Dtsch. Chem. Ges. 1894, 27, 433.

(8) (a) Dunstan, W. R.; Carr, F. H. Ber. Dtsch. Chem. Ges. 1895, 28, 1379. (b) Freund, M. Ber. Dtsch. Chem. Ges. 1895, 28, 2537. (c) Freund, M. Ber. Dtsch. Chem. Ges. 1895, 28, 192.

(9) (a) Freudenberg, W. Ber. Dtsch. Chem. Ges. 1936, 69, 1962. (b) Majima, R.; Suginomé, H. Ber. Dtsch. Chem. Ges. 1924, 57, 1466. (c) Schneider, W. Chem. Ber. 1956, 89, 768.

(10) (a) Barger, G.; Field, E. J. Chem. Soc., Trans. 1915, 107, 231. (b) Brady, O. L. J. Chem. Soc., Trans. 1913, 103, 1821. (c) Carr, F. H. J. Chem. Soc., Trans. 1912, 101, 2241. (d) Dunstan, W. R.; Andrews, A. E. J. Chem. Soc., Trans. 1905, 87, 1636. (e) Dunstan, W. R.; Carr, F. H. J. Chem. Soc., Trans. 1894, 65, 290. (f) Dunstan, W. R.; Carr, F. H. J. Chem. Soc., Trans. 1894, 65, 176. (g) Dunstan, W. R.; Carr, F. H. J. Chem. Soc., Trans. 1895, 67, 459. (h) Dunstan, W. R.; Harrison, E. F. J. Chem. Soc., Trans. 1894, 65, 174. (i) Henry, T. A.; Sharp, T. M. J. Chem. Soc. 1931, 581. (j) Jowett, H. A. D. J. Chem. Soc., Trans. 1896, 69, 1518. (k) Lawson, A. J. Chem. Soc. 1936, 80. (l) Lawson, A.; Topps, J. E. C. J. Chem. Soc. 1937, 1640.

(11) Jacobs, W. A.; Elderfield, R. C. J. Am. Chem. Soc. 1936, 58, 1059.

(12) (a) Cookson, R. C.; Trevett, M. E. J. Chem. Soc. 1956, 3121. (b) Wiesner, K.; Götz, M.; Simmons, D. L.; Fowler, L. R.; Bachelor, F. W.; Brown, R. F. C.; Büchi, G. Tetrahedron Lett. 1959, 1, 15.

(13) Pelletier, S. W.; Oeltmann, T. N. Tetrahedron 1968, 24, 2019.

(14) (a) Jacobs, W. A. J. Org. Chem. 1951, 16, 1593. (b) Jacobs, W. A.; Pelletier, S. W.J. Am. Chem. Soc. 1954, 76, 4048. (c) Jacobs, W. A.; Pelletier, S. W. J. Am. Chem. Soc. 1954, 76, 161. (d) Jacobs, W. A.; Pelletier, S. W.J. Am. Chem. Soc. 1956, 78, 3542. (e) Jacobs, W. A.; Pelletier, S. W. J. Org. Chem. 1957, 22, 1428. (f) Locke, D. M.; Pelletier, S. W. J. Am. Chem. Soc. 1958, 80, 2588. (g) Locke, D. M.; Pelletier, S. W. J. Am. Chem. Soc. 1959, 81, 2246. (h) Pelletier, S. W.J. Am. Chem. Soc. 1960, 82, 2398. (i) Pelletier, S. W.; Jacobs, W. A. J. Am. Chem. Soc. 1954, 76, 4496. (j) Pelletier, S. W.; Jacobs, W. A. J. Am. Chem. Soc. 1956, 78, 4139. (k) Pelletier, S. W.; Jacobs, W. A.; Rathgeb, P. J. Org. Chem. 1956, 21, 1514. (l) Solo, A. J.; Pelletier, S. W. J. Am. Chem. Soc. 1959, 81, 4439.

(15) Pelletier, S. W.; Jacobs, W. A. J. Am. Chem. Soc. 1956, 78, 4144.

(16) (a) Guthrie, R. W.; Henry, W. A.; Immer, H.; Wong, C. M.; Valenta, Z.; Wiesner, K. Collect. Czech. Chem. Commun. 1966, 31, 602. (b) Wiesner, K.; Armstrong, R.; Bartlett, M. F.; Edwards, J. A. J. Am. Chem. Soc. 1954, 76, 6068. (c) Wiesner, K.; Edwards, J. A. Experientia 1955, 11, 255. (d) Wiesner, K.; Figdor, S. K.; Bartlett,
M. F.; Henderson, D. R. Can. J. Chem. 1952, 30, 608. (e) Wiesner, K.; Taylor, W. I.; Figdor, S. K.; Bartlett, M. F.; Armstrong, J. R.; Edwards, J. A. Chem. Ber. 1953, 86, 800.

(17) (a) Wiesner, K. Chem. Soc. Rev. 1977, 6, 413. (b) Wiesner, K. Tetrahedron 1985, 41, 485.

(18) (a) Liu, X. Y.; Qin, Y. Asian J. Org. Chem. 2015, 4, 1010. (b) Zhu, G.; Liu, R.; Liu, B. Synthesis 2015, 47, 2691.

(19) Narita, K.; Fujisaki, N.; Sakuma, Y.; Katoh, T. Org. Biomol. Chem. 2019, 17, 655 .

(20) Menger, M.; Lentz, D.; Christmann, M. J. Org. Chem. 2018, 83, 6793.

(21) (a) Sharpe, R. J.; Johnson, J. S. J. Org. Chem. 2015, 80, 9740. (b) Kim, D. E.; Zweig, J. E.; Newhouse, T. R. J. Am. Chem. Soc. 2019, 141, 1479.

(22) Enomoto, M.; Morita, A.; Kuwahara, S. Angew. Chem. Int. Ed. 2012, 51, 12833.

(23) Yang, M.; Yang, X.; Sun, H.; Li, A. Angew. Chem. Int. Ed. 2016, 55, 2851.

(24) Teranishi, T.; Murokawa, T.; Enomoto, M.; Kuwahara, S. Biosci., Biotechnol., Biochem. 2015, 79, 11.

(25) Li, H.; Chen, Q.; Lu, Z.; Li, A. J. Am. Chem. Soc. 2016, 138, 15555.

(26) (a) Suzuki, H.; Aoyagi, S. Org. Lett. 2012, 14, 6374. (b) Mori, N.; Kuzuya, K.; Watanabe, H. J. Org. Chem. 2016, 81, 11866. (c) Suzuki, H.; Aoyagi, S. Chem. Commun. 2011, 47, 7878.

(27) Shi, Y.; Wilmot, J. T.; Nordstrøm, L. U.; Tan, D. S.; Gin, D. Y.J. Am. Chem. Soc. 2013, 135, 14313.

(28) Marth, C. J.; Gallego, G. M.; Lee, J. C.; Lebold, T. P.; Kulyk, S.; Kou, K. G. M.; Qin, J.; Lilien, R.; Sarpong, R. Nature 2015, 528, 493.

(29) Wiesner, K.; Tsai, T. Y. R.; Huber, K.; Bolton, S. E.; Vlahov, R. J. Am. Chem. Soc. 1974, 96, 4990.

(30) Wiesner, K. Pure Appl. Chem. 1975, 41, 93.

(31) (a) Tsai, T. Y. R.; Tsai, C. S. J.; Sy, W. W.; Shanbhag, M. N.; Liu, W. C.; Lee, S. F.; Wiesner, K. Heterocycles 1977, 7, 217. (b) Lee, S.-F.; Sathe, G. M.; Sy, W. W.; Ho, P.-T.; Wiesner, K. Can. J. Chem. 1976, $54,1039$.

(32) Wiesner, K.; Tsai, T. Y. R.; Nambiar, K. P. Can. J. Chem. 1978, 56, 1451.

(33) (a) Tsai, T. Y. R.; Nambiar, K. P.; Krikorian, D.; Botta, M.; MariniBettolo, R.; Wiesner, K. Can. J. Chem. 1979, 57, 2124. (b) Wiesner, K. Pure Appl. Chem. 1979, 51, 689.

(34) Nishiyama, Y.; Yokoshima, S.; Fukuyama, T. Org. Lett. 2017, 19, 5833.

(35) Nagata, W.; Sugasawa, T.; Narisada, M.; Wakabayashi, T.; Hayase, Y.J. Am. Chem. Soc. 1963, 85, 2342.

(36) Masamune, S. J. Am. Chem. Soc. 1964, 86, 291.

(37) Guthrie, R. W.; Valenta, Z.; Wiesner, K. Tetrahedron Lett. 1966, 7, 4645.

(38) Nagata, W.; Sugasawa, T.; Narisada, M.; Wakabayashi, T.; Hayase, Y. J. Am. Chem. Soc. 1967, 89, 1483.

(39) Ihara, M.; Suzuki, M.; Fukumoto, K.; Kametani, T.; Kabuto, C. J. Am. Chem. Soc. 1988, 110, 1963.

(40) Ihara, M.; Suzuki, M.; Fukumoto, K.; Kabuto, C. J. Am. Chem. Soc. 1990, 112, 1164.

(41) Liu, X.-Y.; Cheng, H.; Li, X.-H.; Chen, Q.-H.; Xu, L.; Wang, F.-P. Org. Biomol. Chem. 2012, 10, 1411.

(42) (a) Masamune, S. J. Am. Chem. Soc. 1964, 86, 290. (b) Nagata, W.; Narisada, M.; Wakabayashi, T.; Sugasawa, T. J. Am. Chem. Soc. 1964, 86, 929. (c) Valenta, Z; Wiesner, K.; Wong, C. M. Tetrahedron Lett. 1964, 5, 2437.

(43) Nagata, W.; Narisada, M.; Wakabayashi, T.; Sugasawa, T. J. Am. Chem. Soc. 1967, 89, 1499.

(44) Wiesner, K.; Uyeo, S.; Philipp, A.; Valenta, Z. Tetrahedron Lett. 1968, 9, 6279. 
(45) (a) Wiesner, K.; Ho, P.-T.; Tsai, C. S. J. Can. J. Chem. 1974, 52, 2353. (b) Wiesner, K.; Ho, P.-T.; Tsai, C. S. J.; Lam, Y.-K. Can. J. Chem. 1974, 52, 2355.

(46) Sethi, S. P.; Atwal, K. S.; Marini-Bettolo, R. M.; Tsai, T. Y. R.; Wiesner, K. Can. J. Chem. 1980, 58, 1889.

(47) Muratake, H.; Natsume, M. Angew. Chem. Int. Ed. 2004, 43, 4646.

(48) (a) Muratake, H.; Natsume, M.; Nakai, H. Tetrahedron 2006, 62, 7093. (b) Peese, K. M.; Gin, D. Y. J. Am. Chem. Soc. 2006, 128, 8734.

(49) Peese, K. M.; Gin, D. Y. Chem. Eur. J. 2008, 14, 1654.

(50) Cherney, E. C.; Lopchuk, J. M.; Green, J. C.; Baran, P. S. J. Am. Chem. Soc. 2014, 136, 12592.

(51) Nishiyama, Y.; Han-ya, Y.; Yokoshima, S.; Fukuyama, T. J. Am. Chem. Soc. 2014, 136, 6598.

(52) Kou, K. G. M.; Li, B. X.; Lee, J. C.; Gallego, G. M.; Lebold, T. P.; DiPasquale, A. G.; Sarpong, R. J. Am. Chem. Soc. 2016, 138, 10830.

(53) Li, X.-H.; Zhu, M.; Wang, Z.-X.; Liu, X.-Y.; Song, H.; Zhang, D.; Wang, F.-P.; Qin, Y. Angew. Chem. Int. Ed. 2016, 55, 15667.

(54) Cheng, H.; Zeng, F.-H.; Yang, X.; Meng, Y.-J.; Xu, L.; Wang, F.-P. Angew. Chem. Int. Ed. 2016, 55, 392.

(55) Liu, J.; Ma, D. Angew. Chem. Int. Ed. 2018, 57, 6676.

(56) Kou, K. G. M.; Pflueger, J. J.; Kiho, T.; Morrill, L. C.; Fisher, E. L.; Clagg, K.; Lebold, T. P.; Kisunzu, J. K.; Sarpong, R. J. Am. Chem. Soc. 2018, 140, 8105.

(57) Zhou, S.; Guo, R.; Yang, P.; Li, A. J. Am. Chem. Soc. 2018, 140, 9025.

(58) Curran, T. T.; Hay, D. A.; Koegel, C. P.; Evans, J. C. Tetrahedron 1997, 53, 1983.

(59) Al Dulayymi, A. R.; Al Dulayymi, J. R.; Baird, M. S.; Gerrard, M. E.; Koza, G.; Harkins, S. D.; Roberts, E. Tetrahedron 1996, 52, 3409.

(60) Forsyth, C. J.; Clardy, J. J. Am. Chem. Soc. 1990, 112, 3497.

(61) Prabhakaran, J.; Lhermitte, H.; Das, J.; Sasi-Kumar, T. K.; Grierson, D. S. Synlett 2000, 658.

(62) Marx, J. N.; Cox, J. H.; Norman, L. R. J. Org. Chem. 1972, 37, 4489.

(63) Bandyopadhyaya, A. K.; Manion, B. D.; Benz, A.; Taylor, A.; Rath, N. P.; Evers, A. S.; Zorumski, C. F.; Mennerick, S.; Covey, D. F. Bioorg. Med. Chem. Lett. 2010, 20, 6680.

(64) Lee, J.; Kim, M.; Chang, S.; Lee, H.-Y. Org. Lett. 2009, 11, 5598.

(65) Cuerva, J. M.; Campaña, A. G.; Justicia, J.; Rosales, A.; OllerLópez, J. L.; Robles, R.; Cárdenas, D. J.; Buñuel, E.; Oltra, J. E. Angew. Chem. Int. Ed. 2006, 45, 5522.

(66) Zhou, R.-J.; Dai, G.-Y.; Zhou, X.-H.; Zhang, M.-J.; Wu, P.-Z.; Zhang, D.; Song, H.; Liu, X.-Y.; Qin, Y. Org. Chem. Front. 2019, 6, 377.

(67) Nishiyama, Y.; Yokoshima, S.; Fukuyama, T. Org. Lett. 2016, 18, 2359.

(68) Pelletier, S. W.; Parthasarathy, P. C. Tetrahedron Lett. 1963, 4, 205.

(69) Zhu, M.; Li, X.; Song, X.; Wang, Z.; Liu, X.; Song, H.; Zhang, D.; Wang, F.; Qin, Y. Chin. J. Chem. 2017, 35, 991.

(70) Han, G.; LaPorte, M. G.; McIntosh, M. C.; Weinreb, S. M.; Parvez, M. J. Org. Chem. 1996, 61, 9483.

(71) Sasano, Y.; Nagasawa, S.; Yamazaki, M.; Shibuya, M.; Park, J.; Iwabuchi, Y. Angew. Chem. Int. Ed. 2014, 53, 3236.

(72) Pflueger, J. J.; Morrill, L. C.; deGruyter, J. N.; Perea, M. A.; Sarpong, R. Org. Lett. 2017, 19, 4632.

(73) Griffith, W. P.; Ley, S. V.; Whitcombe, G. P.; White, A. D. J. Chem. Soc., Chem. Commun. 1987, 1625.

(74) Lebel, H.; Paquet, V. J. Am. Chem. Soc. 2004, 126, 320.

(75) Donnelly, D. M. X.; Finet, J.-P.; Rattigan, B. A. J. Chem. Soc., Perkin Trans. 1 1993, 1729.

(76) Dessolin, M.; Guillerez, M.-G.; Thieriet, N.; Guibé, F.; Loffet, A. Tetrahedron Lett. 1995, 36, 5741.
(77) Kulbitski, K.; Nisnevich, G.; Gandelman, M. Adv. Synth. Catal. 2011, 353, 1438.

(78) Heinzman, S. W.; Ganem, B. J. Am. Chem. Soc. 1982, 104, 6801.

(79) Trost, B. M.; Tang, W. J. Am. Chem. Soc. 2002, 124, 14542.

(80) Zhang, Q.; Zhang, Z.; Huang, Z.; Zhang, C.; Xi, S.; Zhang, M. Angew. Chem. Int. Ed. 2018, 57, 937.

(81) Weitz, E.; Scheffer, A. Ber. Dtsch. Chem. Ges. 1921, 54, 2327.

(82) Chen, Y.-K.; Peddinti, R. K.; Liao, C.-C. Chem. Commun. 2001, 1340.

(83) Chittimalla, S. K.; Shiao, H.-Y.; Liao, C.-C. Org. Biomol. Chem. 2006, 4, 2267.

(84) Herrmann, J. L.; Kieczykowski, G. R.; Schlessinger, R. H. Tetrahedron Lett. 1973, 14, 2433.

(85) Hibino, J. H.; Okazoe, T.; Takai, K.; Nozaki, H. Tetrahedron Lett. 1985, 26, 5579 .

(86) Bal, B. S.; Childers, W. E.; Pinnick, H. W. Tetrahedron 1981, 37, 2091.

(87) Shigeru, I.; Teruaki, M. Chem. Lett. 1989, 18, 1071.

(88) Hagiwara, K.; Tabuchi, T.; Urabe, D.; Inoue, M. Chem. Sci. 2016, 7, 4372.

(89) Tabuchi, T.; Urabe, D.; Inoue, M. J. Org. Chem. 2016, 81, 10204.

(90) Minagawa, K.; Urabe, D.; Inoue, M. J. Antibiot. 2017, 71, 326.

(91) Liu, M.; Cheng, C.; Xiong, W.; Cheng, H.; Wang, J.-L.; Xu, L. Org. Chem. Front. 2018, 5, 1502.

(92) Cheng, H.; Xu, L.; Chen, D.-L.; Chen, Q.-H.; Wang, F.-P. Tetrahedron 2012, 68, 1171.

(93) Li, Y.-L.; Liu, M.-C.; Meng, Y.-J.; Xu, L. Tetrahedron 2016, 72, 3171.

(94) (a) Trost, B. M.; Ferreira, E. M.; Gutierrez, A. C. J. Am. Chem. Soc. 2008, 130, 16176. (b) Trost, B. M.; Gutierrez, A. C.; Ferreira, E. M. J. Am. Chem. Soc. 2010, 132, 9206.

(95) Zhou, X.-H.; Liu, Y.; Zhou, R.-J.; Song, H.; Liu, X.-Y.; Qin, Y. Chem. Commun. 2018, 54, 12258.

(96) Cheng, H.; Zeng, F.-H.; Ma, D.; Jiang, M.-L.; Xu, L.; Wang, F.-P. Org. Lett. 2014, 16, 2299.

(97) Matsuzawa, A.; Kasamatsu, A.; Sugita, K. Tetrahedron Lett. 2016, $57,4585$.

(98) Sparrow, K.; Barker, D.; Brimble, M. A. Tetrahedron 2011, 67, 7989.

(99) Liu, Z.-G.; Xu, L.; Chen, Q.-H.; Wang, F.-P. Tetrahedron 2012, 68, 159.

(100) Yang, T.-K.; Hung, S.-M.; Lee, D.-S.; Hong, A.-W.; Cheng, C.-C. Tetrahedron Lett. 1989, 30, 4973.

(101) Goodall, K. J.; Brimble, M. A.; Barker, D. Tetrahedron 2012, 68, 5759.

(102) Liu, X.-Y.; Qin, Y. Nat. Prod. Rep. 2017, 34, 1044.

(103) Yang, X.; Cheng, B.; Cheng, H.; Xu, L.; Wang, J.-L. Chin. Chem. Lett. 2017, 28, 1788.

(104) Hamlin, A. M.; Lapointe, D.; Owens, K.; Sarpong, R. J. Org. Chem. 2014, 79, 6783.

(105) Chen, D. L.; Wang, F. P. Chin. Chem. Lett. 2012, 23, 1378.

(106) Tang, D.-H.; Ma, D.; Cheng, H.; Li, Y.-L.; Xu, L. Org. Biomol. Chem. 2016, 14, 2716.

(107) Liu, Z.-G.; Cheng, H.; Ge, M.-J.; Xu, L.; Wang, F.-P. Tetrahedron 2013, 69, 5431.

(108) Haruta, J.; Nishi, K.; Matsuda, S.; Akai, S.; Tamura, Y.; Kita, Y. J. Org. Chem. 1990, 55, 4853.

(109) Staben, S. T.; Kennedy-Smith, J. J.; Toste, F. D. Angew. Chem. Int. Ed. 2004, 43, 5350.

(110) Nagata, W.; Hirai, S.; Kawata, K.; Aoki, T. J. Am. Chem. Soc. 1967, 89, 5045.

(111) Mei, R.-H.; Liu, Z.-G.; Cheng, H.; Xu, L.; Wang, F.-P. Org. Lett. 2013, 15, 2206. 
(112) Chou, H.-H.; Wu, H.-M.; Wu, J.-D.; Ly, T. W.; Jan, N.-W.; Shia, K.S.; Liu, H.-J. Org. Lett. 2008, 10, 121.

(113)Jiang, M.-L.; Meng, Y.-J.; Xiong, W.-Y.; Xu, L. Tetrahedron Lett. 2016, 57, 1610.

(114) Liu, Y.; Zhang, Y.; Wang, X.; Fu, S.; Liu, B. Synlett 2018, 29, 1978.

(115) Liu, Y.; Wang, X.; Chen, S.; Fu, S.; Liu, B. Org. Lett. 2018, 20, 2934.
(116) Doering, N. A.; Kou, K. G. M.; Norseeda, K.; Lee, J. C.; Marth, C. J.; Gallego, G. M.; Sarpong, R. J. Org. Chem. 2018, 83, 12911.

(117) Takaya, Y.; Ogasawara, M.; Hayashi, T. Tetrahedron Lett. 1999, 40, 6957.

(118) Yang, Z.-K.; Chen, Q.-H.; Wang, F.-P. Tetrahedron 2011, 67, 4192. 